\title{
Hallazgos de mosaicos romanos en Hispania (1977-1987)
}

\author{
J. M. Blázquez Martínez * \\ G. López Monteagudo * \\ M. L. Neira Jiménez * \\ M. P. San Nicolás Pedraz *
}

Con motivo de la celebración del V Coloquio Internacional sobre Mosaicos Antiguos, celebrado en Bath en el año 1987, decidimos presentar una comunicación que diera a conocer los últimos hallazgos de mosaicos romanos en Hispania. Nos planteamos este objetivo para facilitar a la comunidad científica internacional interesada en el tema el conocimiento de mosaicos que, o bien habian sido publicados de forma dispersa en medios de dificil acceso y escasa difusión, o bien se hallaban inéditos o se conocian solamente a través de noticias muy vagas y escuetas. De este modo, no haciamos sino seguir las pautas de otros paises, conscientes de lo útil que resulta a cualquier investigador el poder contar con un repertorio accesible. Dada la amplitud del tema, estimamos conveniente iriciar nuestro trabajo relacionando los mosaicos publicados o conocidos a partir de 1977, de forma que en la fecha de la celebración del Congreso en 1987, completaran una década.

Al haber transcurrido varios años desde entonces, algunos mosaicos han sido ya objeto de una completa publicación con posterioridad a 1987 , $y$ asi se hace constar en las notas a pie de página y en la bibliografia. Deliberadamente no hemos incluido algunos recientes e importantes hallazgos, como los mosaicos de Complutum (Alcalá de Henares), porque pensamos que han tenido la debida difusión '. Por ctra parte, nos ha parecido oportuno incorporar algunos mosaicos que, aunque bien publicados, merecen ser mencionados por su temática inédita en España. Este

\footnotetext{
* Departamento de Historia Antigua y Arqueologia. Centro de Estudios Históricos. CSIC. Fernandez Galiano. 1984a; Blazouez et all. 1989b.
} 


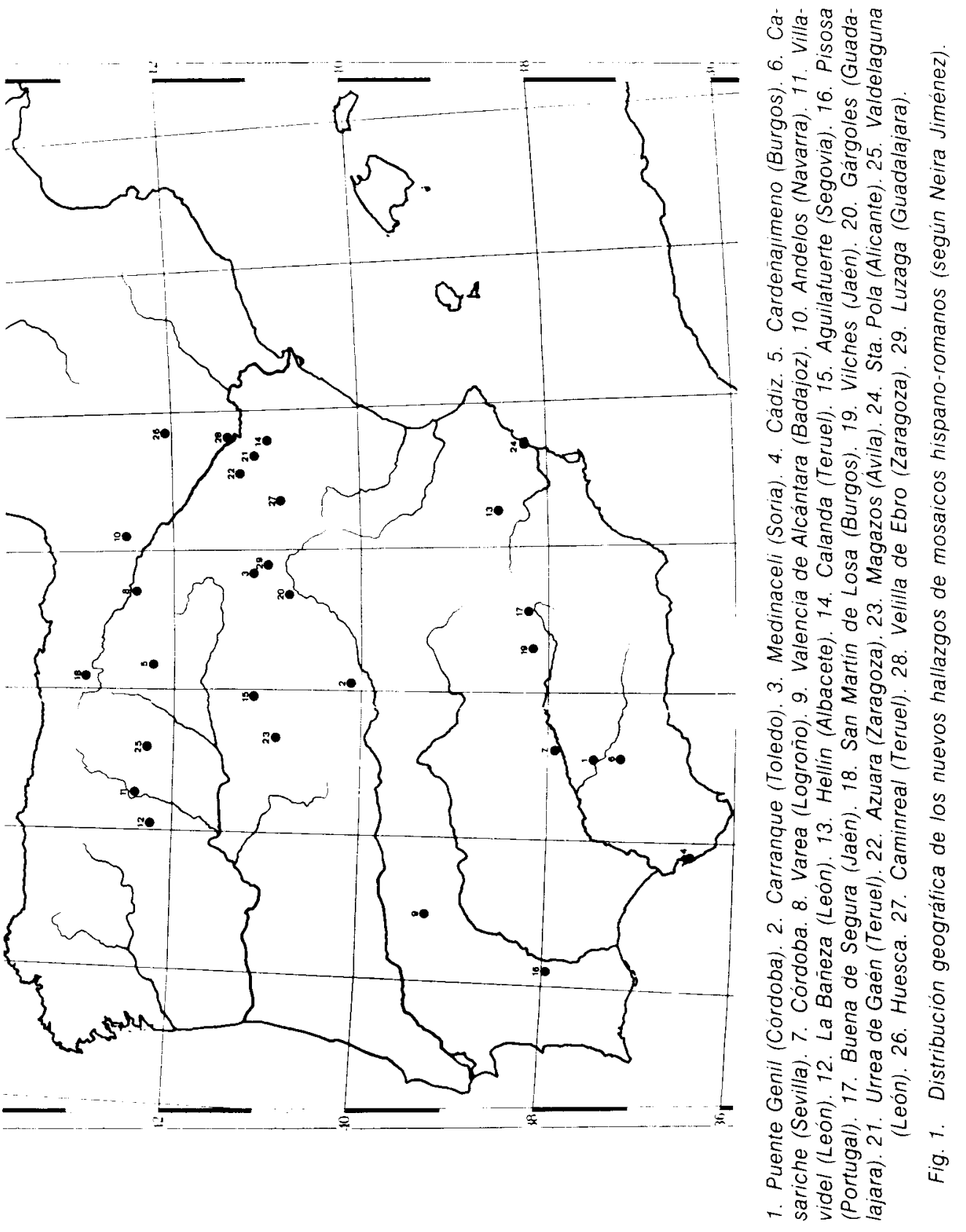


es el caso de los mosaicos de Atalanta y Meleagro, de Cardeñajimeno (Burgos), el Juicio de Paris. de Casariche (Sevilla) y las Metamorfosis, de Carranque (Toledo).

Asi pues, iniciamos con este trabajo una serie, dedicada a los mosaicos romanos de Hispania, que se irá publicando de manera sucesiva dividida, por cuestiones de espacio, en varios apartados.

\section{"LA CARIDAD", CAMINREAL (TERUEL) (figs. 2-3)}

El yacimiento arqueológico de "La Caridad", situado a $2 \mathrm{~km}$ del término municipal de Caminreal (Teruel), ha sido objeto de cuatro campañas de excavación (REDón et all., 1986).

El descubrimiento más importante fue la vivienda núm. 1 o casa de Likinete que, aunque no se ha excavado totalmente, presenta una planta cuadrada, de al menos $850 \mathrm{~m}^{2}$, que responde a modelos helenísticos o "pompeyanos" de casa con atrio. Alrededor del atrio se han identificado dieciséis estancias, suponiendo sus excavadores que la núm. 1, con pavimento de signinum, es el oecus ${ }^{2}$. Otro pavimento de signinum cubre la estancia núm. 4. Este último presenta una decoración a base de meandros de esvásticas, no continuas, alternando con rosetas de cuatro pétalos.

El mosaico del oecus mide $6,5 \times 9,2 \mathrm{~m}$ y cubre completamente la estancia. Presenta un esquema compositivo muy original, no habitual en los pavimentos de signinum conocidos. Un filete de teselas blancas enmarca el campo musivo dividido en tres compartimentos rectangulares. El central se halla subdividido a su vez en tres paneles, siendo el del centro de doble tamaño que los dos laterales.

El primer compartimento está compuesto por una reticula de rombos. El tercero presenta una composición a base de meandros de esvásticas no continuas, que dejan un espacio cuadrangular vacio. El compartimento central presenta, como ya se ha dicho, tres paneles: el superior ofrece dos círculos inscritos en cuadrados; uno de ellos con rosas de seis pétalos, obtenidas por circunferencias secantes, y en los ángulos dos peces y dos estrellas de cinco puntas; el otro, con una roseta de pétalos rom-

Este pavimento fue dado a conocer en la Mesa Redonda Hispano-Francesa sobre El Mo. saico Romano en España (Madrid 23-24 de abril de 1985). cf. Rfoon et all. 1989. 11-45 


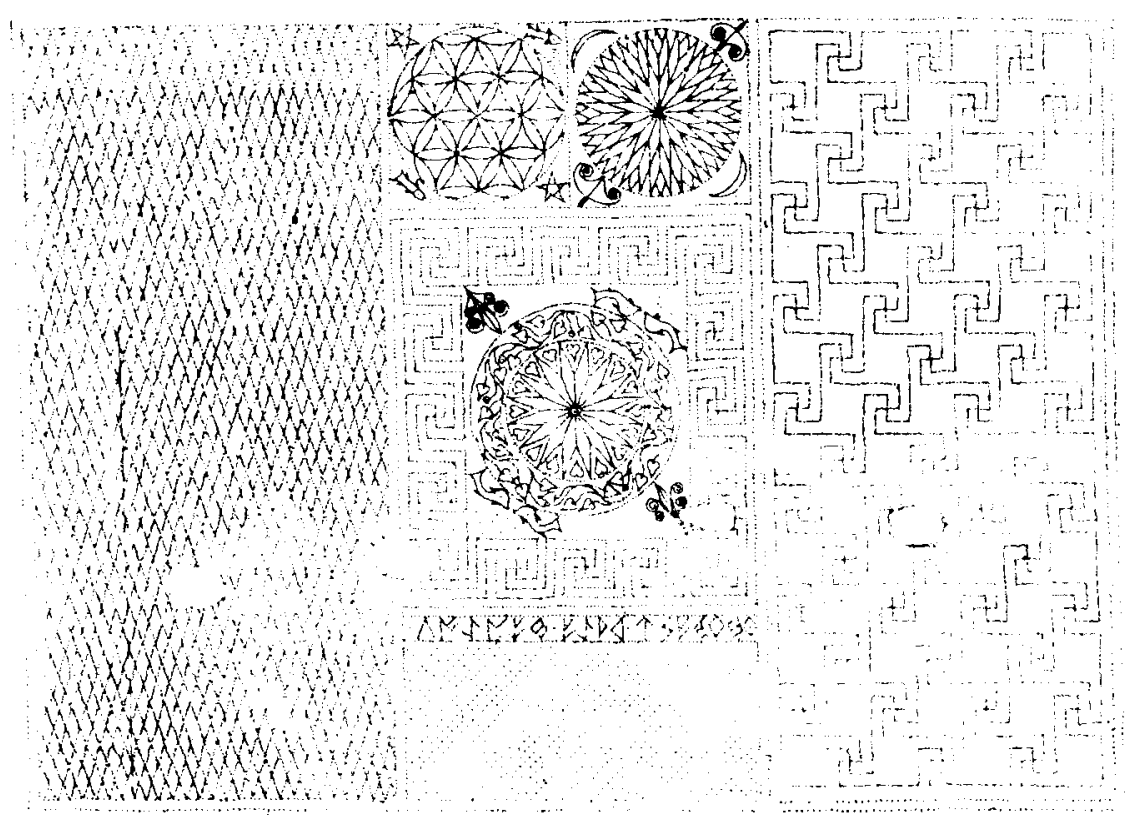

Fig. 2. Mosaico de "La Caridad», Caminreal (Teruel) (según Redón).

boidales y en los ángulos dos peltas y dos crecientes lunares. El panel del centro, enmarcado por una orla de esvásticas de doble vuelta, ofrece una corona de hojas de hiedra (hederae), formando un círculo, y en su interior una roseta de dieciséis pétalos romboidales con hojas acorazonadas entre sus vértices. En los ángulos, dos pares de delfines afrontados $y$ dos flores de lis. El panel inferior contiene una cartela en alfabeto ibérico y una composición de teselas compuestas oblicuamente. El epígrafe, realizado con teselas blancas, ha sido leído de la forma siguiente: "Likinete, de los usecerdenses, lo hizo."

En cuanto a la cronología, el análisis provisional del material y de los restos arquitectónicos proporciona una fecha final de ocupación en el primer tercio del siglo I a.C.

Estos pavimentos de Caminreal, del tipo de los mosaicos de opus signinum de Pompaelo y Andión (Navarra) (BLÁzQuEz et all., 1985, 13-1558-59, fig. 6, láms. 1-2 y 37) y de Celsa (Zaragoza) (BeltRán et all., 1984, 86 y ss., figs. $31,34,35,52 a$ y b, 60, 61-63), pertenecen a un tipo de 

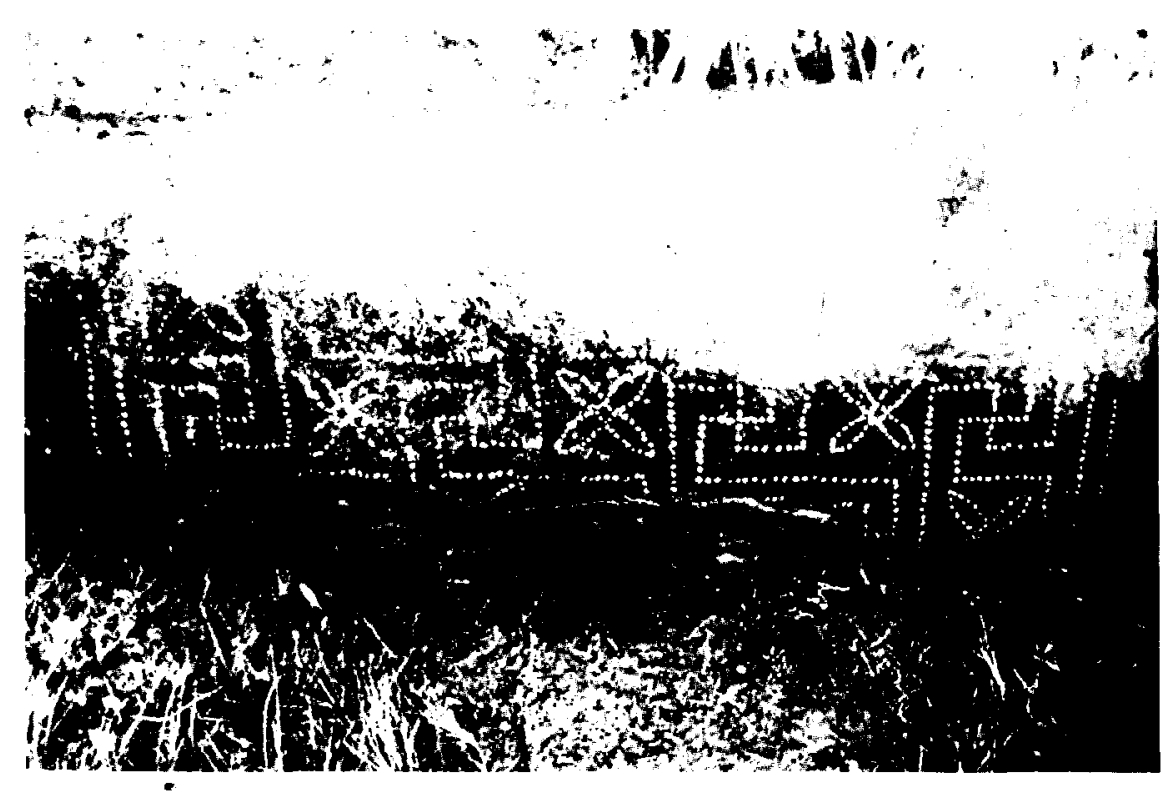

Fig. 3. Mosaico de "La Caridad", Caminreal (Teruel) (seguin Redon).

pavimènto que es el más antiguo de Hispania, fechado a finales de la República y hallado en las regiones más romanizadas.

CELSA, VELILLA DE EBRO (ZARAGOZA) (figs. 4-6)

Los mosaicos descubiertos en la "Casa de los Delfines" son todos de opus signinum y corresponden a dos fases cronológicas, ya que las casas A y $\mathrm{B}$, con un desarrollo independiente del año 36 a.C. al cambio de Era, se reunifican a partir de este momento en una sola unidad, la casa $C$, designada como Casa de los Delfines por la decoración de sus pavimentos (Beltrán et all., 1984; Beltrán, 1985).

CASA A

El pavimento del atrium testudinatum está realizado con teselas blancas embutidas en la masa de mortero “rojo", dando lugar a motivos deco- 


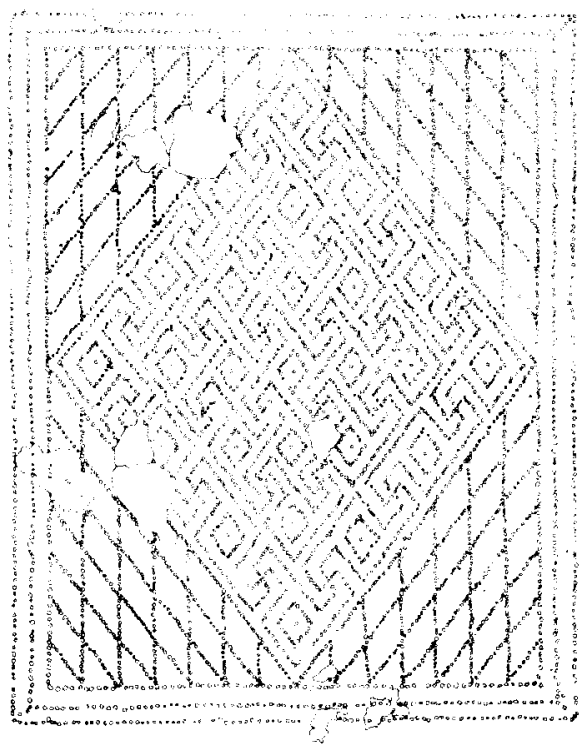

Fig. 4. Mosaico de Celsa, Velilla de Ebro (Zaragoza) (según Beltrán).

rativos geométricos a base de un rombo central con esvásticas romboidales y rombos, rodeado todo de una retícula también de rombos. En Hispania este mismo motivo solamente se conoce en un pavimento inédito de Ampurias, realizado con teselas blancas y negras, en la Casal de la ciudad romana. El motivo decorativo de esvásticas romboidales y rombos es poco frecuente, aparece en Ostia en una casa republicana fechada a fines del siglo ॥ a.C. (BECATTI, 1961, 19-20, núm. 24, lám. IV) y en Paestum (BLAKE I, 27).

\section{CASA C}

El mosaico del tablinium ofrece una composición de meandros de esvásticas con una vuelta, conteniendo en el centro un cuadrado de 120 $\mathrm{cm}$ de lado que inscribe una corona circular, dibujada por una línea de esvásticas enlazadas, y retícula de rombos dispuesta en sentido radial en su interior. En cada una de las enjutas se ha dibujado un delfín.

El pavimento del cubículo 8 está dividido en dos zonas por una banda de seis delfines centrados en una roseta de cuatro pétalos. El panel superior está decorado a base de meandros de esvásticas. 


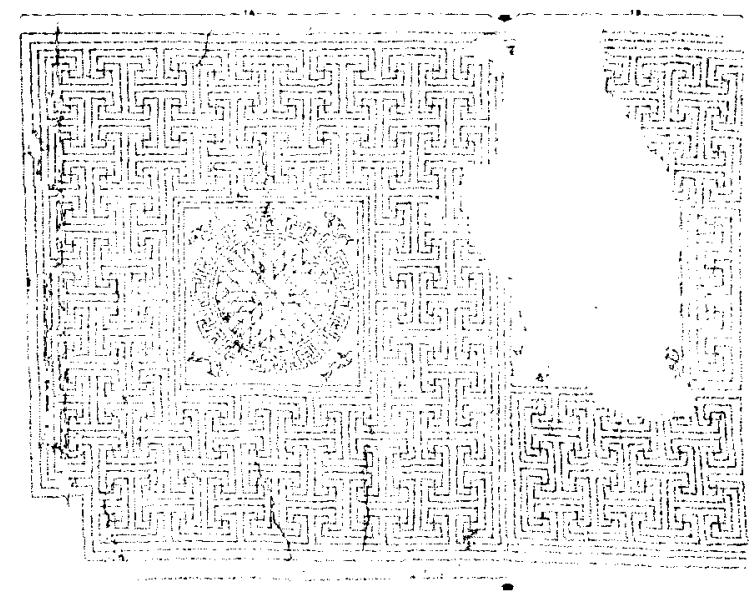

Fig. 5. Mosaico de Celsa, Velilla de Ebro (Zaragoza) (según Beltrán).

El motivo del meandro de esvásticas es relativamente frecuente en suelos de opus signinum, así como su combinación con algún motivo central. Paralelos muy próximos para el motivo del tablinium, con círculo central con retícula de rombos y delfines en los ángulos, todo ello dentro de un campo de meandros de esvásticas, se encuentran en Pompeya (Blake 1, 25-26, lám. III,1; Pernice, 1938, láms. XI,3; XXVII,1; XLVI,6) y ya en Hispania en pavimentos de Badalona (BARRAL, 1978, 83, núm. 57), Itálica (BLANCO, 1978a, 44, núm. 26), Murcia (BLÁzQUEZ, 1982a, 65-66, núm. 60), Cartagena (BlázQuez, 1982a, 69-70, núm. 69), Pamplona, Andión (BLÁzQuez et all., 1985, 13-15, 58-59, núms. 1 y 40) y Caminreal (REDÓN et all., 1986).

La estancia 14, abierta al patio, se corresponde perfectamente con la exedra. Una tabula lusoria, realizada con teselas blancas, indica claramente el carácter de ocio y reposo de esta estancia. Dos circunferencias concéntricas, de 80 y $40 \mathrm{~cm}$ de diámetro, encierran una roseta de seis pétalos de la que parten cuatro brazos rectangulares de $40 \mathrm{~cm}$ de largo por $6 \mathrm{~cm}$ de ancho.

Pavimentos similares a los de Celsa de opus signinum y mortero blanco, con o sin decoración, jalonan el actual territorio navarro-aragonés: Pamplona, Andión y Santacara (BLÁzQUEZ et all., 1985, 13-15, 58-59 y 73), Inestrillas y Alfaro (Hernández, 1982, 165-167, fig. 15), Uxama (PALOL, 1976, 266) y Caminreal (REDÓN et all., 1986). Varios de ellos presentan 
Fig. 6. Mosaico de Celsa, Velilla de Ebro (Zaragoza) (según Beltrán).

cronologías anteriores a los de Celsa, que se remontan a los inicios del segundo cuarto del siglo I a.C., mostrando todos la existencia de una cierta tradición musiva en la zona. Las coincidencias estilísticas con los centros itálicos son claras, a pesar del desfase cronológico existente ya que los pavimentos de signinum itálicos se fechan a finales del siglo ॥ a.C.

"LOS PALACIOS", LUZAGA (GUADALAJARA) (fig. 7)

El yacimiento de "Los Palacios" se halla en las inmediaciones de Luzaga, partido judicial de Sigüenza. Las excavaciones de urgencia llevadas a cabo pusieron al descubierto las estructuras de un edificio, al que corresponde la habitación del mosaico que tal vez pudiera identificarse con una piscina (ABASCAL y SÁNCHEZ, 1985, 313-325, fig. 7).

El mosaico de opus signinum presenta, sobre un fondo de teselas blancas, el mismo tipo de decoración sobre todo el campo, incluyendo la cenefa que delimita la parte central del pavimento mediante una línea de color negro. Los motivos decorativos consisten en pequeñas flores cuadradas dispuestas geométricamente, formando puntos de retícula, en las que aparece una cruz central en blanco, rellenándose los ángulos con tesela negra y festoneando toda la flor una línea de teselas amarillas. De mayor tamaño y dispuestas irregularmente son las que decoran la cenefa. 


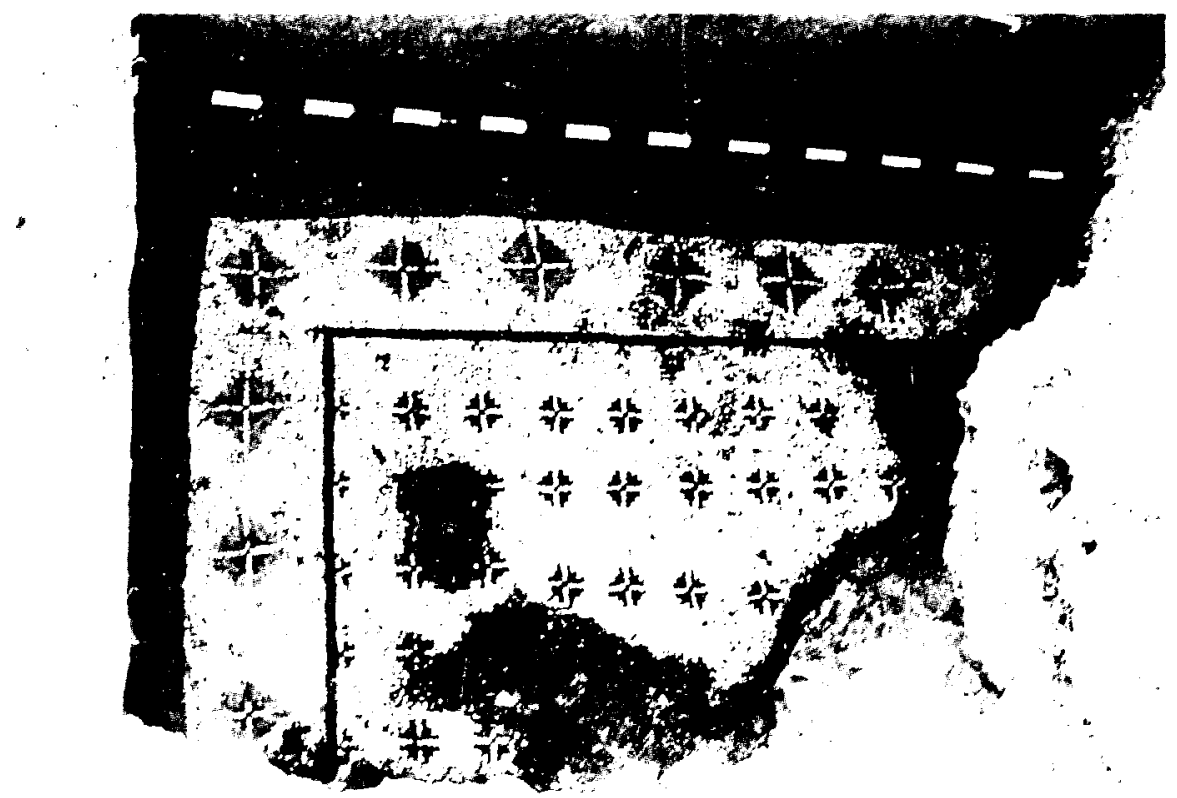

Fig. 7. Mosaico de "Los Palacios", Luzaga (Guadalajara) (según Abascal).

Cruces de Malta dentro de una retícula de rombos se encuentran en un mosaico de la villa soriana de Los Quintanares y en otro de la villa romana de Albesa (Lérida). Fuera de Hispania, esta decoración sigue un modelo bien conocido en la musivaria romana, como se ve en los mosaicos de Byblos, Utica, Bulla Regia, Antioquia, Siponto y Aquileia, datados todos ellos en los siglos II y III d.C. Otro paralelo muy próximo es un mosaico de Cartago fechado en la mitad del siglo iv (BLÁzQUEZ y OrTEGO, 1983, 19-20, núm. 2; BLÁZQUEZ et all., 1989, 13-15, núm. 1, lám. 1).

Hileras de flores de Malta aparecen en otro mosaico soriano procedente de Cuevas de Soria (Blazquez y Ortego, 1983, 78, núm. 73, fig. 22).

Según sus excavadores, el hallazgo de Luzaga se enmarca probablemente dentro de un conjunto urbano cuya cronología, por los descubrimientos realizados (sigillatas sobre todo), parecen corresponder al siglo I d.C., y más concretamente a la segunda mitad. 
VALDELAGUNA (LEÓN) (fig. 8)

En la primavera de 1976 se puso al descubierto en la granja agrícola de Valdelaguna (León) un mosaico geométrico perteneciente a una villa romana, situada en las orillas del río Cea, a $2,5 \mathrm{~km}$ de Sahagún (CASTRO et all., 1976, 28-30).

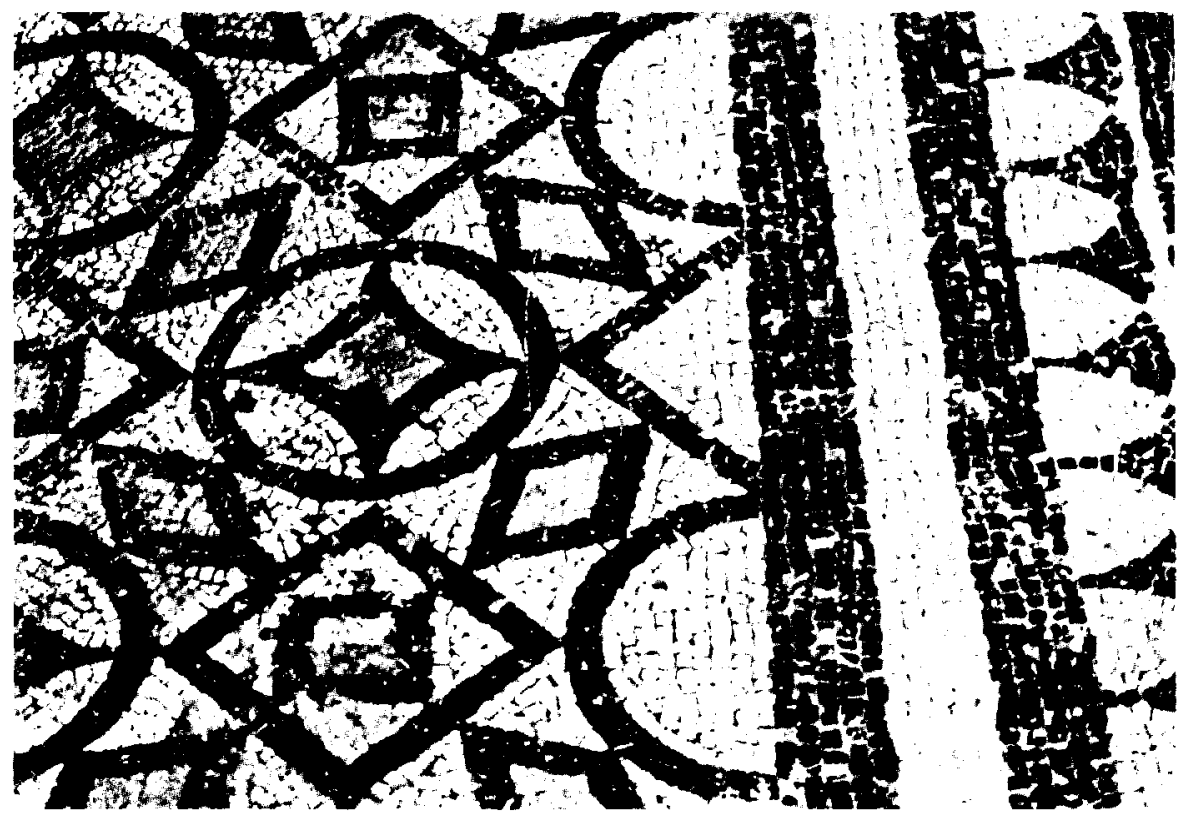

Fig. 8. Mosaico de Valdelaguna (León) (según Castro).

El mosaico, cortado actualmente por un muro, mide $6,30 \times 5,60 \mathrm{~m}$ y está realizado con teselas de mármol azul oscuro, casi negro, y blanco, con escasa participación de otras rojas y amarillas. Puede decirse que se trata de un mosaico con decoración en negro sobre fondo blanco.

Los lados menores del pavimento llevan una orla de ojivas delimitando las dos líneas que bordean el campo musivo por sus cuatro lados. Éste presenta una decoración a base de círculos, cuadrados y rombos combinados tangencialmente. Los círculos encierran cuadrados de lados cur- 
vos, que semejan una estrella de cuatro puntas, cuyos vértices tocan el círculo. Los cuadrados llevan en su interior otro cuadrado más pequeño, cuyos ángulos convergen en los lados del cuadrado mayor. Tanto los cuadrados curvilíneos, como estos más pequeños están realizados con teselas rojas bordeadas de azul oscuro. Los espacios entre los círculos y los cuadrados se han rellenado con rombos, cuyos vértices tocan los lados de los cuadrados siendo esta vez las teselas amarillas. El resultado final es una retícula de imbricaciones geométricas.

Este esquema decorativo tuvo su máximo apogeo en los siglos I y II. La misma composición, aunque algo más sencilla, se encuentra en el lado sur del peristilo de la villa romana de Liédena (Navarra) (BLÁzQUEz et all., 1985,36 , núm. 14, lám. 23) y ya más recargada de motivos se repite en la villa romana de Santa Cristina de la Polvorosa (Zamora) (GAGo, 1984, 50-51). Composiciones semejantes son frecuentes en mosaicos africanos

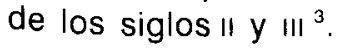

Los hallazgos arqueológicos, cerámicas, encima del mosaico proporcionan una cronología en el siglo ॥, fecha que coincide con la aportada por el estudio estilístico y de los paralelos (CASTRO, 1976).

\section{HUESCA}

En el Ayuntamiento de Huesca se conserva un fragmento de pavimento de tema geométrico, en blanco y negro, que guarda estrecha relación con el mosaico oscense de las murallas (TARRATS I Bou, 1985, 145-146, fig. 1 , lám. 5,2).

Enmarcado por tres bandas, el campo del mosaico se compone de una serie de hiladas yuxtapuestas de cuadrados blancos y negros, formando damero; un cuadrado blanco y otro negro alternativamente son divididos en cuatro triángulos por medio de líneas diagonales, resultando parejas de triángulos opuestos por su vértice, respectivamente de blanco sobre negro y de negro sobre blanco.

En Hispania existen pavimentos similares procedentes de la región laietana, datables en los tres primeros siglos de nuestra Era (BARRAL, 1978, 109-110). Fuera de ella, se documentan paralelos prácticamente exactos en Roma, Ostia y en Pompeya en casas del Segundo y Tercer Estilo. En Timgad el mismo motivo aparece fechado a comienzos del siglo III d.C. (TARRats I Bou, 1985, 145; OVAdiah, 1980, pl. XXIX, fig. 78).

\footnotetext{
${ }^{3}$ Todos los paralelos han sido recogidos por J. M. Blázquez, cf. BLAzouez et all., 1985, 36.
} 
En cuanto a la cronología del mosaico oscense, se puede estimar el siglo \| d.C., teniendo en cuenta su relación estilística con el pavimento de las murallas, datado con seguridad en esta época.

\section{HUESCA (fig. 9)}

En 1975 se halló un mosaico muy cerca del supuesto emplazamiento del foro de la antigua Osca romana. En la actualidad se conserva en el Museo Arqueológico Provincial de Huesca (TARRATs I Bou, 1985, 139-152). El pavimento, muy fragmentado y restaurado posiblemente en la antigüedad en algunos sectores con mortero, mide $8,9 \times 6,5 \mathrm{~m}$ y está realizado en blanco y negro, a excepción del "emblema» que es polícromo, con teselas de color verde, rojo y granate.

El mosaico se halla enmarcado por dos bandas, la exterior lisa y la otra formada por una serie alternativa de torres con ventana y almenas en forma de $T$. Las esquinas, de las que sólo se conservan dos, van decoradas con una torre dispuesta en ángulo de $135 .^{\circ}$. El campo musivo está constituido por una cuadrícula de ciento sesenta y siete casetones, cada uno de los cuales encierra tres cuadrados inscritos en alternancia de colores. Sobre el eje longitudinal del pavimento, y desplazado hacia su extremo $E$, aparece un espacio cuadrangular a modo de "emblema", enmarcado por una cenefa de guiloche en la que se combinan los colores blanco, negro, verde, rojo-ladrillo y granate. En el interior tres filetes dobles de color rojo, verde y rojo respectivamente, sirve de marco al tema central compuesto por cubos adosados en perspectiva o scutulatum. Este motivo compositivo se logra dando distinta coloración — blanco, verde, negro- a la trama de rombos.

La representación de las murallas, siempre en orlas, es un tema frecuente en la musivaria romana, con una amplia dispersión por las provincias del Imperio a partir de Italia. Su creación se debe, sin embargo, a los mosaístas helenísticos, encontrándose en pavimentos de Delos, Pérgamo, Alejandría, Arsameia y Pompeya. Pero es en época imperial cuando el motivo adquiere pleno desarrollo y se transforma en la representación realista de una muralla, documentándose ampliamente en Pompeya, Ostia, Grecia, Suiza y Francia (BarRal y Navarro, 1975, 503-522). En Hispania las orlas de murallas son muy frecuentes y variadas, encontrándose en pavimentos de Barcelona, Tarragona, Conimbriga, Itálica, La Alcudia de Elche y Pamplona (BLÁzouez et all., 1985, 54-55, lám. 33). El más antiguo es el de Illici, fechado entre mediados del siglo I a.C. y la mitad del i d.C. 


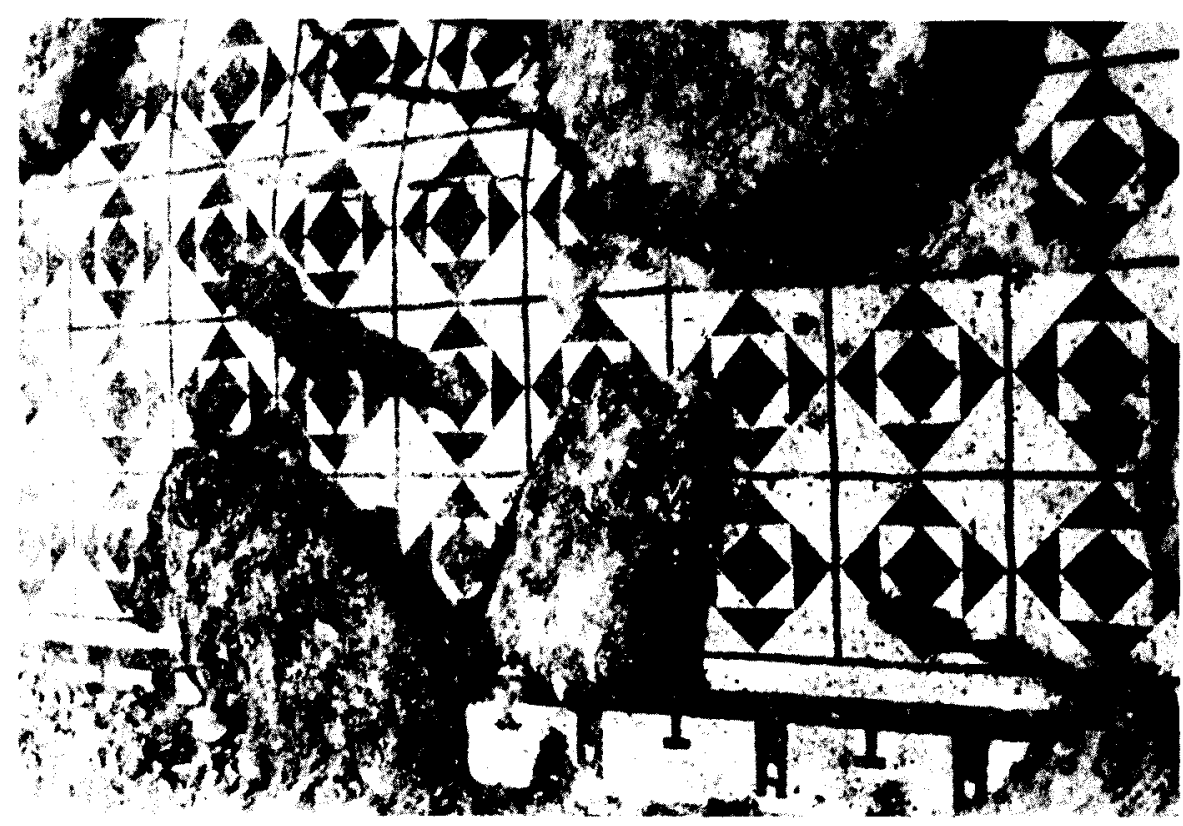

Fig. 9. Mosaico de las murallas de Huesca (según Tarrats i Bou).

(Barral y Navarro, 1975, 517; Ramos, 1983, 98). Los otros se datan grosSO modo en el siglo II.

El esquema decorativo del campo del mosaico está inspirado en los pavimentos de opus sectile hallados en Ostia, encontrándose igualmente en pavimentos marmóreos de Pompeya y Herculano del último período. Su cronología es muy amplia, ya que va desde finales del siglo । a.C. hasta fines del IV, perdurando con algunas variantes. El paralelo en opus tessellatum estilísticamente más próximo al pavimento de Huesca se encuentra en Ostia, con una cronología en el siglo II d.C. (BlAKE II, 88, lám. 15,3).

En cuanto al motivo del emblema, el scutulatum aparece en localidades de ambiente helenístico y se data generalmente en época de Sila (TARRATS I Bou, 1985, 143-144, notas 5 y ss.).

Centrándonos en los paralelos hispanos con el tema de orla de muralla, datados generalmente en el siglo ॥d.C., y en el mosaico de Ostia, que presenta idéntico esquema compositivo en el campo del mosaico y que Blake fecha en el siglo ॥d.C., se puede fechar el mosaico de Huesca en esta misma época. 
GÁRGOLES, CIFUENTES (GUADALAJARA) (fig. 10)

Durante la última campaña de excavaciones dirigidas en 1976 por la Dra. Carolina Nonell (NONELL, 1980, 13-14, lám. 24) en la villa romana de Gárgoles apareció un mosaico, que apenas ha tenido difusión.

Mide 1,65 x 1,50 m con teselas de 0,2. El área central es de color blanco y está bordeado por una cenefa de dibujo geométrico en negro, azul, rojo y amarillo, formada por una espiral discontinua, compuesta cada una por dos volutas, en negro, amarillo y azul, que encierra una flor muy simple de hojas azules con flor roja de un solo pétalo.

El campo del mosaico está decorado con un motivo de imbricaciones o composición ortogonal de escamas adyacentes con flor en su interior (BALmelle et all., 1985, figs. 215-216).

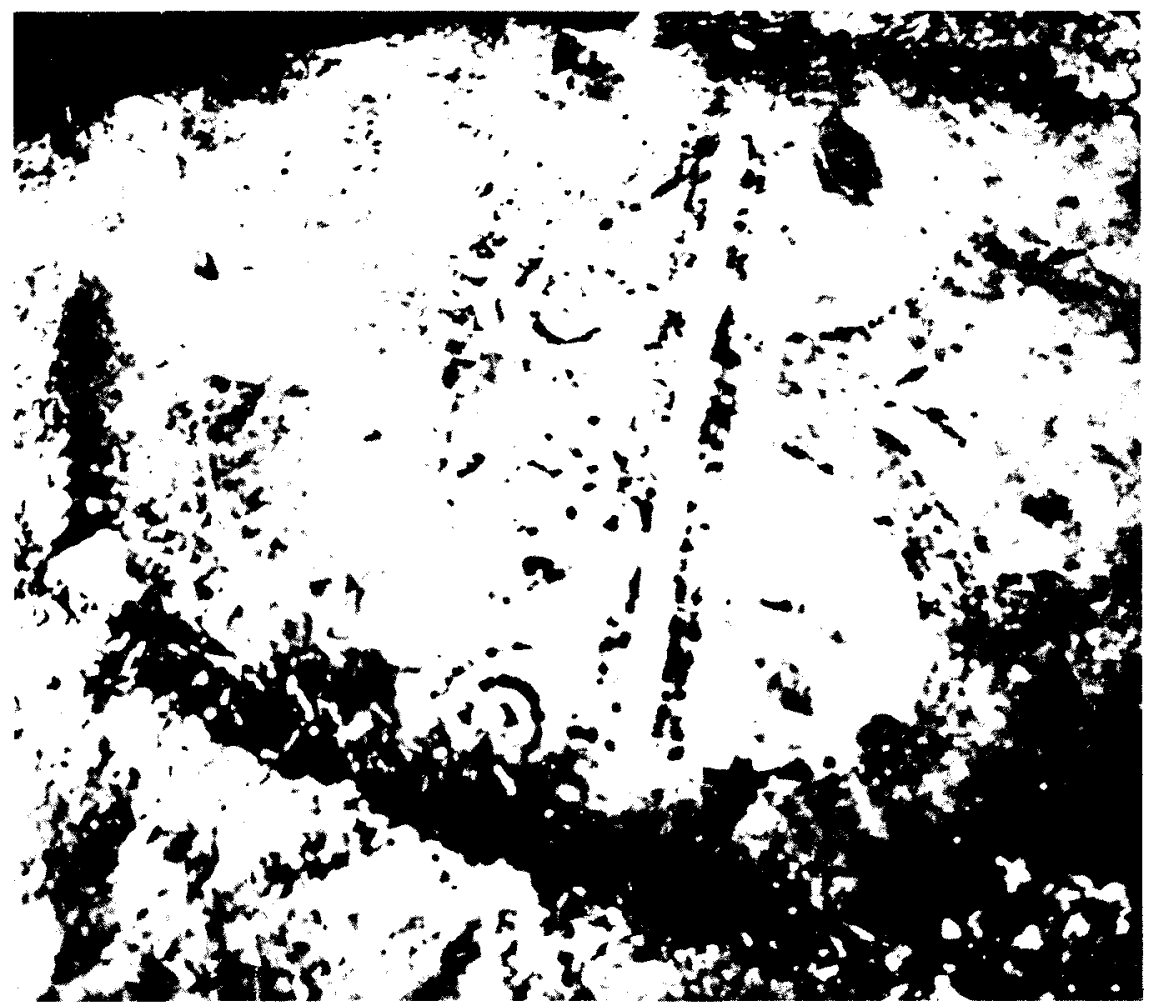

Fig. 10. Mosaico de Gargoles (Guadalajara) (según Nonell). 
Un paralelo exacto está representado en el mosaico del ábside de la sala de juego de Djebel Oust (Túnez) (FENDRI, 1965, 157-171, fig. 12), donde la flor situada en el interior de las imbricaciones es también, como en Gárgoles, una rosa. Otros esquemas similares pueden verse en el mosaico B de la villa romana El Romeral en Albesa (Lérida) (BLÁzQuez et all., 1989, 14-15, núm. 2, láms. 1, 2 y 20), con las escamas adyacentes en cables arpados; y en el mosaico de la habitación VIII de la villa de los Villares en Santervás del Burgo (Soria) (BLÁzQUEz y ORTEGo, 1983, 42, núm. 40, lám. 17), con decoración más pobre, datados en la segunda mitad o fines del siglo iv, fecha que debe corresponder igualmente al mosaico de Gárgoles.

«EL REGADIOO», URREA DE GAEN (TERUEL) (fig. 11)

En la villa romana de "El Regadío" se descubrieron dos mosaicos geométricos que cubrían dos habitaciones comunicadas entre sí por una puerta y cuyos muros estucados iban pintados con motivos geométricos y florales. Los mosaicos, que se guardan en el Museo Arqueológico de Teruel y están en estudio, presentan teselas de color rojo, amarillo, blanco y negro. El material arqueológico excavado da una fecha en torno al siglo III d.C. para el final de la villa (ATRIAN et all., 1980, 231, lám. XXXII; FER. NÁndez Galiano, 1987, 103, núm. 172, lám. XLV).

El mosaico de la galería, enmarcado por una trenza de cuatro cabos, ostenta una decoración geométrica a base de una cuadrícula formada por dos líneas paralelas con cuadrados y rectángulos que, al cruzarse, dan lugar a grandes cuadrados. Los ángulos de los cuadrados o cruces van decorados con nudos de Salomón inscritos en cuadrados que, a su vez, se inscriben en un círculo, el cual va haciendo la unión entre los cuadrados. Los lados del cuadrado se decoran con rombos y losanges. El interior del cuadrado va enmarcado por tres tipos de decoración: trenza de dos cabos, prismas cuadrangulares y rombos tangenciales, que encierran siempre el mismo motivo geométrico: florón recargado con una florecilla en cruz.

Una composición parecida, aunque algo más sencilla, aparece en mosaicos de la villa romana de los Quintanares de Soria (BLÁzQUEz y OrTEGo, 1983, 29-32, núms. 17, 18, 22, 23, láms. 8-9, 30,32) y en el lado oeste del peristilo de la villa navarra de Liédena (BLÁzauez et all., 1985, 40-41, núm. 20, lám. 26). Fuera de Hispania, se documenta también esta composición en mosaicos de África, Galia e Italia (BLÁzQUez et all., 1985, 41, con todos los paralelos). 


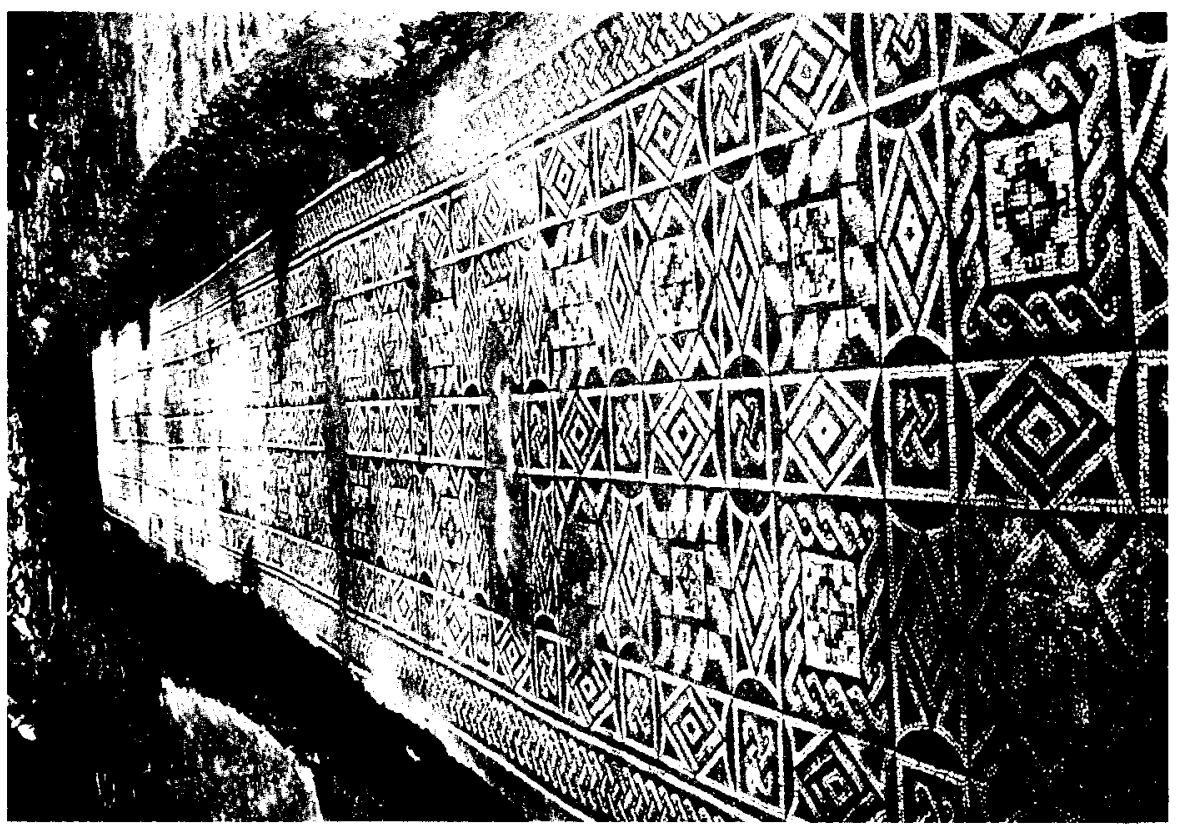

Fig. 11. Mosaico de "El Regadio», Urrea de Gaén (Teruel) (según Atrián).

"LA MALENA», AZUARA (ZARAGOZA) (fig. 12)

A finales de 1986 fueron descubiertos restos arqueológicos de una villa romana en unos terrenos, propiedad de don Santiago Corzán, situados en el término municipal de Azuara, a unos $60 \mathrm{~km}$ de Zaragoza. Entre los hallazgos de fragmentos de capiteles, columnas de mármol, estatuas, cerámica y utensilios de uso común destaca la existencia de mosaicos polícromos de tema geométrico, que pavimentaban cuatro estancias de la zona noble de la villa denominada La Malena ${ }^{4}$.

Las primeras excavaciones de urgencia, llevadas a cabo por el Departamento de Cultura del Gobierno autónomo aragonés, sacaron a la luz un mosaico rectangular. El pavimento está enmarcado por una trenza y una composición ortogonal de círculos y cuadrados tangentes por el vér-

Los mosaicos procedentes de esta villa han sido objeto de varias publicaciones por sus excavadores, cf. Royo 1991, 231-235; 1992, 148-161; Royo et all., 1991, 225-230; 1991a, $209-$ $214 ; 1991 \mathrm{~b}, 215-221$. 


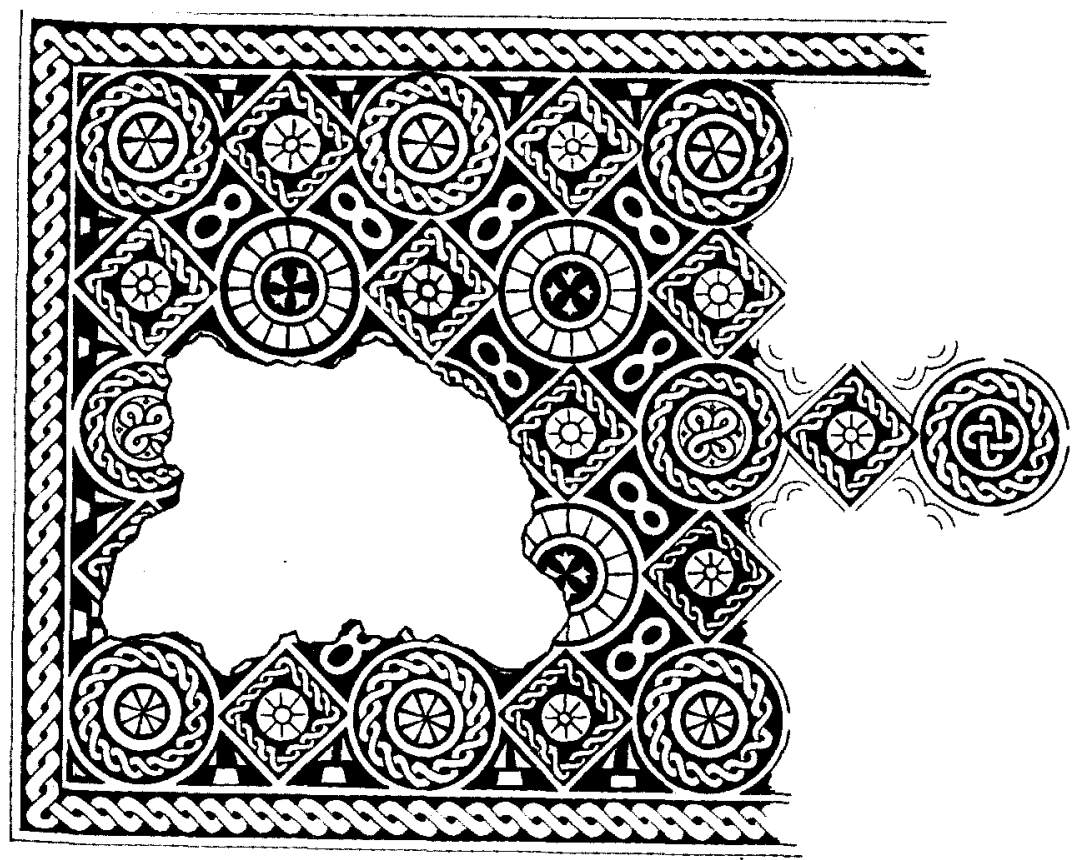

Fig. 12. Mosaico de "La Malena», Azuara (Zaragoza) (Dibujo de D. Salas).

tice, formando bobinas, ocupa el campo del mosaico. En la mayoría de los círculos y cuadrados, bordeados por una trenza, se inscribe otro círculo decorado en su interior por un nudo de Salomón, flores de loto, rosetas de ocho pétalos y aspas, mientras que figuras con forma de ocho decoran el interior de las bobinas.

La composición ortogonal de círculos y cuadrados tangentes por el vértice formando bobinas está bien representada en Galia y Germania, como recoge Le Décor Géométrique de la Mosaïque Romaine (BALMELLE et all., 1985, lám. 156), donde se citan los ejemplos de Souzy-la Briche, Sainte Colombe, Fliessem y Rottweil. No obstante, los paralelos más cercanos, incluso con los mismos ornamentos, se encuentran en Hispania. Idéntica composición se halla en un mosaico recientemente descubierto en Valencia de Alcántara (Cáceres) ${ }^{5}$; en un mosaico de Talavera de la

\footnotetext{
${ }^{5}$ Vid. infra. Aquí los círculos, bordeados por una trenza, contienen círculos concéntricos; los cuadrados, rosetas de cuatro pétalos; y las bobinas, figuras de ocho idénticos a las del mosaico de La Malena.
} 
Reina, hoy en el Museo de Santa Cruz (Toledo) (Blázquez, 1982b, 43-46, núm. 3, fig. 21, lám. 35); en un mosaico de la villa romana de Requejo, Santa Cristina de la Polvorosa (Zamora) (Regueras, 1984, 41-49; 1990: 651-654, fig. 9, láms. V-VI), cuya única variación reside en que los círculos inscriben círculos, los cuadrados otros cuadrados, y van decorados con figuras geométricas más complejas, como nudos de Salomón compuestos, que en el mosaico de La Malena; su cronología debe oscilar entre los siglos III y IV; y en un mosaico de Cardeñajimeno (LANCHA y BARTOLOMÉ, 1988, 307-308, fig. 6).

\section{MAGAZOS (ÁVILA) (fig. 13)}

En el término municipal de Magazos, a $9 \mathrm{~km}$ de Arévalo (Ávila) se descubrió un mosaico romano durante las labores de arado realizadas en la finca propiedad de don Cándido Sánchez Rodríguez a últimos de noviembre de 1945 , que ha permanecido inédito hasta la fecha ${ }^{6}$.

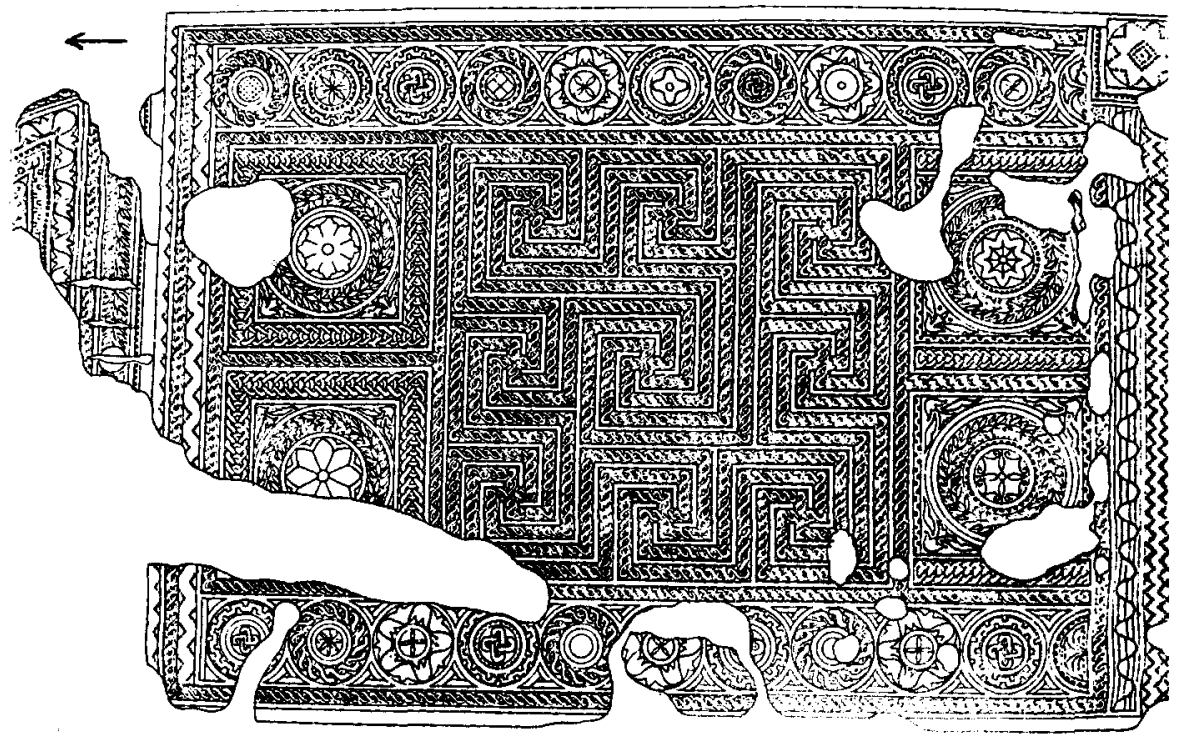

Fig. 13. Mosaico de Magazos (Ávila).

${ }^{6}$ A. Molinero dio la noticia del hallazgo de un mosaico, pero sin describirlo, cf. Molinero, 1952, 159-163. 
El pavimento, de forma rectangular, está enmarcado por una trenza y presenta en los lados mayores una orla de círculos tangentes con variados motivos decorativos. Estos círculos inscriben en su interior otros círculos concéntricos. En el anillo externo alternan las trenzas, las líneas dentadas y afrontadas y las líneas de cálices, alternativamente invertidas, adyacentes; mientras que la decoración del círculo central varía entre las rosetas de cuatro pétalos, los nudos de Salomón, rosetas de ocho pétalos, etc. En los lados menores aparecen dos cuadrados bordeados por una orla de guiloches apretado con centro curvo y ojales (BALMELLE et all., 1985, lám. $75 a, b)$, en los que se inscriben otro cuadrado y un círculo. En los ángulos resultantes del círculo inscrito en el cuadrado están representadas flores de loto. Los círculos están bordeados por una corona de laurel y contienen en su interior otros tres círculos concéntricos. Decorando el círculo más interno se encuentran motivos geométrico-florales, distintos en cada caso.

El gran cuadrado, que ocupa el centro de este mosaico rectangular, presenta una composición de líneas desplazadas de meandros de esvásticas con doble vuelta, en trenzas de dos cabos, motivo que aparece en el mosaico de la habitación núm 5 de la villa romana de El Ramalete, Tudela (Navarra) (BLÁzQUEZ et all., 1985, 69-73, núm. 45, fig. 11, láms. 4142), combinado con meandros de esvásticas con codo y vuelta invertida, fechado en un momento avanzado del siglo iv.

SANTA POLA (ALICANTE) (figs. 14-15)

En las excavaciones de 1983 realizadas en el parque «El Palmeral», al noroeste de Santa Pola (Alicante), antiguo Portus Illicitanus, se descubrió una villa de patio-peristilo, tipo de construcción mediterránea que se da en otros puntos de la Península lbérica (SÁNCHEZ et all., 1986a, 39 y ss.; SÁNCHEZ et all., 1986b, 58 y ss.). Se trata de una vivienda señorial de grandes dimensiones, con gran patio central rodeado de un corredor pavimentado con mosaicos, al que dan acceso una serie de estancias. Dos de estas estancias, las que corresponden al oecus y al triclinium, destacan por su decoración pavimental y pintura mural.

El corredor del peristilo ofrece una decoración de tipo geométrico a base de meandros de esvásticas en doble $T$, realizados en color negro sobre fondo blanco, y cuadrados que encierran nudos de Salomón sencillos y dobles, en rojo, negro, ocre y blanco, inscritos en círculos y rombos alternativamente. En algunos trozos se ha conservado una orla decorada con follaje de volutas. 


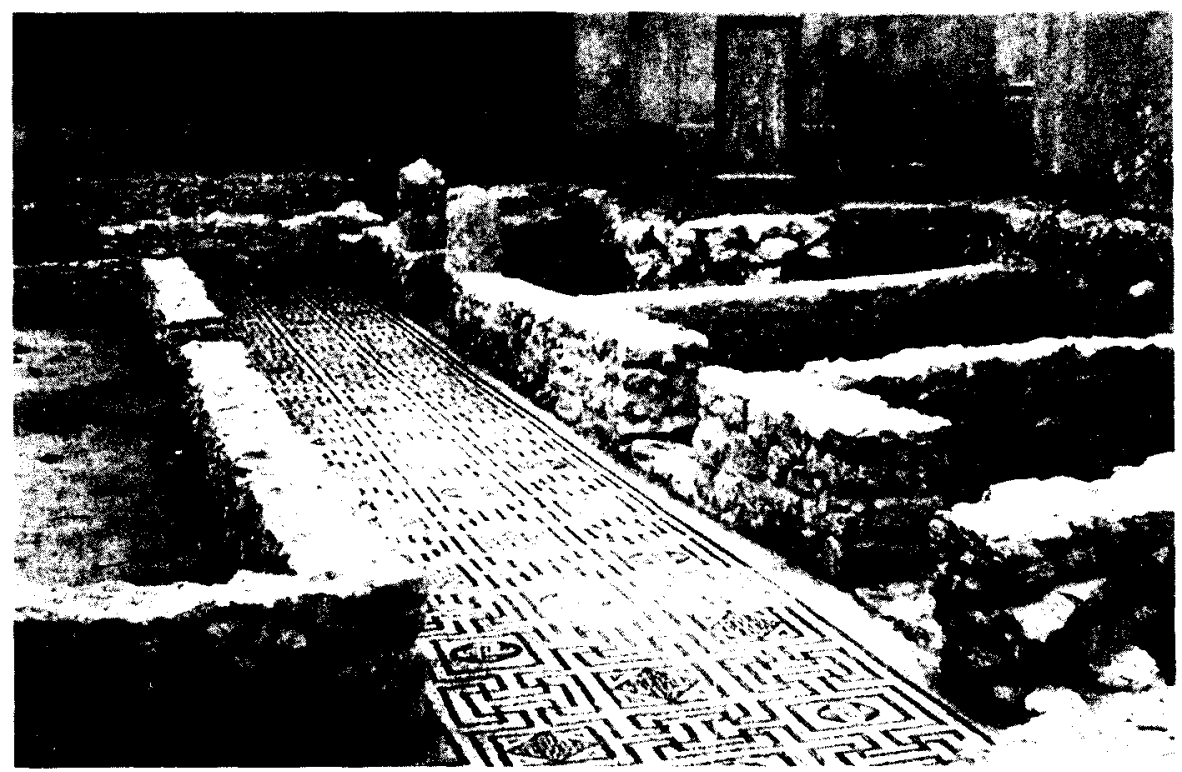

Fig. 14. Mosaico de Sta. Pola (Alicante) (según Sánchez).

El motivo geométrico formado por meandros de esvásticas en doble $T$ es muy abundante en la musivaria romana. Formando cenefa se encuentra en pavimentos de Aquileia, Carpentras, de la primera mitad del siglo III, Itálica, Moncada (Valencia), Los Torrejones de Yecla (Murcia), Rielves (Toledo) y Uxama (Soria). Decorando todo el campo del mosaico aparece en pavimentos de Mazarrón (Murcia), Mataró (Barcelona), Velilla de Ebro (Zaragoza) y fuera de Hispania en Pompeya y Jerusalén (RAmallo, 1985, 82-85, 149-151, fig. 30, láms. XXXVII-XXXVIIIb, LXXVII; OVADIAH, 1980, pl. XVI, fig. 36). Aunque se documenta con anterioridad, esta composición estuvo muy en boga en el siglo IV.

De una de las estancias que dan al corredor procede un mosaico también geométrico enmarcado por una cenefa de meandros de esvásticas, en negro sobre fondo blanco. En los ángulos se ha dibujado un cuadrado que encierra un nudo de Salomón simple inscrito en un círculo. El campo musivo ofrece una composición geométrica a base de octógonos entrelazados por pequeños cuadrados. Los octógonos contienen en su interior otros octógonos dentados en donde se inscriben alternativamente rosetas de doce pétalos y nudos de Salomón inscritos en un rombo. Los cuadrados encierran a su vez otros cuadrados pequeños re- 


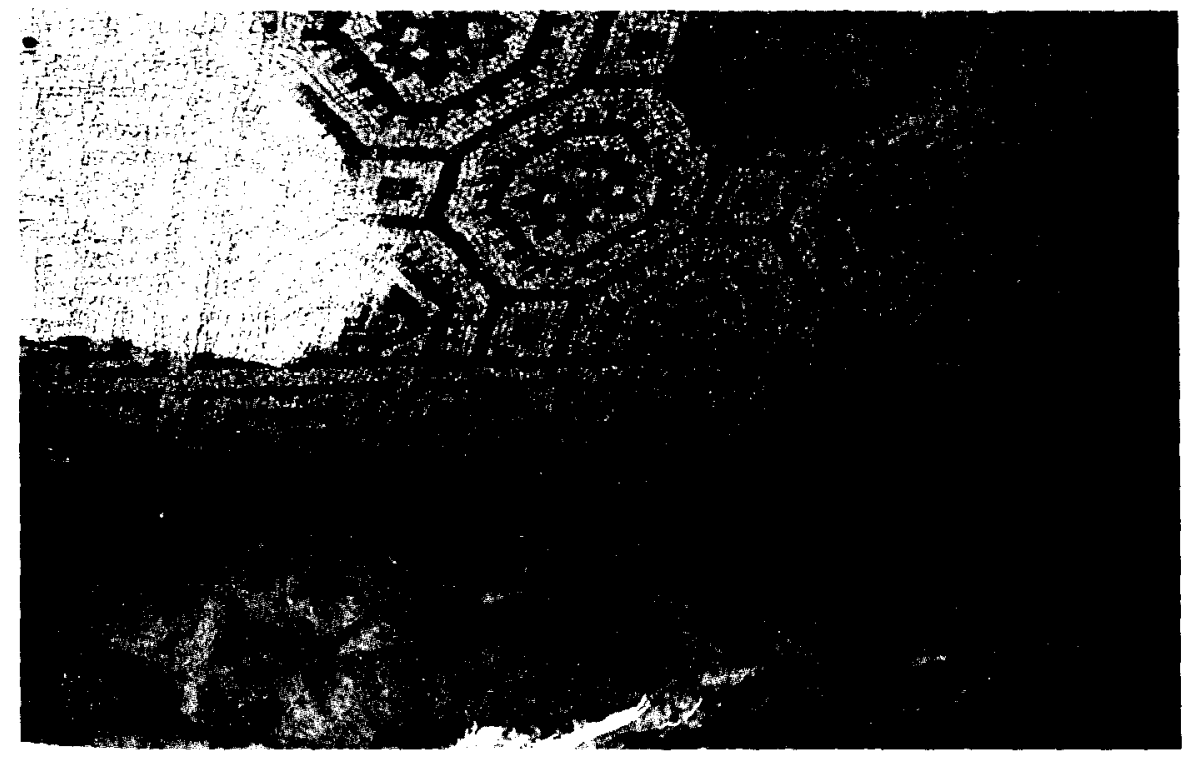

Fig. 15. Mosaico de Sta. Pola (Alicante) (según Sánchez).

llenos de teselas de color ocre.

Este esquema decorativo a base de grandes octógonos unidos por pequeños cuadrados se repite en mosaicos hispanos de las villas romanas de Los Quintanares (Soria) (BLÁzQUEz y OrTEGO, 1983, 26-27, lám. 28) y de Villafranca (Navarra) (BLÁZQUEZ et all., 1985, 75-77, fig. 12, láms. 4448, 58-60). Fuera de Hispania se encuentra la misma composición en Pompeya (Ovadiah, 1980, fig. 102, lám. XXXVII, procedente de la Casa VIII, ii, 1, de Pompeya). Los meandros de esvásticas continuas no son muy frecuentes en la musivaria romana (OVADIAH, 1980, 100 y ss.) ${ }^{7}$.

Los materiales extraidos en la excavación confieren a la villa una cronología a principios del siglo IV. Esta datación concuerda con el carácter tardio de los motivos ornamentales de los mosaicos, asi como con el material cerámico y numismático (las monedas aparecidas sobre el mosaico ofrecen una datación a partir del 321).

Meandros de esvásticas también aparecen en la orla de mosaicos de Abicada (Portugal), dados a conocer por J. M. Blázquez en el V Coloquio Internacional sobre Mosaicos Antiguos (BATH, 1987). 
CAMPO DE VILLAVIDEL (LEÓN) (figs. 16-18)

En el transcurso de unas labores agrícolas fueron descubiertos en 1982 restos de mosaicos (BLÁZQUEZ, 1985, 107-124) en la villa romana de Campo de Villavidel (León), que desgraciadamente se han destruido, y de los que tan sólo quedan las fotos sacadas por el profesor Mingarro (MingARRO et all., 1986).

La villa, situada a unos $25 \mathrm{~km}$ de León y próxima a las confluencias de los ríos Esla y Bernesga, sería, como la mayoría de las villas hispanas, una explotación agropecuaria. La sala norte estaba pavimentada con un mosaico de cacería, del que, ya en el momento de su descubrimiento, sólo se conservaban los cuartos delanteros de un caballo en actitud de correr, persiguiendo a un ciervo, probablemente herido, del que únicamente nos había llegado parte de la cabeza. Se podia observar también un ramo de hojas lanceoladas entre la cabeza del ciervo y las patas delanteras del caballo, un ramo de hojas alargadas y estrecho sobre la cabeza del animal, tres rayas delante del caballo y parte del escudo del jinete.

Escenas de cacerías son frecuentes en los mosaicos hispanos y más concretamente el tema de la caza del ciervo a caballo ${ }^{8}$. Aparece en el conocido mosaico de Dulcitius de la villa romana de El Ramalete, Tudela (Navarra) (BLÁZQUEZ et all., 1985, 64 y ss., láms. 44, 56), en el mosaico de Cardeñajimeno (Burgos) (BLÁZQUEZ et all., 1986a, 555-567) y en la Gran Caza de la villa de la Olmeda, Pedrosa de la Vega (Palencia) (PALOL y CORTÉs, 1974, 55 y ss., láms. L-LXXII) entre otros, fechados en los finales del siglo IV o comienzos del siguiente.

Como ejemplos africanos pueden mencionarse los pavimentos de la Casa de Isguntus, Hippo Regius, del 310-330 (DuNBABIN, 1978, 55, lám. 29); de la Casa de las Gracias de Cherchel (antigua Caesarea), de la segunda mitad del siglo Iv (DUNBABIN, 1978, 56, lám. 31); de Cartago, 390410 (Dunbabin, 1978, 57-62, 144, lám. 41); de Bordj-Djedid, Cartago, de fines del siglo v o del siglo vi (DunBABIN, 1978, 59, 62, lám. 41); de Djemila (antigua Cuicul), de fines del siglo Iv o principios del $\vee$ (DunBabIN, 1978, $62,78,118$, lám. 45); y de Piazza Armerina (Sicilia), mosaico de influjo africano fechado entre los años 310 y 330 (DunBabin, 1978, 245, lám. 198; CARANDINI et all., 1982, 178, fig. 97).

${ }^{8}$ Sobre mosaicos hispanos con tema de caza, cf. Blázouez y López Monteagudo, 1990, 59 88. Para el tema de la caza en los mosaicos romanos, cf. Lopez Monteagudo, 1991, 497-512. 


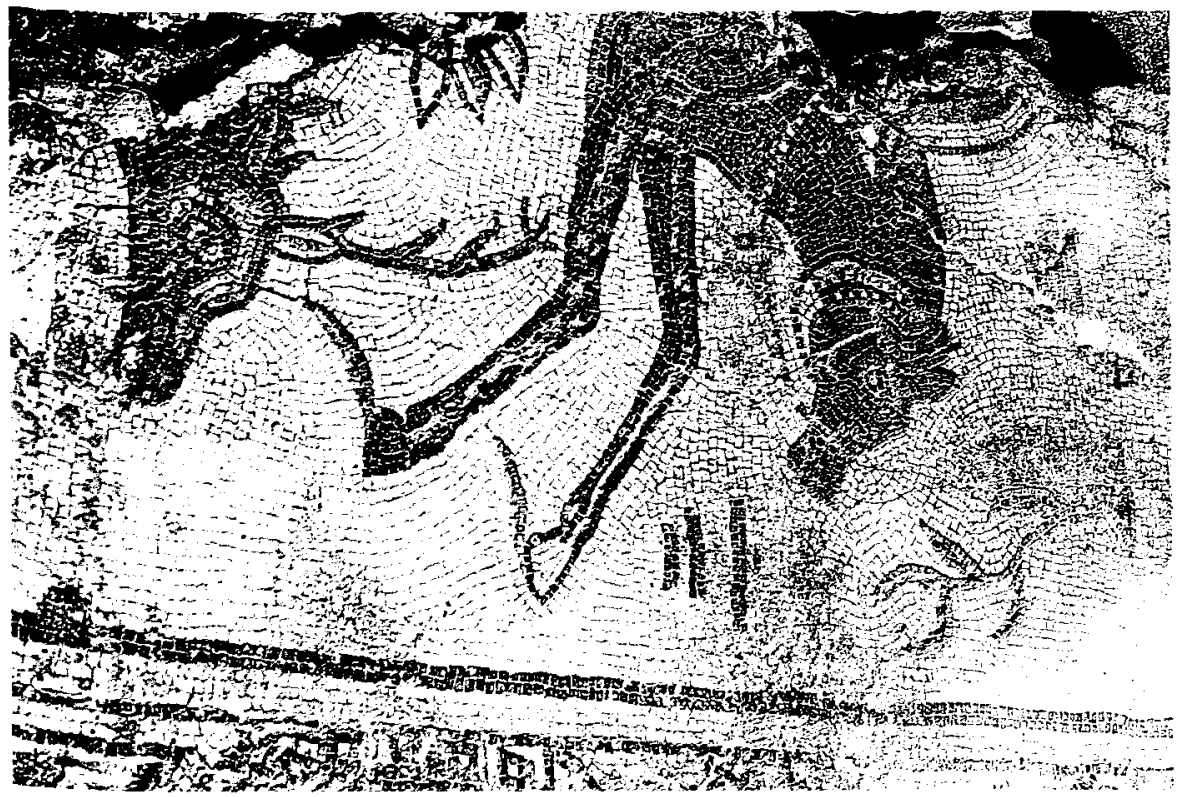

Fig. 16. Mosaico de Campo de Villavidel (León) (según Mingarro).

Analogias más concretas pueden ser citadas. En el Campo de Villavidel el jinete lleva un escudo, del que se puede apreciar una parte, al igual que el cazador del mencionado mosaico de la Casa de Isguntus de Hippo Regius. El tipo del ramo representado delante de la cabeza del caballo es idéntico al aparecido en el mosaico de Khanguet el Hadjaj (DUNBABIN, 1978, 75, lám. 65), con escenas de anfiteatro y al de Thina (DunBabin, 1978, 81, lám. 71) que se fechan al final del siglo Iv o principios del siguiente. Las hojas del arbusto tienen paralelos con las representadas en el mosaico de los Meses y las Estaciones de Dermech, Cartago (DUNBABIN, 1978, 121, lám. 110) de la segunda mitad del siglo iv, y en el mosaico de la Casa de los Caballos también de Cartago (DunBabin, 1978, 85, láms.

$L 75,76)$. La cabeza del caballo es idéntica a la de los ejemplares del mosaico con escenas de circo de Barcelona (BALIL, 1962, 257), que incluso llevan también un collarín en la zona alta del cuello. El ciervo es muy parecido a los existentes en el mosaico de la Gran Caza de Pedrosa de la Vega (Palencia), pero difiere totalmente de los emeritenses (BLANCO, 1978b, 53, lám. 96).

En cuanto a la ejecución puede incluirse en la corriente estilística de carácter impresionista que, como indicó Balil, se documenta ya en los 
mosaicos severianos de Conimbriga, y se repite en el de Dulcitius y en los cuadritos con escenas de caza de Baños de Valdearados (BLÁzQUEZ, 1985, 111).

Respecto a la decoración geométrica el mosaico de la sala norte presentaba octógonos, hexágonos, rombos y cuadrados en el centro y triángulos sobre los bordes, todos ellos enmarcados por una fila de cables. Las figuras geométricas van decoradas en el interior con peces y ostras, nudos de Salomón, flores, diversas figuras geométricas, rombos inscritos con roleos, que giran a la derecha, y líneas de puntos superpuestas, alternando las blancas con las negras y las marrones.

La decoración de peces es bien conocida en los mosaicos del Bajo Imperio de Hispania. Pares de peces dentro de figuras geométricas aparecen en los mosaicos de San Martín de Losa (Burgos) (ABÁSOLO, 1983, 248, fig. 14, láms. III-IV, X-XIII) ${ }^{9}$, de Vega de Ciego (Asturias) (EscortelL, 1975, 56, láms. LV-LVIII) de finales del siglo IV o comienzos del siguiente, y de Ucero (BLÁZQUEZ y ORTEGo, 1983, 50, fig. 3). Sobre la representación de peces en general sabemos que en Galicia trabajó en el siglo IV una escuela de musivarios especializados (BALIL, 1975, 259, láms. CIII-CVI), y peces encontramos decorando una piscina en el sur de Lusitania (HausCHILD, 1979, 214, láms. 54-57), así como en un mosaico de Complutum (Fernández Galiano, 1984a, 100 y ss.) ${ }^{10}$.

Para los autores que han dado a conocer estos pavimentos uparece ser que las representaciones de pisciformes y la ostrea de Campo de Villavidel están realizadas por artesanos de segunda fila y con poca experiencia en las artes de la musivaria, mientras que el clipeus de la sala norte fue confeccionado por un especialista y su estilo no corresponde al resto de las partes del mosaico de esta misma sala", observación que indica claramente que en un mismo mosaico trabajaban varias manos, dejándose las partes más nobles a los mejores artesanos (Mingarro et all., 1986, 27).

La decoración de cuadritos con peces es usual también en mosaicos bajoimperiales de fuera de la Península. Baste recordar los ejemplos de Leptis Magna (AurigemmA, 1960, 52, láms. 107, 109, 111) y varios de Zliten

${ }^{9}$ En este caso dentro de octógonos, mientras que en Villavidel los peces se hallan dentro de hexágonos.

${ }^{10}$ Otros mosaicos hispanos decorados con peces han aparecido en Pedrosa de la Vega (PALOL y CORTÉs, 1974, 81, figs. 13-52, láms. XXXVI, XLVI-XLVII), Quintanilla de la Cueza (GARCia GUINEA, 1982, 26 y ss., láms. 41, 25), Santervás del Burgo (BLÁZQUez y OrTEgo, 1983, 49 y ss., láms. 22, 48), El Ramalete (BLÁzQuez et all., 1985, 62 y ss., fig. 9) y Conimbriga (BAIRRÁo Oleiro, 1965, 260, fig. 5). 


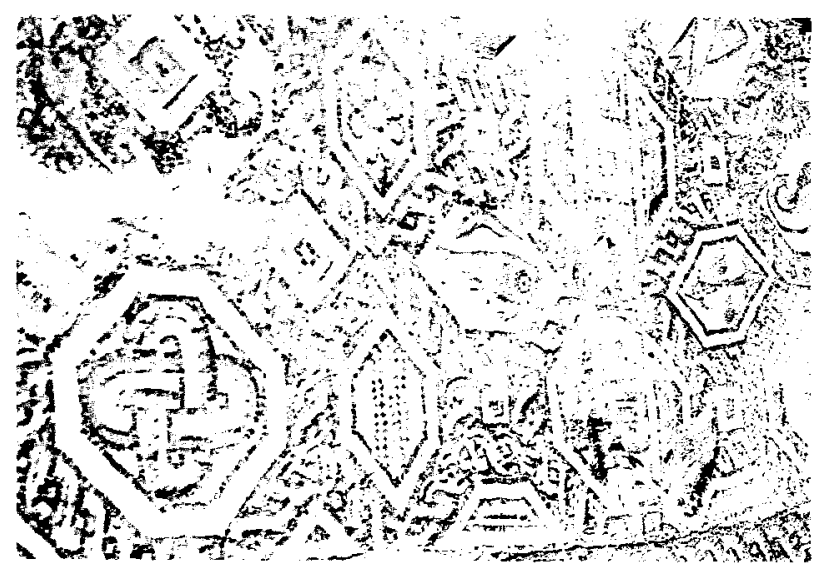

Fig. 17. Mosaico de Campo de Villavidel (León) (según Mingarro).

(Aurigemma, 1960, 55, láms. 126, 128, 135-140, 177-178) ${ }^{11}$, del edificio absidal de Tegea, de la segunda mitad del siglo $v$ (SPIRO, 1978, 185, láms. 201-202, 204); de la basílica de Delfos, datada a finales del siglo $\mathrm{V}$ o comienzos del siguiente (SPIRO, 1978, 245, lám. 269); de la basílica de Klapsi, de la primera mitad del siglo vı (Spıro, 1978, 297, láms. 317-319, 338-343, 347); de la basilica Gamma de Nea Archialos, de fines del siglo $\checkmark$ o comienzos del siguiente (Spiro, 1978, 321, lám. 367), etc. La cronología de estos edificios probaría la pervivencia del tema de los peces durante mucho tiempo en la musivaria oriental.

El mosaico de la sala sur está decorado con cuadrados, semicírculos, círculos y rectángulos curvilíneos. En el interior de estas figuras se han colocado motivos vegetales, hojas lanceoladas, acorazonadas, flores de lis y de loto, y geométricos como los nudos de Salomón, cuadrados, rombos, triángulos, etc.

Paralelos se encuentran en pavimentos de la provincia de Zamora, que se hallaron en la villa romana de Requejo, Santa Cristina de la Polvorosa (Gago, 1984, 50; Regueras, 1984, 42-49; 1990, 637-696). Los tres temas florales son próximos a los representados en Vienne (LANCHA, 1983, 245) y en un caso en Lambesis (Germain, 1983, 173, lám. CCXXXV,3).

Una variante del esquema decorativo del mosaico de Campo de Villavidel, un tanto más refinado, pues los lados de las figuras geométricas,

"Sobre la representación de peces en mosaicos del norte de África, vid. PICARD et all., 1977,32 y ss. 


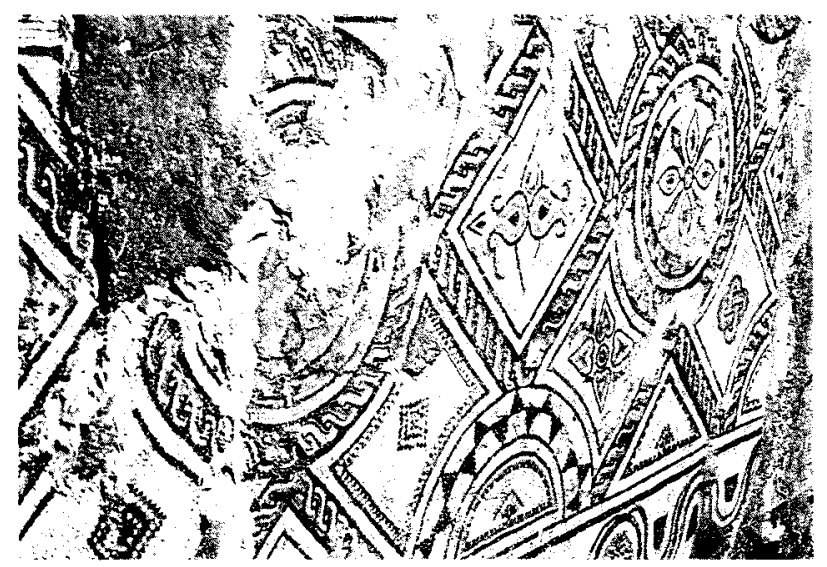

Fig. 18. Mosaico de Campo de Villavidel (León) (según Mingarro).

rectángulos y rombos, se subdividen en arcos, una o dos veces, es el mosaico de Complutum con el tema de Júpiter y Leda (FERNÁndez Galiano, 1984a, 203, fig. 13, lám. CIX). Todos estos paralelos son interesantes para conocer la extensión dentro de Hispania de los talleres que utilizaban los mismos esquemas y la misma temática, que formaba una gran unidad estilistica, que comprendía desde los Pirineos hasta Asturias y León, la meseta castellana hasta Ciudad Real y Emerita Augusta (FERnÁndez GALIANO, 1984a, 110, 132, 186, 213).

\section{QUINTANA DEL MARCO (LEÓN) (figs. 19-21)}

En una colección particular de la provincia de León se conservan, procedentes de la villa de Quintana del Marco, varios fragmentos de mosaicos polícromos de gran belleza e interés iconográfico ${ }^{12}$.

El primero de ellos, que es el que presenta la escena figurada, corresponde a una orla de $80 \mathrm{~cm}$ de ancho. Ofrece una franja de rectángulos

\footnotetext{
${ }_{12}$ Agradecemos al profesor Dr. Julio Mangas la noticia de estos hallazgos, así como las fotografías que ahora publicamos. Los mosaicos han sido publicados por nosotros con posterioridad al Congreso de Bath, cf. López MONTEAGudo et all., 1988, 795-798, figs. 12, 15 y 16.
} 
verticales curvilineos, en oposición de colores, que enmarca una orla de tipo floral, con hojas de acanto y flores de cuatro pétalos. Dentro de esta decoración fitomorfa barroquizante es posible distinguir, a pesar de su mal estado de conservación, la figura de un cazador dentro de un roleo de acanto, con una franja que le atraviesa el pecho desde el hombro izquierdo. Está visto de perfil y lleva una jabalina en la mano derecha. Su actitud es la de acecho o acometida a una fiera que no se ha conservado.

Las escenas de cacería son frecuentes en mosaicos sirios y africanos del Bajo Imperio (LAvin, 1963, 179; DunbabIN, 1978, 45; López MonteaGUDO, 1991, 497-511). En Hispania se documentan numerosas escenas de caza, que han sido recogidas por dos de nosotros en un trabajo reciente (BLÁzQUez y López MonteAgudo, 1990, 59-88). El paralelo más cercano para la escena representada en el mosaico de La Bañeza se encuentra en la orla del mosaico de Atalanta, en Apamea de Siria, compuesta por grandes roleos de hojas de acanto, en uno de los cuales se ha colocado la figura de un cazador que, con una jabalina, acomete a una fiera situada en el roleo contiguo. Este mosaico se fecha en el último cuarto del siglo v (DuLIÈRE, 1969, 125, lám. LIla; BALTY, 1977, 118-122, núms. 5456). Una composición semejante se encuentra asimismo en la orla del mosaico de la Sala de Hipólito en la iglesia de la Virgen de Madaba, con una cronología ya en la mitad del siglo vi (PICCIRILlo et all., 1986, 48,

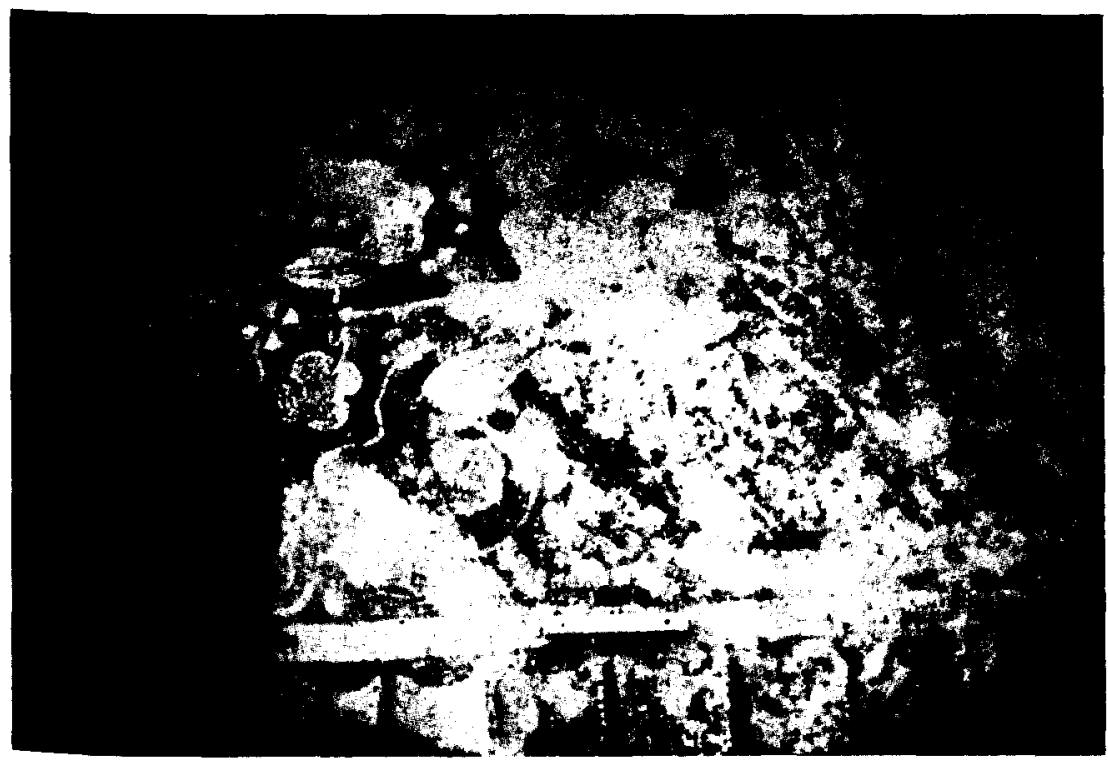

Fig. 19. Mosaico de La Bañeza (León) (Foto cortesia J. Mangas). 


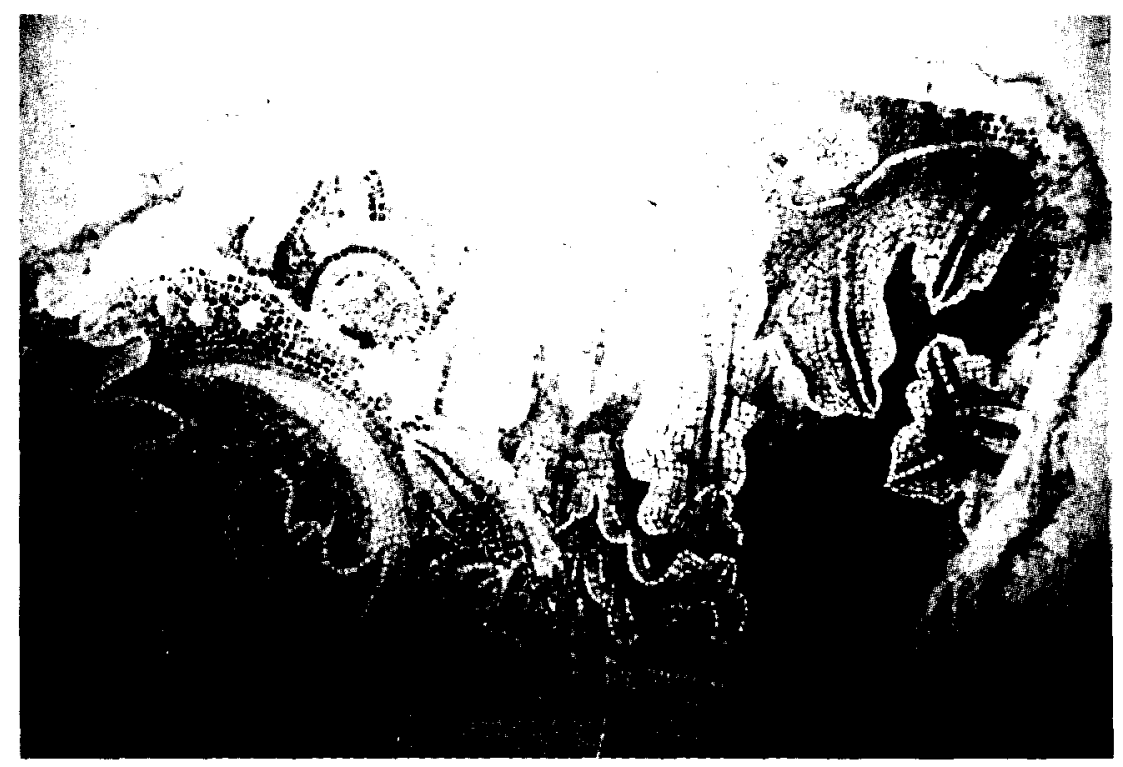

Fig. 20. Mosaico de La Bañeza (León) (Foto cortesia J. Mangas).

núms. 15-16, lám. IV). Muy anterior a estas fechas, ya que se data a mediados del siglo III, es la orla de Shahba Philippopolis con putti cazadores entre roleos de acanto (BALTY, 1977, 24, núm. 7). El mosaico de La Bañeza se puede fechar, por los paralelos iconográficos y estilísticos, en el Bajo Imperio.

El segundo fragmento corresponde a otra orla decorada con grandes hojas de acanto, muy semejante a la ya publicada por uno de nosotros (BLÁZQUEZ, 1977-1978, 274-275, fig. 7), procedente de la villa romana de Quintana del Marco. Es un tema decorativo muy frecuente en mosaicos del siglo III y del Bajo Imperio, encontrándose en varios pavimentos de Timgad (GermaIn, 1969, láms. XX, XXI, XLIV, XLV, LXXXI, LXXXII) y en la villa constantiniana de Antioquia (LEVI, 1947, 226) con el que ofrece una semejanza notable.

Otros dos fragmentos ofrecen una decoración geométrica a base de octógonos concéntricos, con flores de seis pétalos en el interior, alternando con rectángulos y cuadrados que encierran dos círculos concéntricos. Todas las figuras geométricas van contorneadas por un sogueado que enlaza unas y otras. Estos fragmentos son exactamente iguales a los ya publicados procedentes de la villa romana de Quintana del Marco 


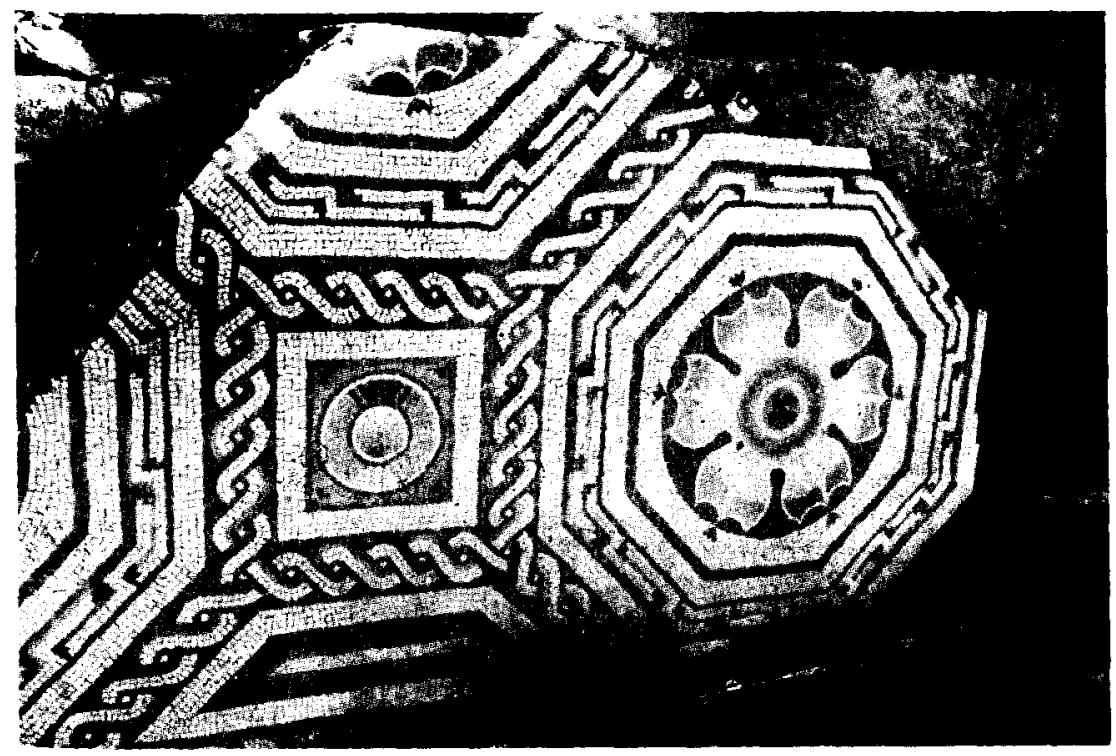

Fig. 21. Mosaico de La Bañeza (León) (Foto cortesia J. Mangas).

(BLÁzQuez, 1977-1978, 275, fig. 8), por lo que hay que suponer que todos pertenecen al mismo mosaico. Un esquema compositivo semejante se ve en mosaicos sorianos de Santervás del Burgo (BLÁZQUEZ y ORTEGO, 1983, 38, lám. 13) y en la villa romana de Rielves (Toledo) (FERNÁNDEZ CASTRo, 1982, 61 y ss., figs. 31, 37), de mediados del siglo IV. Fuera de Hispania, algunos de los motivos decorativos, como el rosetón dentro de un rectángulo, se encuentran en un mosaico de Antioquía de la misma fecha (LEVI, 1947, lám. CXVIc).

\section{HELLIN (ALBACETE) (figs. 22-23)}

La villa está situada al norte del casco urbano de Hellín. En 1925 se halló un mosaico, con una variada y exquisita decoración, que se conserva en muy mal estado en el Museo Arqueológico de Albacete (RAmallo y JORDAN, 1985, 16) ${ }^{13}$. Al parecer se trata de un pavimento de triclinium con

\footnotetext{
13 Agradecemos a la Directora del Museo Arqueológico de Albacete las facilidades y el permiso para fotografiar este mosaico, que ha sido objeto de un estudio completo por nosotros, cf. BLÁZQUEZ et all., 1989, 47-49, láms. 16, 17, 32 y 33 .
} 
la típica disposición en T más U. En su estado actual mide $6,38 \times 4,29$ $\mathrm{m}$, siendo su longitud original de $8,35 \mathrm{~m}$. Lo que resta del pavimento son una serie de cenefas y orlas que enmarcan un rectángulo de $1,70 \times 1,30$ $\mathrm{m}$ realizado en opus signinum.

En la $U$ se ha conservado una franja, de $1,57 \mathrm{~m}$ de ancho, con decoración de damero de cuadrados blancos y negros, de $45 \mathrm{~cm}$ de lado, sobre los que se superponen flores cuatripétalas que determinan círculos secantes, en beige-amarillo verdoso. Dos bandas, la primera con dos hileras negras, bordean una cenefa de trenza de cuatro cables, a la que sigue una orla con roleos de acanto, que encierran distintos animales,
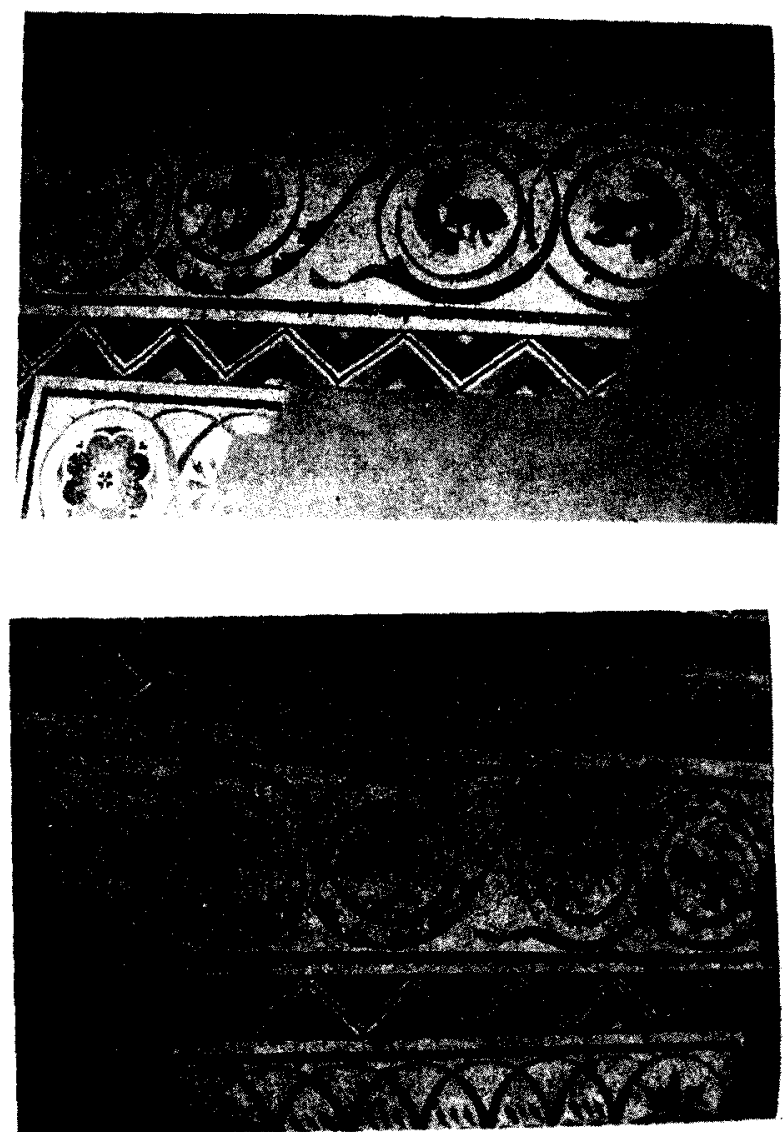

Fig. 22. Mosaico de Hellin (Albacete) (Foto López Monteagudo). 

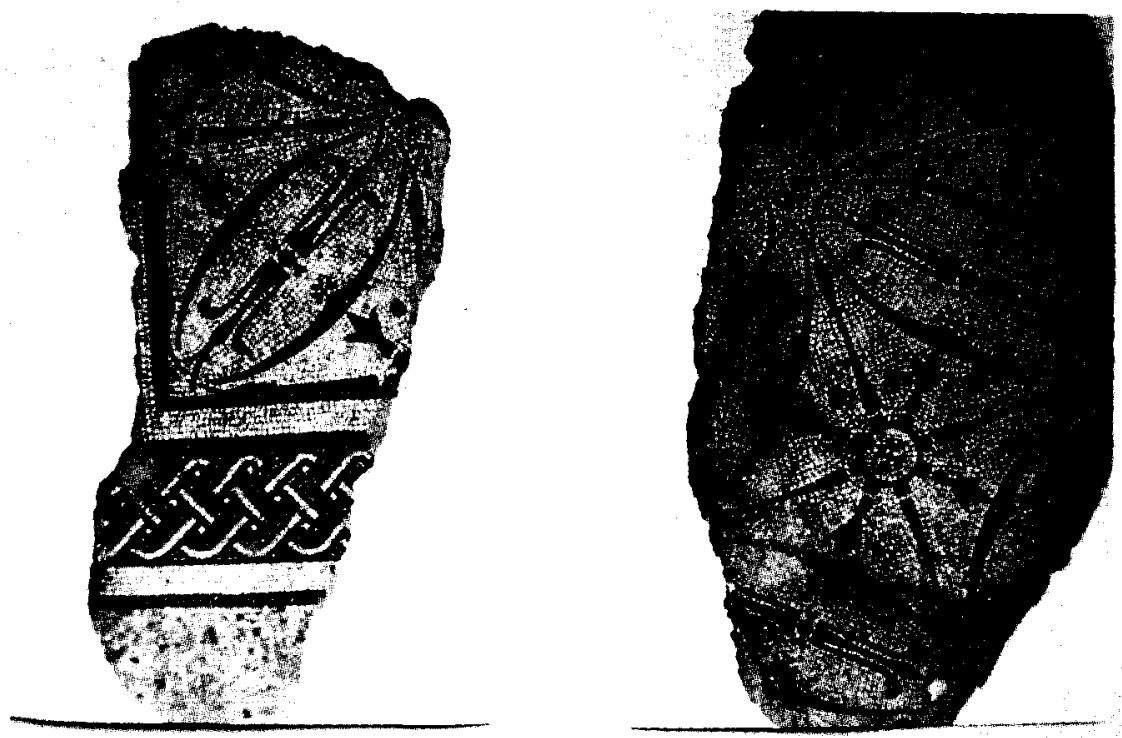

Fig. 23. Mosaicos de Hellin (Albacete) (Fotos López Monteagudo).

entre dos hileras negras. Sigue otra cenefa con decoración de escuadras alineadas, alternativamente invertidas, y otra orla entre hileras negras con cintas entrecruzadas de trazos negros, rojos y amarillos, atrevesada por una línea de espiga con florones en los ángulos.

Del vástago horizontal de la $T$ se han conservado dos fragmentos con una decoración fitomorfa geometrizante. Uno de ellos corresponde al ángulo, viéndose parte de la trenza de cuatro cables. De este mosaico nos interesa fundamentalmente la orla de roleos de acanto, en grupos de dos con animales enfrentados y colocados cada uno dentro de un roleo. En la asociación animalística se ha elegido siempre un hervíboro y un depredador, y de esta forma se ven, empezando por la izquierda, león y toro, gamo y león (?), búfalo y oso, alce y leopardo, gamo y lobo. Un paralelo muy próximo se encuentra en la orla del mosaico del triclinium de la Casa de la Procesión Dionisíaca de EI Djem, en donde se documenta exactamente la misma disposición con pares de animales enfrentados, de mediados del siglo " (FouCHER, 1963, 53, fig. 1, lám. XVI). Este mosaico se fecha a mediados del siglo $\|$ d.C. Otros paralelos, con la misma cronología, son la orla del mosaico de Rímini con distintos animales dentro de espirales de acanto, y el mosaico de las Termas de los Siete Sabios 
de Ostia, en cuyo campo se distribuyen veintitrés animales entre las espirales que forman los distintos roleos de acanto (RAMALLO y JORDÁN, 1985, con todos los paralelos). En Hispania se documenta una orla con roleos de acanto, encerrando animales en Cardeñajimeno (Burgos) y en La Bañeza (León), como se ha indicado anteriormente.

En cuanto a los fragmentos con decoración geométrica floral, se integran dentro de las concepciones tradicionalmente llamadas de estilo florido, que tanto abundan en el norte de Africa (GozLAN, 1983, 1979, láms. CIX-CXI). La composición a base de damero de cuadros y círculos secantes es rara en Hispania, documentándose solamente en un pavimento de Jumilla y fuera de la Península en dos mosaicos de la villa romana de Gurgi (RAmallo y JORDÁN, 1985, 18). Las cintas onduladas, atravesadas por una fila de espigas, se encuentran en mosaicos de Ostia, Germania y norte de África (RAMALLO y JORDÁN, 1985, 20, 21). En Hispania, un paralelo exacto en Complutum (FERnÁndez Galiano, 1984a, lám. XLIII).

La cronología propuesta para el mosaico de Hellín es a finales del siglo $\|$ o primer cuarto del 111 , conjuntándose las precisiones estilísticas del pavimento y los hallazgos arqueológicos (cerámica y monedas predominantemente de los Antoninos).

"CAMINO DE ALBALATE», CALANDA (TERUEL) (fig. 24)

En la excavación de esta villa se pusieron al descubierto varios mosaicos que decoraban tres habitaciones. La primera con un mosaico de tipo geométrico con combinación de trenzados; la segunda, que describiremos seguidamente, daba acceso mediante unas escaleras, también cubiertas de mosaico, a una habitación semicircular decorada con mosaico de motivos geométricos y florales. Todos ellos se hallan en el Museo Arqueológico de Teruel y están en estudio (ATRIAN et all., 1980, 137-138, lám. XXXI; Fernández Galiano, 1987, 101-102, núms. 158-160, lám. XLIV).

El mosaico de la segunda habitación, enmarcado por una greca de nudos trenzados y pequeños delfines y de un borde dentado, presenta como motivo central seis recuadros bordeados por una trenza de dos cabos, que va formando octógonos en tres de los paneles. En cada uno de los recuadros o paneles se ha representado la figura de un animal. En la parte superior y de izquierda a derecha aparecen: caballo, jabalí y pantera; abajo y siguiendo el mismo orden: león, asno y leopardo. Todos aparecen sobre un fondo de paisaje indicado mediante rocas, árboles, ramas y motivos fitomorfos. El panel que contiene la representación de la pantera va enmarcado por un filete dentado. 


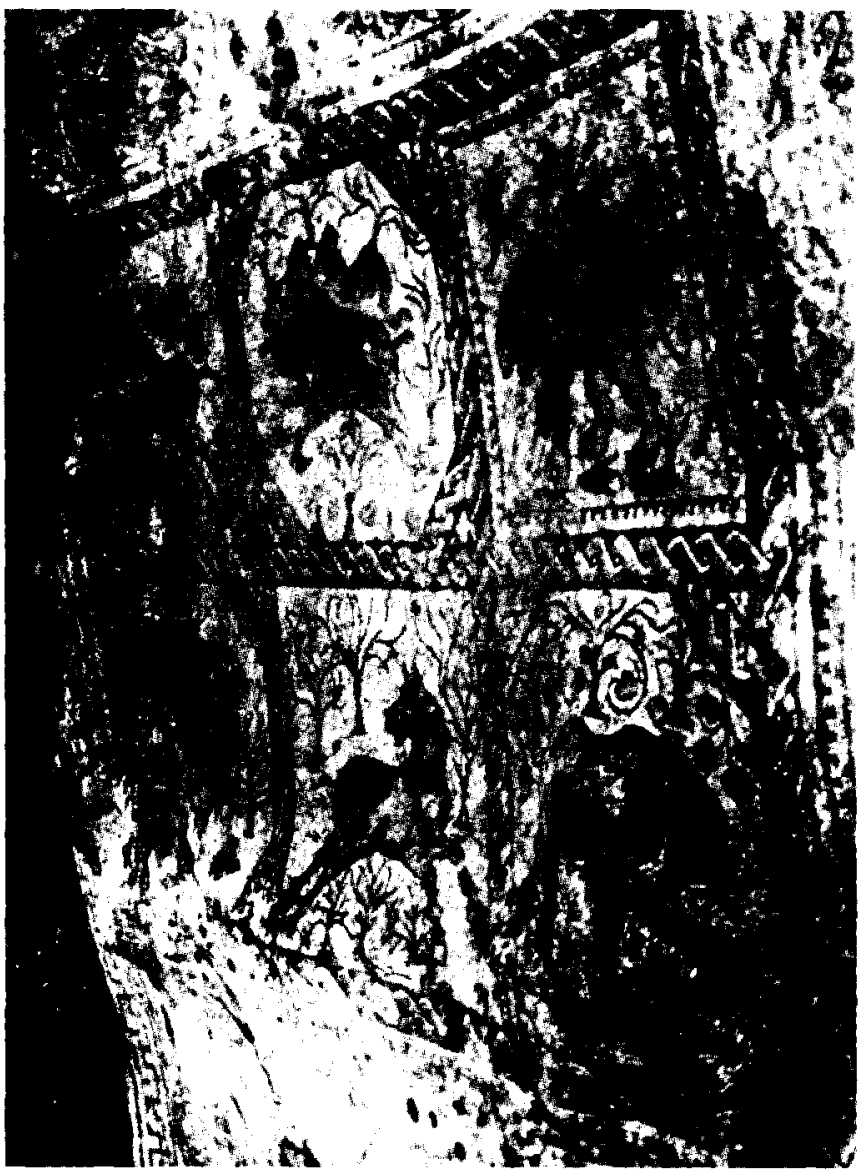

Fig. 24. Mosaico de "Camino de Albalate», Calanda (Teruel) (según Atrián).

El material arqueológico recogido en la excavación proporciona una cronología de mediados del siglo Iv para el final de la villa.

El mosaico con la representación de los seis animales es único en Hispania y hay que encuadrarle, con toda seguridad, en la serie de mosaicos romanos con representación de las fieras del anfiteatro, que tan frecuentes son en el norte de África (BLÁzQUEZ et all., 1990, 195-199) en donde, a veces, aparecen las fieras acompañadas de su nombre y de un número romano indicativo, según Lavin, de la cantidad de ejemplares de cada especie que tomaron parte en el munus (LAVIN, 1963, 235; DUNBABIN, 
1978, 46). La participación de asnos en los venationes del anfiteatro está documentada también en el mosaico del frigidarium XV de la Casa de Asinius Nica, en Djemila, de fines del siglo $\mathrm{V}$ o comienzos del $\vee$ (BLANCHARD, 1975, 85-96, láms. XVI-XX).

CÓRDOBA (fig. 25)

El 26 de octubre de 1965 el periódico $A B C$ de Sevilla publicó una pequeña reseña y una fotografía de un mosaico romano descubierto durante las labores de cimentación de un edificio en una plaza de Córdoba. La inexistencia de su publicación hasta la fecha nos induce a darlo a conocer aquí.

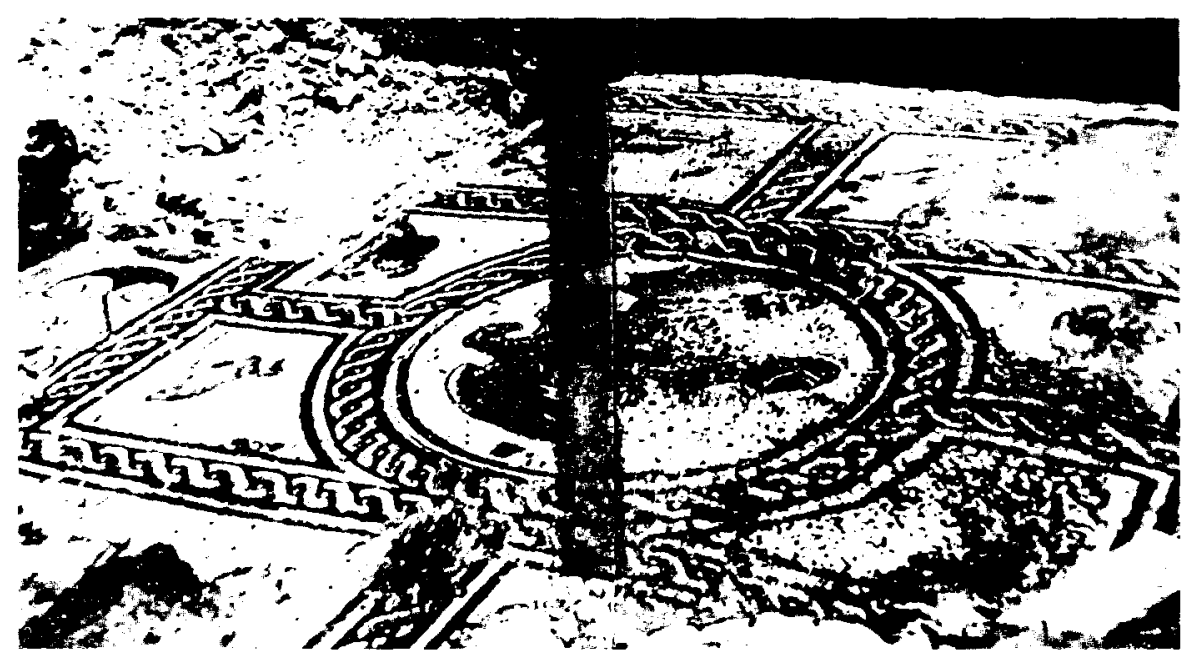

Fig. 25. Mosaico de Córdoba (Foto "ABC" de Sevilla).

El mosaico está enmarcado por una línea de peltas verticales, afrontadas a cada lado de un cuadrado sobre la punta (BALMELLE et all., 1985, fig. 59a). Cuadros en torno a un gran medallón central, bordeados por una trenza, forman el campo del mosaico. En el interior de estos cuadros se hallan representadas distintas aves, como sucede en el recientemente descubierto mosaico de Beas de Segura (Jaén), estudiado a continuación, 
y en otros muchos de Hispania y fuera de la Península ${ }^{14}$. En el medallón central destaca majestuosa la figura de un águila sobre el globo terráqueo 15.

BEAS DE SEGURA (JAÉN) (fig. 26)

En los meses de noviembre y diciembre de 1985 fue puesto al descubierto un mosaico de pájaros en la villa romana situada al suroeste del arroyo del Ojanco, en Beas de Segura (Jaén), perteneciente a la última fase de ocupación de la villa ${ }^{16}$.

El mosaico (BLÁZQUez et all., 1986b, 227-232), muy deteriorado especialmente en la parte central, va enmarcado por una orla decorada con follaje de acanto estilizado y forma una retícula de cuadrados con los ángulos curvos, separados en sus vértices por círculos, en los que se inscriben rosetas estilizadas. En el interior de los cuadrados aparecen alternativamente distintas aves, entre las que pueden identificarse una avefría y una perdiz, y motivos geométricos como las rosetas de hojas acorazonadas o lanceoladas, de flores de loto estilizadas y otras rodeadas de peltas.

La decoración a base de pájaros dentro de cuadros es frecuente en mosaicos de Hispania. Treinta y dos cuadros con aves de vistoso plumaje en diferentes actitudes están documentadas en un mosaico italicense de la llamada Casa de los Pájaros (García y Bellido, 1979, 13, fig. 22, lám. VIII; LuzóN, 1975, 96 y ss., lám. VIII); cuatro rectángulos con pájaros rodean el medallón con la figura de Dioniso del mosaico de Baco (GARCíA Y BELLIDo, 1979, 132, lám. IX) hallado también en la citada casa, ambos fechados en la segunda mitad del siglo II, así como en un pavimento de la villa de Albesa (Lérida), datado en el siglo iv (BALIL, 1965, 288, fig. 10; BlázQuez et all., 1989, 14-15, núm. 2, láms. 1, 2 y 20); y en un mosaico de la villa vallisoletana de la Granja de José Antonio (RIVERA y WATTENBERG, 1955, 145 y ss., lám. II). Aves rodeando un círculo central, con águila en

4 Todos los paralelos de mosaicos con representación de pájaros dentro de recuadros 0 de círculos están recogidos por Blázquez, ct. BLAzQUEz et all., 1986b, 228-229.

${ }^{15}$ En una anterior publicación (BLÁZQUEZ et all., 1986b, 228, fig. 7) se hacía referencia a este mosaico y se daba una fotografía parcial de uno de los recuadros con pájaro en su interior. Ahora se presenta el mosaico completo.

${ }^{16}$ Queremos agradecer a F. Hornos, M. Castro y J. Crespo la colaboración prestada al facilitarnos los datos contenidos en el informe de la excavación de urgencia, aún inéditos, asi como las fotografias. 


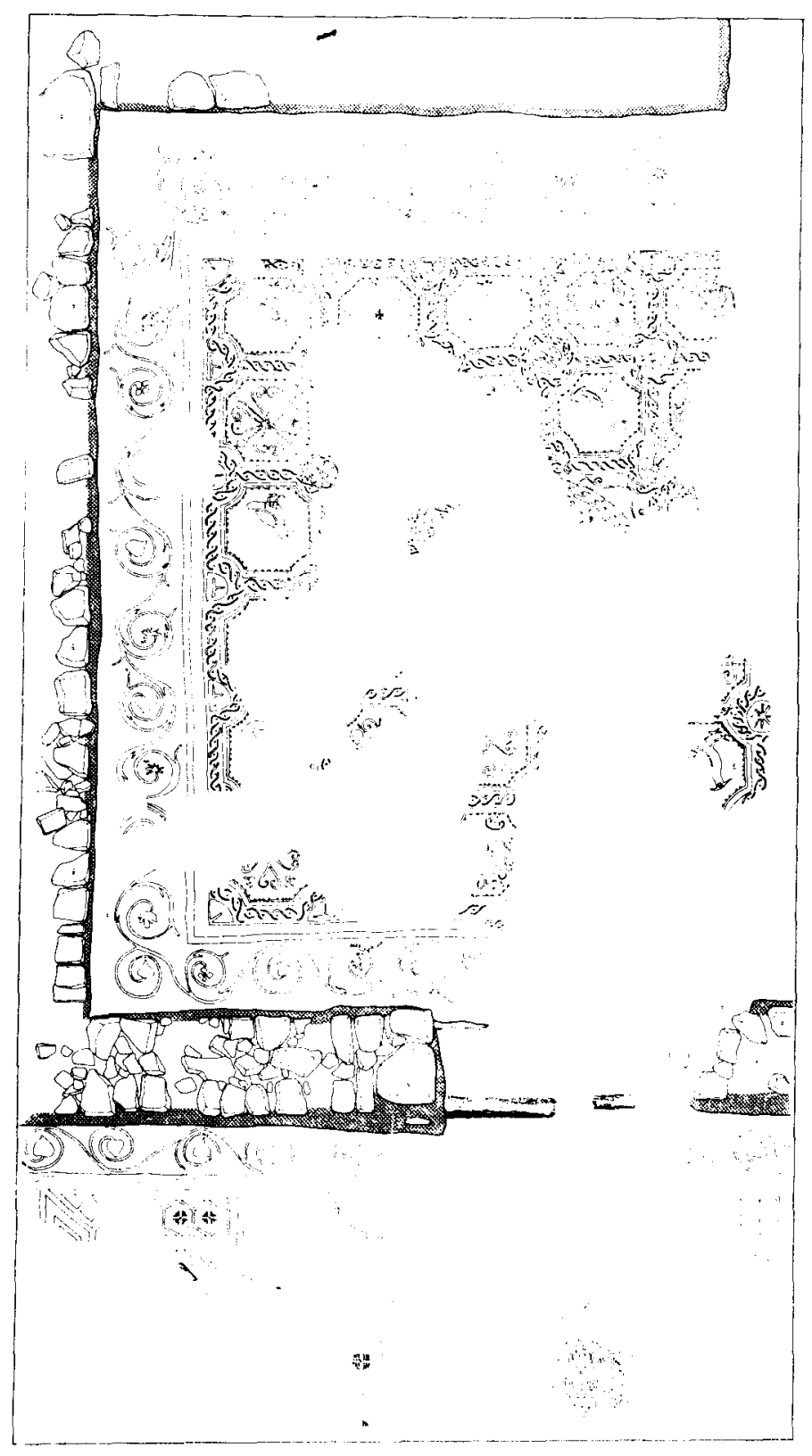

Fig. 26. Mosaico de Beas de Segura. 


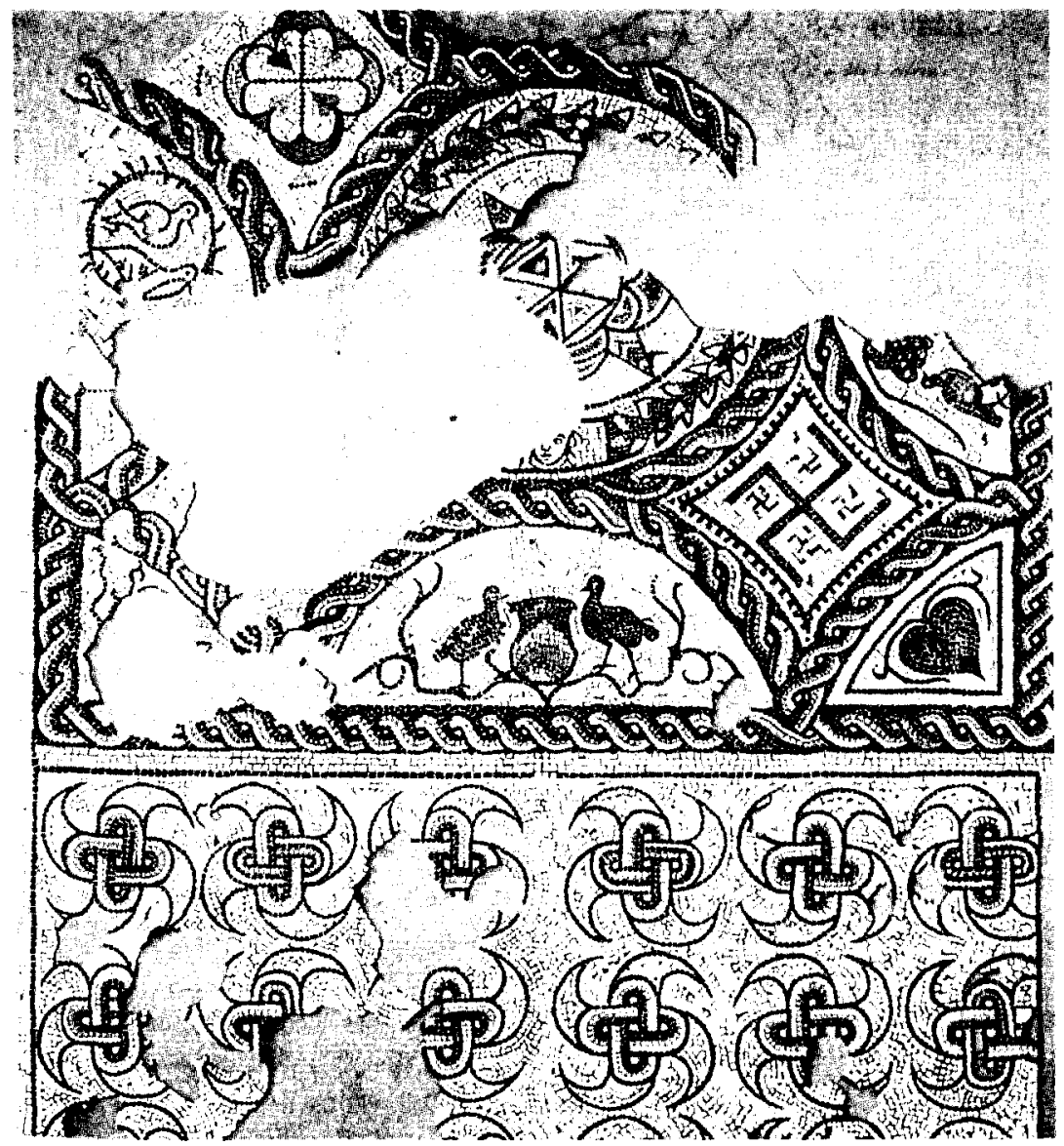

Fig. 27. Mosaico de Pisòes (Portugal) (segun Mac Millan).

Su interior, y enmarcadas por una trenza aparecen también en el mosaico de Córdoba citado anteriormente. Estilísticamente el mosaico de Beas de Segura puede fecharse en el siglo Iv.

\section{PISÔES (PORTUGAL) (fig. 27)}

La villa romana de Pisôes está situada a $7 \mathrm{~km}$ de Beja (Pax lulia) parroquia de Sâo Tiago Maior, en el corazón de la región cerealista más productiva de Portugal. 
Sus mosaicos destacan por la sobriedad, ya que no hay escenas de cacería, ni mitológicas. La mayoría de ellos son geométricos, a excepción del que presentamos aquí. Sin embargo, todos destacan por la finura del colorido y lo escogido de sus motivos (MACMILLAN, 1986, 38; VARGAS CosTA, 1988, 95-135).

Entre todos los mosaicos descuella el que parece corresponder a la cámara principal. Bastante deteriorado, cubre un espacio de $5 \times 4 \mathrm{~m}$ y se divide en tres paneles, siendo el del centro el mejor trabajado y el único de toda la villa que tiene motivos figurativos. Presenta una composición de esquema a compás, como otros mosaicos hispanos (FERNÁNDEZ GALIANO, 1980) ${ }^{17}$. El medallón central ostenta una decoración geométrica, mientras que las lunetas van decoradas con motivos de pájaros: dos pájaros flanqueando un recipiente; paloma picoteando un racimo de uvas; círculo con dos pájaros y restos de las patas de una zancuda; la cuarta se ha perdido. De los ángulos subsiste solamente uno decorado con una hoja acorazonada. Los dos espacios curvilíneos que quedan están decorados con una cruz gamada uno y el otro con cuatro peltas encadenadas. El panel de la entrada muestra una decoración a base de grupos de cuatro peltas unidas por un nudo de Salomón. Los colores son suaves, en la gama del siena, ocre, amarillo, rosa y azul pálidos.

AGUILAFUENTE (SEGOVIA) (figs. 28-29)

El mosaico de los caballos pavimentaba el oecus de la villa de Santa Lucía (LUCAS, 1977, 239-255; 1986-1987, 219-235). Aunque sólo se ha recuperado un tercio de la superficie, es posible delimitar el espacio primitivo y reconstruir teóricamente la composición de opus tessellatum.

El pavimento, que cubría un espacio de $9,80 \times 8,30 \mathrm{~m}$ presenta una composición ortogonal de cuadrados de trenza polícroma de dos cabos, que encierran variados motivos decorativos: círculos, cuadrados de punta, florones estrellados de ocho puntas, nudos de Salomón, flores y hojas, ruedas, peltas albergando triángulos escalonados, etc. La combinación de colores, con predominio del rojo y blanco sobre el amarillo y negro, produce la sensación de un abigarrado tapiz de gran efecto visual y acusado

17 Otros dos mosaicos con la misma composición son los de Casariche (Sevilla) y Carranque (Toledo). vid. intra. 


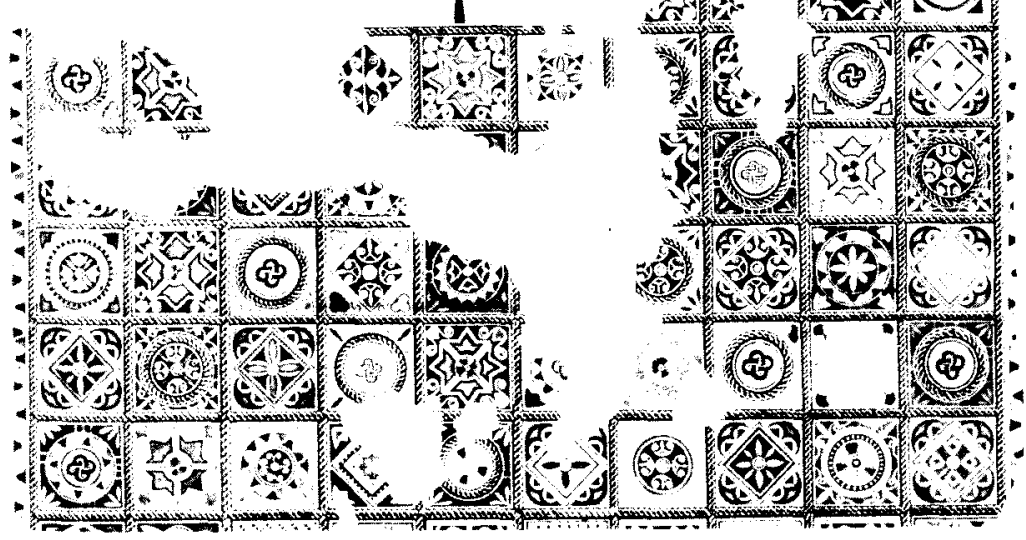

Fig. 28. Mosaico de Aguilatuente (Segovia) (según Lucas).
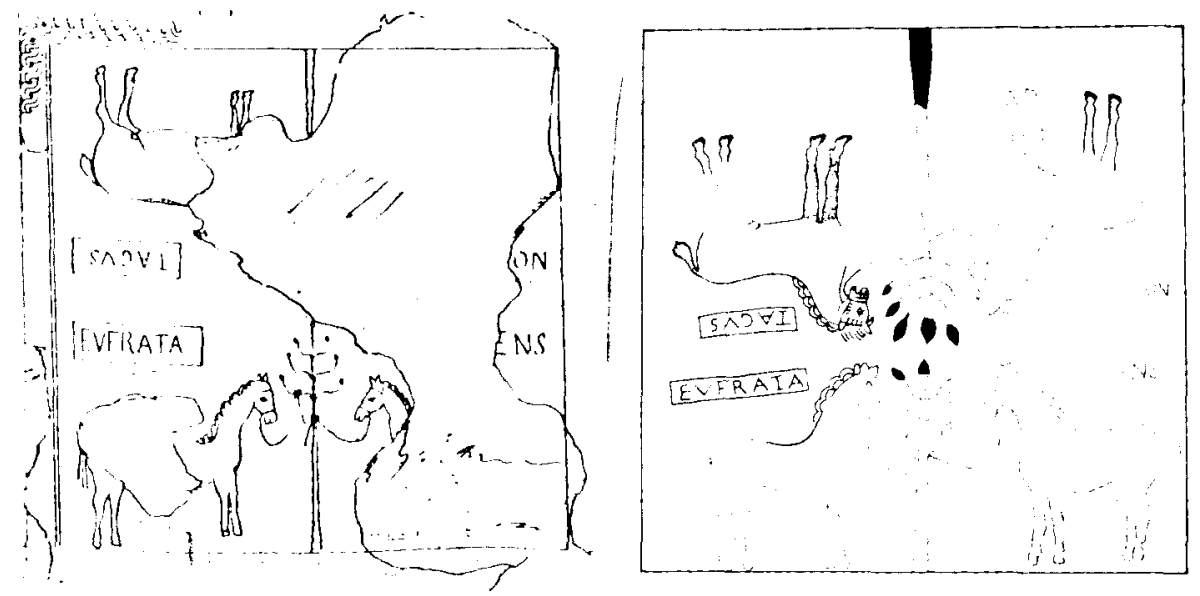

Fig. 29. Mosaico de Aguilafuente (Segovia). A) Dibujo del emblema según el arquitecto Asensio (1868). B) Reconstrucción teórica según la documentación actual.

(Dibujo R. Lucas). 
cromatismo, en el que contrasta el color blanco del "emblema" descentrado.

El "emblema" es un cuadrado de $2,30 \mathrm{~m}$ de lado, bordeado por la trenza divisoria y enmarcado por un filete de color rojo. El motivo decorativo lo forman dos parejas de caballos afrontados atados a un árbol, en total simetria, siguiendo el modelo $b$ o heráldico propuesto por Ennaifer (ENNAIIFER, 1983, 827). Lo más interesante de este mosaico son las cartelas que acompañan a los caballos, con indicación de sus nombres: EVFRATA, TAGVS,... ENS y NO..., que se encuentran atestiguados como nombres de caballos en otros documentos de Hispania y del norte de África (LOPEZ Monteagudo, 1992, 965-1011).

El modelo seguido en la organización de la superficie ha sido ampliamente estudiado por Lancha, recogiendo los valiosos comentarios de Stern sobre la decoración múltiple y la posible función del emblema descentrado en los triclinios en sigma (LANCHA, 1977, cap. I).

En Hispania se conoce un buen elenco de mosaicos de este tipo. El repertorio de época severiana pervive en el siglo iv acusando reinterpretaciones, conservadurismo y adaptaciones regionales, no del todo ajenas al vigor y cromatismo africano. La disposición de los caballos y la doble óptica son deudoras de las magníficas composiciones de los mosaicos núms. 57.113 y 57.120 de la Casa de Sorothus en Hadrumetum, fechados en el siglo III (Foucher, 1960, láms. XXVII-XXX). Sin embargo, el tratamiento del árbol sigue los modos de hacer de los talleres figurativos de Trier (PARLASCA, 1959, láms. 92, 99, 100 y F), siendo estilísticamente semejante a los arbolitos de los mosaicos de Santiponce (BLANCO, 1978, lám. 40) y de las Cuatro Estaciones de Córdoba (BlÁzQuEz, 1981, lám. 84).

En pavimentos africanos es más frecuente atar a las bestias a pilones - columnas (Casa de Ariadna, mosaico de Sidi Abdallah, de Pompeianus en Cirta, etc.) que a árboles. En Hispania, sin embargo, se comprueba cierta constancia en representar caballos aislados o en parejas con un simple roza! que insinúa la doma y el reposo atado o no a un árbol (caballo laureado de Véjer (BLÁzQUEZ, 1982, núm. 50, lám. 42), mural de Aguilafuente, dos ladrillos de la Bética, etc.).

\section{SAN MARTÍN DE LOSA (BURGOS) (figs. 30-32)}

A finales de 1972 se hallaron restos de una villa en la finca Los Casarejos, en la localidad burgalesa de San Martín de Losa, a $111 \mathrm{~km}$ al norte de la capital. Durante los trabajos de excavación realizados en 1976 


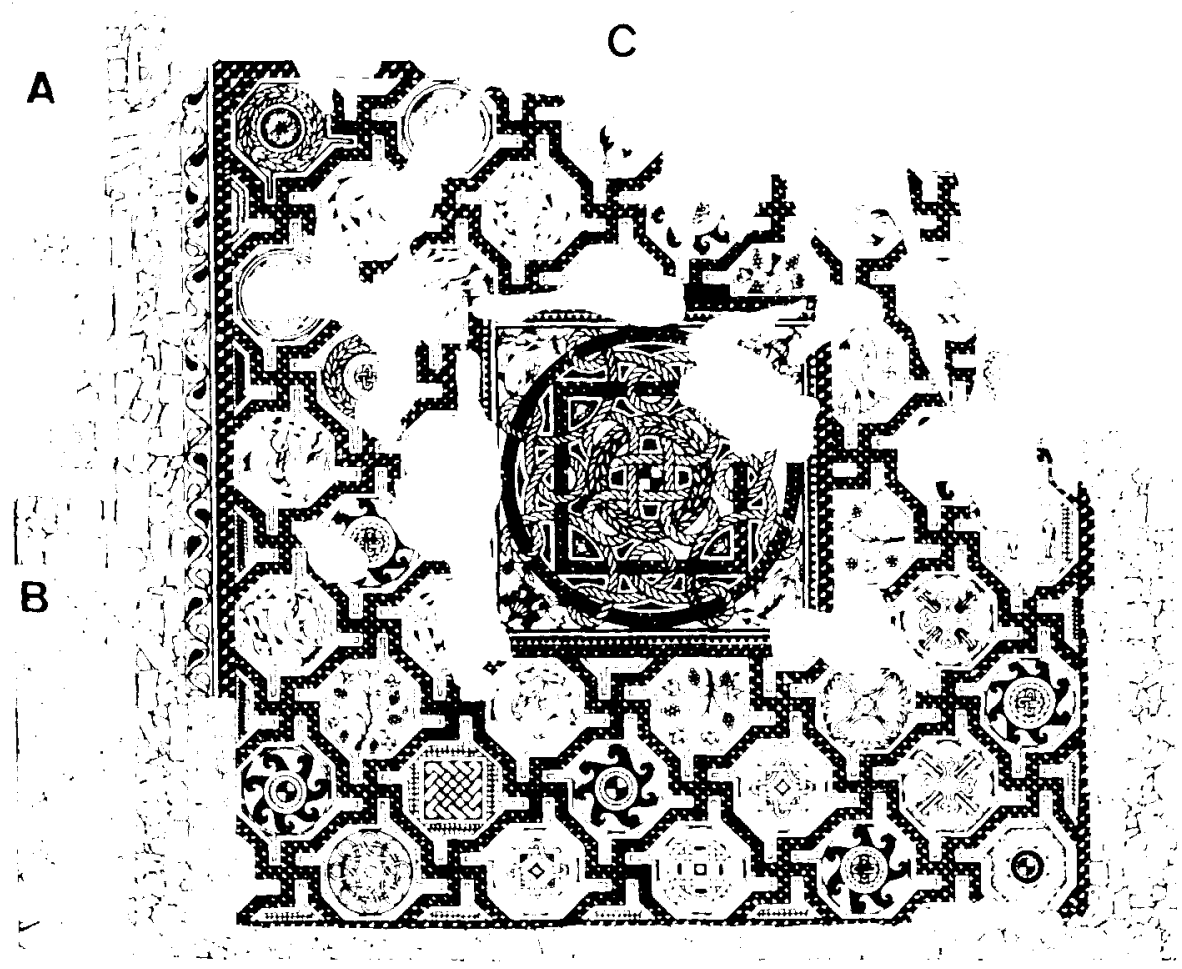

Fig. 30. Mosaico de S. Martín de Losa (Burgos) (según Abásolo).

se descubrió una habitación completa pavimentada con un mosaico polícromo (ABÁsolo, 1983, 233-269).

Las medidas máximas originales de la habitación $C y$, por tanto, del mosaico son $8,60 \times 8,15 \mathrm{~m}$. La orla, de la que tan sólo se conservaba parte del lado oeste del cuadrado, se compone de un tallo sinusoide del que salen zarcillos o pámpanos en teselas rojas y negras, y hojas cordiformes alargadas de color rojo, amarillo, rosa y gris claro alternativamente. A continuación otra cenefa, de damero, con dos hileras de cuadrados, divididos en triángulos con bordes dentellados, en rojo, amarillo, blanco y negro.

El campo del mosaico presenta una composición ortogonal de octógonos adyacentes formando cuadrados que se han convertido en esvásticas enlazadas entre los lados de los octógonos. Giran hacia la derecha 


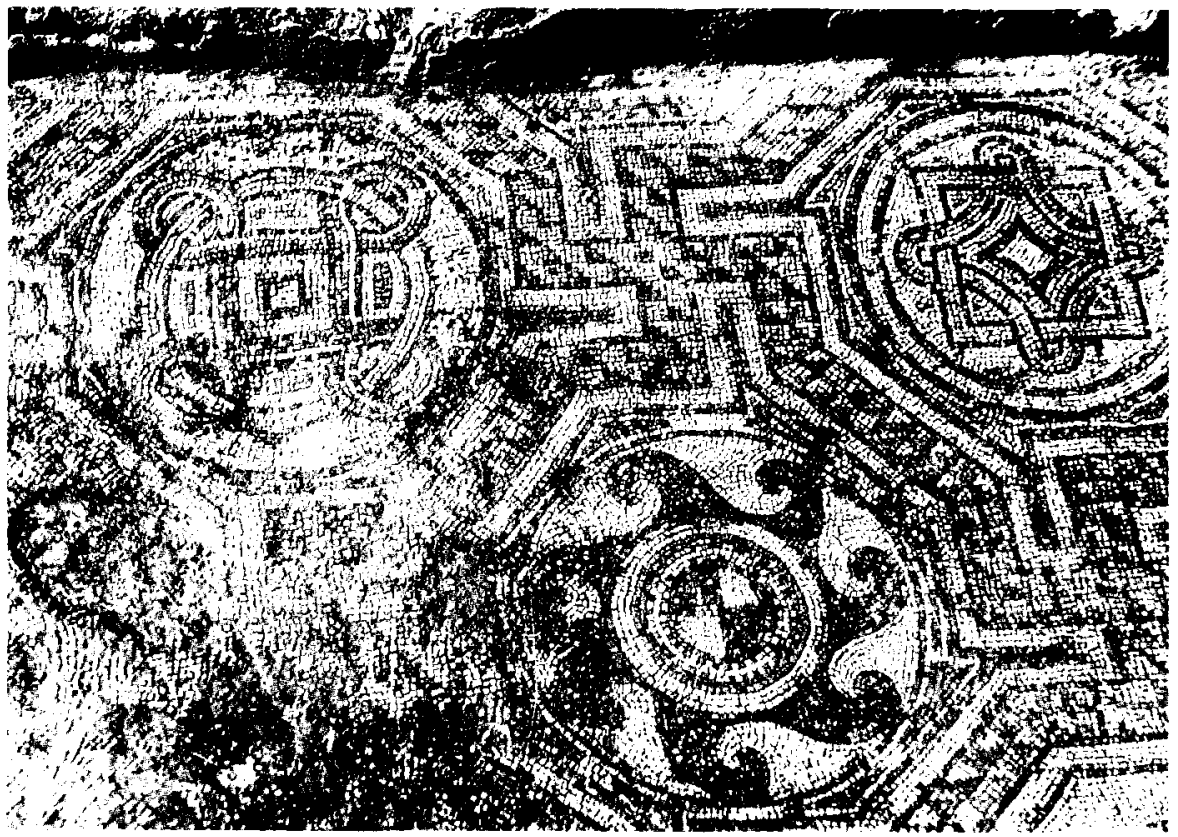

Fig. 31. Detalle del mosaico de S. Martin de Losa (Burgos) (según Abásolo).

y están compuestas por el mismo damero de la cenefa descrita. Este motivo aparece también en un mosaico (A17) del lado oeste del peristilo de la villa romana de Liédena (Navarra), fechado en el siglo II (BLÁZQUEZ et all., 1985, 40, núm. 19, figs. 4 y 29, lám. 26, con paralelos de fuera de la Península); en la orla del mosaico de peces, procedente de la Fábrica de Armas, hoy en el Museo Arqueológico de Toledo (BlázQuez, 1982b, 36-40, núm. 26, láms. 20-23, 47-48); y en Rielves (Toledo) (FERNÁNDEz CASTRO, 1982, 70, fig. 36), con un esquema más complicado, donde se insertan cuatro esvásticas entre los octógonos, cuyos lados delinean y dan cabida a un hexágono.

Los octógonos muestran una variadísima decoración. Unos inscriben círculos con motivos geométricos conocidos, como los entrelazados, nudos de Salomón, rosetas, roleos, trenzados, laurel, peltas y vegetales, como vides, pámpanos, zarcillos, etc. Otros octógonos presentan en su interior peces, delfines y monstruos marinos, bien solos, por parejas o incluso devorándose entre ellos.

En el centro de toda esta composición se encuentra el «emblema», un 


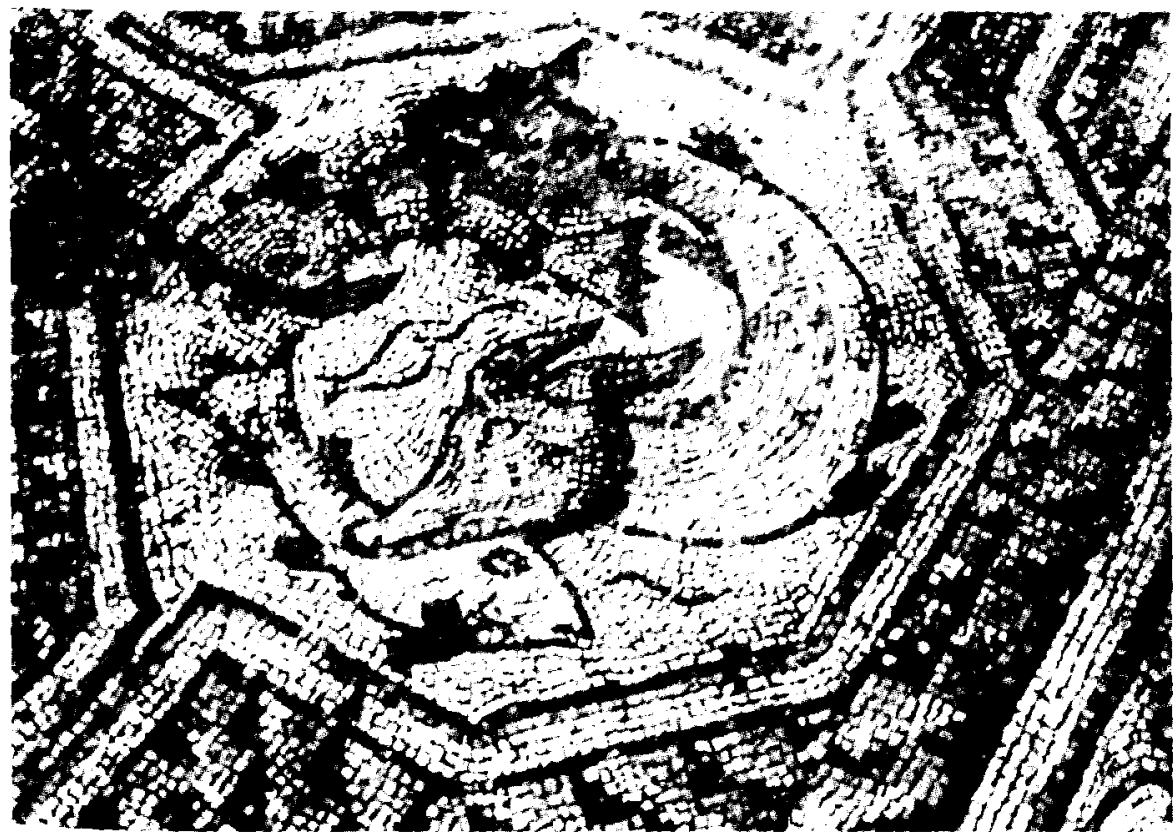

Fig. 32. Detalle del mosaico de S. Martín de Losa (Burgos) (según Abásolo)

gran cuadrado de $3,40 \mathrm{~m}$ de lado formando un damero de cuadrados rojos, amarillos, blancos y negros divididos en dos triángulos por una diagonal, exacto al damero de la cenefa exterior y de los octógonos. A continuación otras dos cenefas $u$ orlas formando cuadrados inscritos. La primera se compone de teselas rojas con dentado negro al exterior, y la segunda de dos filas de teselas negras. Tangente a este último cuadrado, un círculo del citado damero.

En los cuatro espacios entre el cuadrado y el círculo están representados: (SW) una crátera con pie troncónico y base curva en teselas rojas ribeteadas en negro, con cuerpo semiesférico gallonado en rojo, blanco y negro, separado de aquél por una pequeña esfera. El cuello tiene forma de embudo y a los lados se dibujan dos asas de volutas en "S" que van desde el borde hasta el comienzo del cuerpo. De la boca de la crátera salen a cada lado dos hojas de parra y en ella beben dos pájaros - posiblemente palomas-- posados en las asas; (SE) un delfín devorando un pez y otro delfín más pequeño pero con las mismas características; (NW) un delfín y un salmonete o similar con temas de relleno vermiformes y 
una esvástica también en negro; (NE) una crátera muy destruida, que parece ser exacta a la de la esquina SW.

Inscrito en el círculo hay un cuadrado de 1,82 m de lado formado por el mencionado damero. En las esquinas, dentro de un triángulo resultante del cruce de un trenzado, se encuentran cuatro flores de loto, una en cada esquina, de las que se conservan tres. En el centro del emblema existe un sogueado desarrollado a partir de un círculo dividido en cuatro cuadrantes (dos rojos y dos amarillos) formando cuatro aros cruzados por una guirnalda, en los espacios libres, trapecios de lados curvos. Al exterior de la guirnalda el trenzado se prolonga en motivo sin fin en nuevos círculos, cruzándose con los dameros de los cuadrados y con el círculo externo.

Abásólo (ABÁsolo, 1983, 233-269), basándose en los motivos decorativos del mosaico, paralelos y cronología que ofrecen los hallazgos cerámicos, data la villa de Los Casarejos y el mosaico a fines del siglo Iv o incluso a principios del $v$.

\section{"CERRILLO DEL CUCO", SANTAGÓN, VILCHES (JAÉN) (fig. 33)}

El mosaico cubría totalmente la superficie de una habitación cuadrada de $6,5 \times 6,5 \mathrm{~m}$ con paredes cubiertas de estuco y decoradas con pinturas murales. Los excavadores piensan que esta zona de la casa estaba destinada a residencia del dominus y que debió construirse probablemente en el siglo III o comienzos del Iv (MOLINos et all., 1982, 306-312; BLÁZQUEZ et all., 1987, 275-279, figs. 1-3).

El mosaico presenta un extraordinario colorido a base de teselas amarillas, azules, violeta de distintos tonos de intensidad, blancas (todas ellas de cuarcita); rojas y anaranjadas (cerámica); y negras (pasta vítrea). La distribución del color no se alterna de manera permanente y regular. La gran calidad técnica se manifiesta en el tamaño de las teselas que son de $1 \mathrm{~cm}\left(7.700 \mathrm{~m}^{2}\right)$.

Una ancha cenefa de $1 \mathrm{~m}$ rodea todo el mosaico, alternándose en ella diversos motivos decorativos (ribetes simples, dobles y triples, bandas, dientes de sierra, líneas quebradas, cordón, etc.). El esquema compositivo se organiza en torno a una gran estrella de ocho puntas, formada por dos cuadrados contrapuestos. Un círculo, con una decoración de cordón, circunscribe la estrella. Otro círculo, de similares características, se inscribe en la misma y en su interior aparece el tema central con animales de distinto tipo y símbolos solares. A pesar de ser ésta una de las zonas más deterioradas del mosaico, se pueden distinguir peces, un reptil cua- 


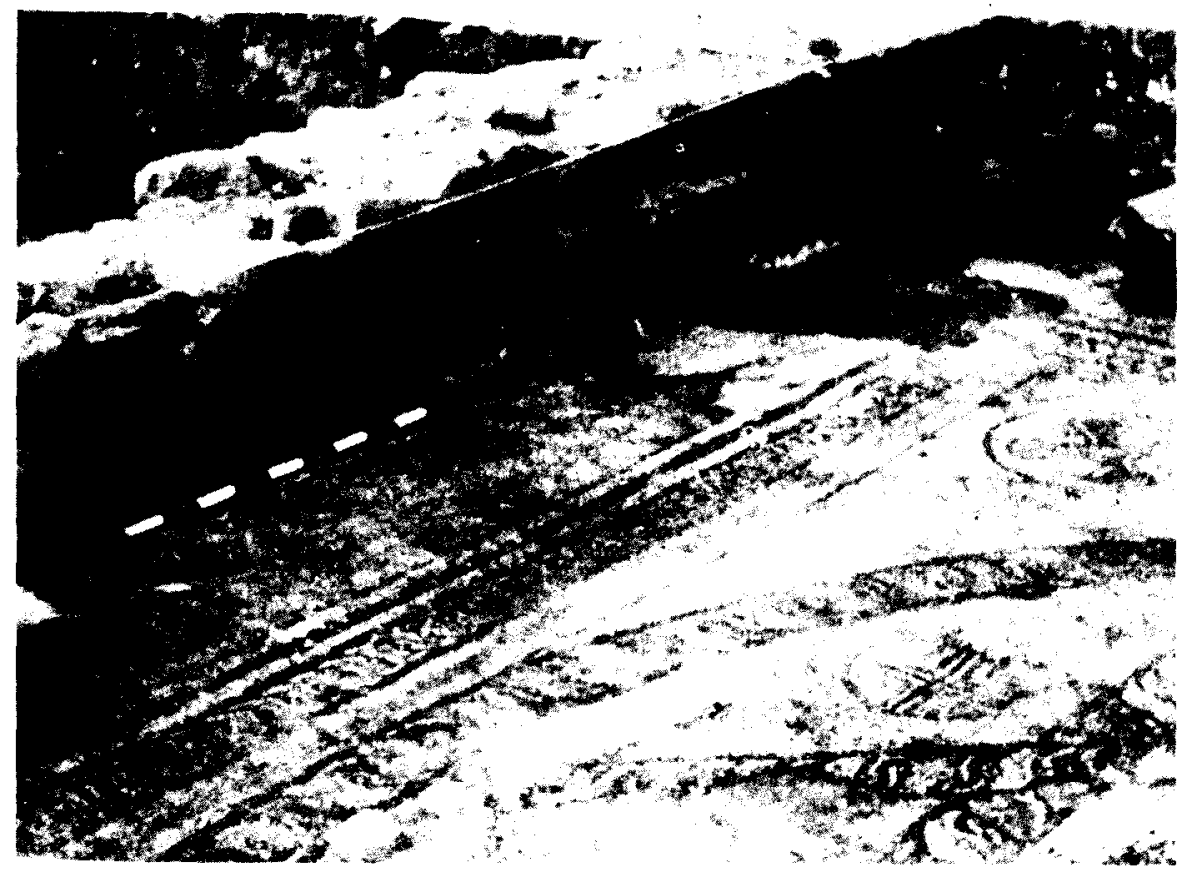

Fig. 33. Mosaico de "Cerrillo del Cuco", Vilches (Jaen) (segün Molinos).

drúpedo de larga cola, una serpiente, un cuadrúpedo sin determinar y, posiblemente, un cangrejo de mar. Junto a estos temas aparece una roseta helicoidal de veintiún radios.

Las esquinas conservadas del mosaico presentan dos circulos de 55 $\mathrm{cm}$ de diámetro con una decoración cuadrilobular en su interior. Dentro de cada uno de los triángulos isósceles formados por las intersecciones de dos cuadrados, aparecen círculos de 20 a $25 \mathrm{~cm}$ de diámetro con una decoración a base de aspas en su interior. En el espacio formado por el círculo exterior y la estrella de ocho puntas aparecen otros círculos semejantes a los anteriores, con cruces en su interior.

El motivo central del mosaico de Vilches, compuesto por dos cuadrados que se entrecruzan formando una estrella de ocho puntas, constituye un tema frecuente en los mosaicos hispanos. Se encuentra en varios mosaicos de Itálica de los siglos II-III (BLANCO, 1978a, núms. 3, 5, 13, láms. 11-13, 1516, 34-35); en el mosaico de Diana cazadora de Comunión (Álava) (BLÁzQUEZ, 1982b, núm. 2, fig. 3, lám. 41), fechado en época severiana; en un mosaico del siglo IV procedente de la villa romana de Tarazona de la Mancha (Al- 
bacete) (BlázQuez et all., 1989, 55-56, núm. 40, fig. 16, lám. 40); en otro de Cuevas de Soria, de época bajoimperial (BLÁzQuez y OrTEGo, 1983, núm. 57, lám. 25), etc. Se encuentra asimismo en diferentes mosaicos ingleses del Bajo Imperio, lo que demuestra que esta composición decorativa pervive hasta épocas tardías (BLÁzQUEZ, 1982b, 14).

La importancia de este mosaico giennense radica en que en él es perfectamente visible la descomposición que sufren las formas artísticas en las regiones periféricas del Imperio al final de la Antigüedad. Baste fijarse en el círculo con aspa de brazos desiguales en el interior, ejecutado de una manera torpe ${ }^{18}$.

La decoración a base de círculos, que vemos en este mosaico, es típico de los fondos de los mosaicos del Bajo Imperio y debida al horror vacui. En Hispania se encuentra esta característica en el mosaico emeritense de Annius Ponius, fechado en torno al 400 (BLANCO, 1978b, 34, núm. 15, lám. 26a); en el de Estada (Zaragoza), que es probablemente uno de los mosaicos hispanos más tardíos (BLAZQUEZ y GonZÁLEZ, 1972 1974, 429, figs. 5-6; Fernández Galiano, 1987, 67-70, núm. 111, lám. XXXI, 2); en los pavimentos del dominus vitalis de la villa gerundense de Tossa de Mar (BALIL, 1965, 284, figs. 2-3); de Ucero, en Soria (BLÁzouez y Or. TEGO, 1983, 52, núm. 51, lám. 37); de Centcelles (SCHLUNK y HAUSCHILD, 1962, láms. VIII, XIV-XV; ScHLUNK, 1988); y de la villa burgalesa de Baños de Valdearados (ARGENTE, 1979, fig. 19, láms. XI-XIII, XV-XVI).

En el mosaico báquico de esta última villa, el fondo aparece cubierto de rosetas, triángulos, rombos y pájaros volando (ARGENTE, 1979, láms. III-VI; BLÁZQUEZ, 1982c, 402, figs. 1-3). Rosetas dentro de círculos se documentan igualmente en un mosaico de la Alcazaba de Mérida (BLANCO, 1952, 47, fig. 24; BLANCO, 1978b, lám. 27a). La misma decoración aparece también en la villa soriana de Los Quintanares (BLÁZQUEZ y ORTEGO, 1983, 38, núm. 32, lám. 36). Un paralelo para el motivo de círculo con roseta en el interior se encuentra en el mosaico malagueño de Puerta Oscura (BLÁZQUEZ, 1981, 80, fig. 21).

Bianchi Bandinelli veía en el motivo decorativo de rosetas dentro de un círculo el influjo de los temas decorativos que aparecen en las estelas funerarias de la meseta (BIANCHI, 1971, 193 y ss.) y que se documentan también en las estelas de Soria (JIMENO, 1980, 225), La Rioja (ESPINOSA, 1986, núms. 26, 61, figs. 12, 17, 22, 26, 48, 51, 55, 61, 62), Lara de los Infantes (ABÁSOlo, 1974, 169) y Astorga (MAÑANES, 1982, 154).

18 Este fenómeno artístico del final de la Antigüedad ha sido tratado en varias ocasiones (CARANDINI, 1962, 217 y ss: Blazouez, 1986, 463 y ss.). 
La decoración a base de peces aislados es frecuente en el Bajo Imperio, como se ve en los mosaicos de las villas romanas de Vega de Ciego (Asturias), San Martín de Losa (Burgos), Campo de Villavidel (León), Ucero (Soria), Ramalete (Navarra) y la Quintilla (Murcia) (BLÁQUEZ, 1985, 111 y ss., con toda la bibliografía referente al tema).

Por el tratamiento de los temas y los paralelos aducidos, el mosaico de Vilches puede fecharse en el siglo $v$ avanzado, lo que pone de manifiesto un hecho importante y es que la provincia de Jaén ya ha dado dos de los mosaicos más tardíos de la Hispania antigua, éste de Vilches y el de Santisteban del Puerto (BLÁzQuez y González, 1972-1974, 419 y ss., figs. 1-3; BlázQUEZ, 1981, 66 y ss., núm. 51, lám. 59).

\section{CARDEÑAJIMENO (BURGOS) (figs. 34-35)}

El mosaico de Cardeñajimeno (BLÁZqUEZ et all., 1986a, 555-567; LAN CHA y BARTOLOMÉ, 1988, 305-324) consta de un gran cuadro mitológico central, con forma de rectángulo, de cuyos lados menores sobresalen dos apéndices de forma semicircular con decoración de imbricaciones bor deada por una trenza. La orla del cuadro central, que sólo se conserva en los lados menores del citado rectángulo, va también enmarcada por trenzas y se compone de hojas de acanto enrolladas, de colores amari-

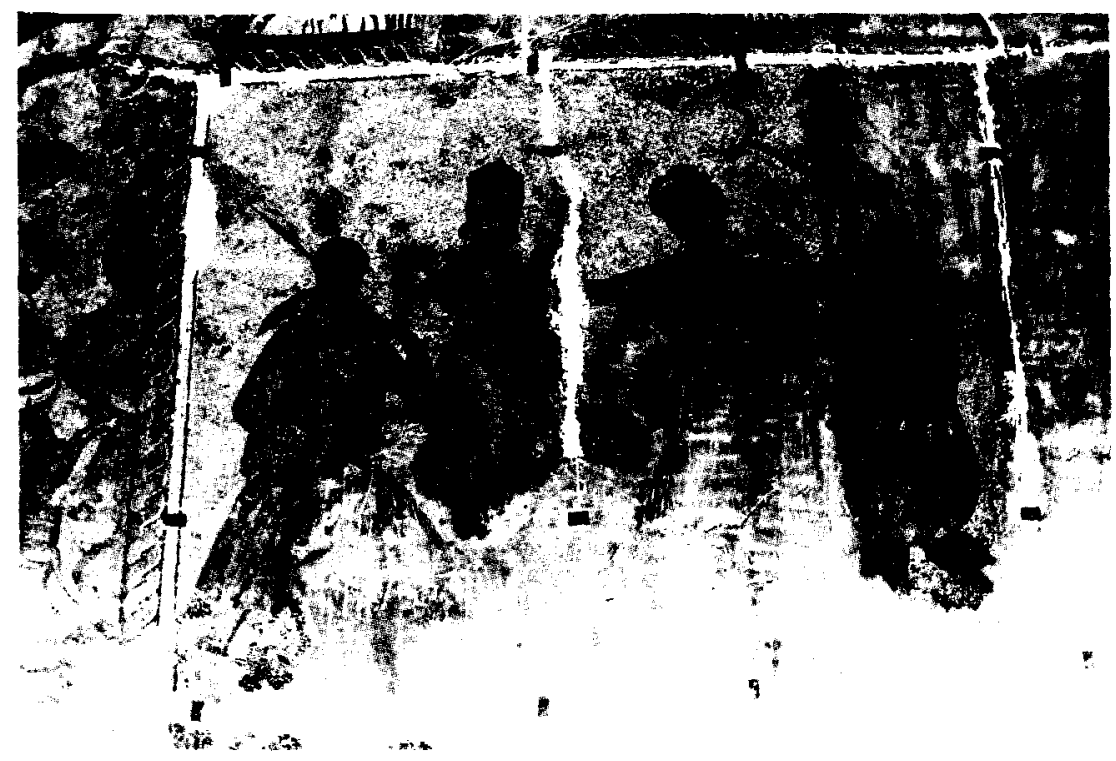

Fig. 34. Emblema del mosaico de Cardenajimeno (Burgos). 
Ilentos y blanquecino, dentro de las cuales se sitúan, alternando, cabezas de felinos y cabezas humanas de largas barbas, arqueados bigotes y rostro alargado. Entre los círculos que forman las hojas de acanto hay flores y en la parte inferior aves caminando en posturas contrapuestas. Paralelos claros se observan en orlas de los mosaicos de Hellín (Albacete) y Quintana del Marco (León), mencionados anteriormente.

Enmarcando el cuadrado central una cenefa, muy deteriorada, presenta diferentes escenas de cacerias: caceria a caballo de ciervos, jabalies, luchas entre fieras (león saltando sobre un toro) y fieras atacando équidos o antílopes, escenas, que se desarrollan en un ambiente campestre formado por árboles, arbustos y peñascos rocosos, y que tienen numerosos paralelos en Hispania y en todo el Imperio (BLÁzQUEz et all., 1986a, 561; Blazquez y López Monteagudo, 1990, 59-88; López Monteagudo, 1991, 497-512).

La escena principal, que ocupa el cuadrado central bordeado por una trenza, representa el conocido tema en el arte antiguo de la caza del jabalí de Calidon. En la composición, única representación musiva de este mito conservada en Hispania ${ }^{19}$, aparecen los dos personajes estelares del mito, Atalanta y Meleagro, acompañados de un sirviente, quizás como representante de los numerosos personajes que intervinieron en la cacería ${ }^{20}$.

El mito, descrito por Apollodoro (Bibliot. 8, 2-3), sirvió frecuentemente como motivo de inspiración artística en el arte griego y romano, apareciendo en relieves del Heroon de Gjolbaschi-Trysa, en Tegea, en los vasos griegos arcaicos (SCHAUENBURG, 1962, 765-776), en el vaso François, del 575 a.C. (ARIAS y HIRMER, 1960, 30, fig. 42; BEAZLEY, 1951, 32-33), en urnas y espejos etruscos (BROMmER, 1961, 983-985), pintura pompeyana (SCHEFOLD, 1957), sarcółagos (SICHTERMANN, 1975, 42-45, láms. 91-109), etc.

En cuanto a las representaciones musivas hay que destacar el mosaico de Antioquia (LEVI, 1947, 68-71, lám. Xla) descubierto en la llamada cHou-

\footnotetext{
19 De la existencia de otro mosaico hispano con la representación de Atalanta y Meleagro, descubierto en Itálica el 20 de febrero de 1874, la autora dice que, gracias a la reproducción en color de Amador de los Ríos, se sabe que el mosaico se componia de un gran rectángulo en cuya entrada se situaba, al igual que en el mosaico de Cardeñajimeno, una escena cine. gética, decoración geométrica y vegetal, así como medallones de trenza, en los que estaban inscritas las representaciones de las estaciones, animales, etc., formando en el eje central tres octógonos de lados curvos. En el superior aparecía, según Celestino, Atalanta y Meleagro, pero aquí sin la presencia clarificadora del jabalí (CELESTINO, 1977, 361-366, lám. XXV).

${ }^{20}$ La lista de héroes que participaron en la cacería fue dada por Ovidio (Met. VIII, 270 y ss.) y por Higinio (Fab. 175)
} 


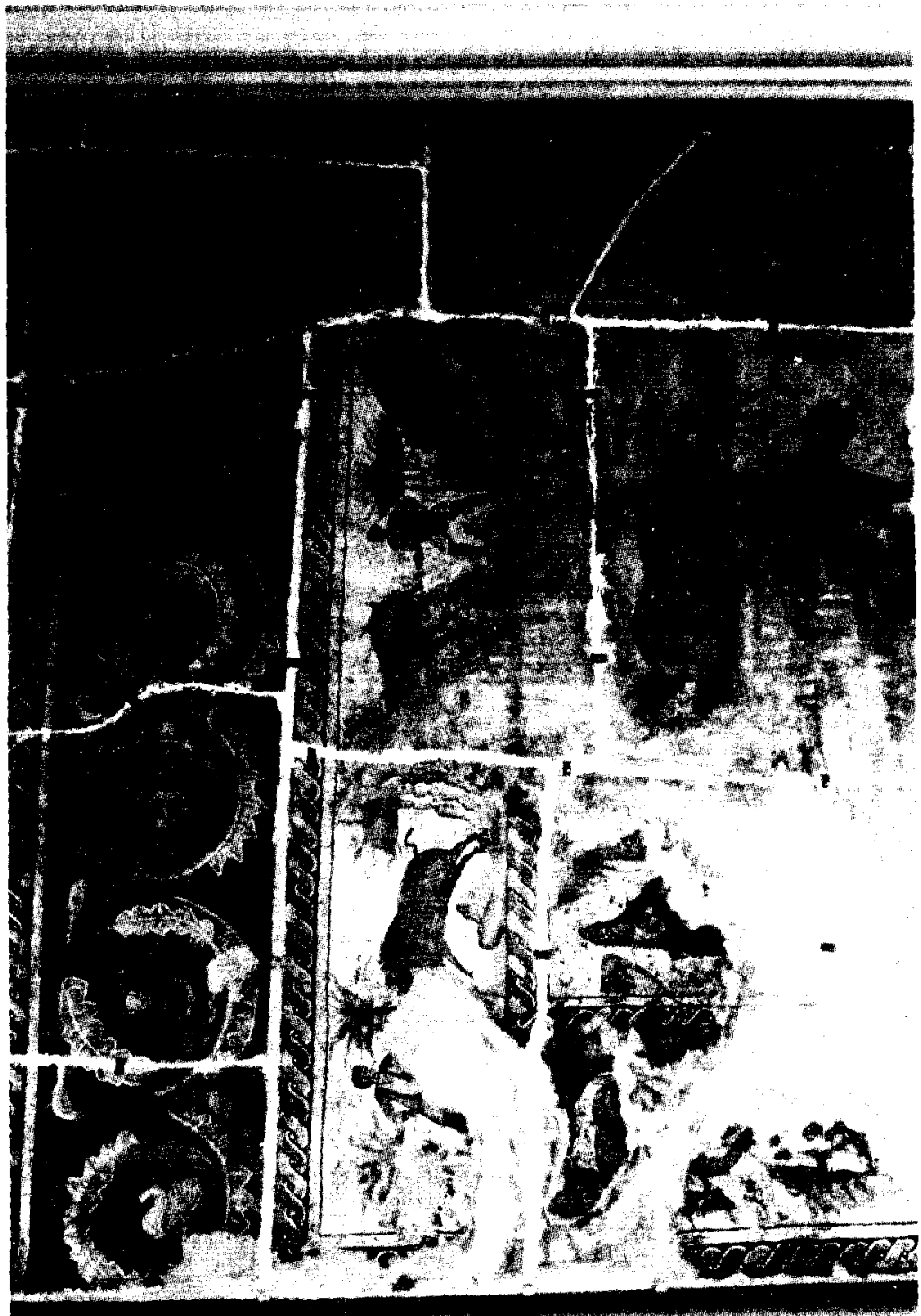

Throw

Fig. 35. Detalles de las orlas del mosaico de Cardeñajimeno (Burgos). 
se of the Red Pavement", en el que también aparecen en la escena tres personajes, Atalanta, Meleagro y un acompañante, con el jabalí muerto entre los dos héroes. No es extraño este parentesco entre un mosaico de Antioquía y un hispano, ya que, como se ha señalado recientemente, se puede advertir el influjo de mosaicos orientales en los hispanos, precisamente en pavimentos que han aparecido no lejos de Cardeñajimeno, en Baños de Valdearados (Burgos), con un esquema muy próximo a uno de Misis Mopsuestia Cilicia), y en la Almunia de Doña Godina (Zaragoza), pariente de un mosaico de la basílica de Ermione (FERnÁndez Galiano, 1983, 423-424, figs. 6-8,2).

Otras representaciones del mito de Atalanta y Meleagro aparecen en mosaicos de Antioquía (LEVI, 1947, 237-240, lám. LVIb) y Apamea (BALTY, 1977, 118-123), del Museo de Chiusi (LEVI, 1947, 239, fig. 91), Biblos (CHÉHAB, 1971, 372, lám. CLXXVIII, 1), Leptis Magna (DuNBABIN, 1978, 52, 264), Antalya (BLÁzQUez y LóPEz MONTEAGUdo, 1986, 233-234, fig. 1) y en otros dos ejemplares citados por LEVI ${ }^{21}$.

Las paralelas señaladas dentro de la Península Ibérica entre el mosaico de Cardeñajimeno y los restantes hispanos llevan a señalar un mismo ambiente artístico (BLÁZQUEZ, 1982b, 49-50) pavimental entre los mosaicos de una amplia zona, que abarca las cuencas de los ríos Segre y Ebro medio, hasta el norte de Portugal, sur de Lusitania española, pasando por León, Burgos, Soria, Valladolid y todo el centro de Hispania. Las características artísticas de estos pavimentos son la tendencia a la policromía, a la decoración geométrica, y a recargar de figuras la composición; diferente a las documentadas en la Bética y en la actual provincia de Murcia.

En el mosaico de Cardeñajimeno el marco de escenas de cacería muestra un influjo africano muy directo (BLÁZQUEZ et all., 1986a, 561 y ss.), posiblemente obra de un musivario africano; en cambio el cuadro mitológico no responde a ningún prototipo determinado de los conocidos. El artista ha interpretado la composición como le ha parecido, sin tener delante modelos concretos ${ }^{22}$. Se puede afirmar que responde a las co-

2' El perdido de Lyon, en el que Meleagro ofrece a Atalanta los despojos de la caza, cuya composición se acerca a la del mosaico hispano, en el que el jabali está ya muerto; y un segundo, hoy en el British Museum, procedente de Halicarnaso en el que ambos héroes, en dos paneles separados, van a caballo. En el pavimento de Cardeñajimeno está representado sólo el caballo. Atalanta a caballo está representada igualmente en el mosaico de Leptis Magna, datado en el siglo II (Aurigemma, 1960, 47, lám. 77). A Meleagro casi siempre se le representa desnudo y con manto al hombro.

${ }^{22}$ Sobre la diversidad en la forma de representar el mito, vid. supra nota 21 (LEVI, 1947, nota 20). 
rrientes temáticas y artísticas generalizadas en el Bajo Imperio y puede ser fechado a finales del siglo IV.

\section{"FUENTE ÁLAMO», PUENTE GENIL (CÓRDOBA) (figs. 36-38)}

En una excavación de urgencia realizada en 1985 en la villa romana de Fuente Álamo (Puente Genil, Córdoba) fue descubierto un mosaico de gran interés iconográfico (LÓPEZ MONTEAGUdo et all., 1988, 785-795) ${ }^{23}$. El pavimento, de forma rectangular, está enmarcado por un filete dentado y una ancha cenefa de círculos imbricados que encierran tres recuadros o paneles, enmarcados por una trenza de cuatro cables en rojo, amarillo, blanco y negro. El fondo es claro y en las figuras predominan los tonos ocres y sienas.

Comenzando por la izquierda, el primer panel representa a Pegaso y a una ninfa que le ofrece un cuenco. La ninfa, totalmente desnuda, está vista de frente y mirando al espectador. Adorna la cabeza con diadema floral. La composición es muy similar a la del mosaico de San Julián de la Valmuza (Salamanca), con representación de la utoilette" de Pegaso, aunque en este último la escena se complica con otras dos ninfas, una que cabalga a Pegaso coronándolo y otra que le peina la cola. Se fecha en el siglo Iv (BLÁZQUEZ, 1982b, 19-20, núm. 12, fig. 12). El tema de Pegaso y las ninfas está bien representado en la musivaria romana. Se encuentra en el mosaico de la Villa del Nilo en Leptis Magna, del siglo Il, en donde Pegaso aparece acompañado de seis ninfas. Solamente con dos ninfas aparece en el mosaico de Antioquía, fechado en el siglo III. La escena es también frecuente en lucernas y terracotas romanas (BLÁzouEz, 1982b, con todos los paralelos).

En el panel central se han representado las Tres Gracias. La Gracia central, totalmente desnuda, aparece de espaldas con la cabeza vuelta hacia la derecha y apoyando las manos en los hombros de sus compañeras. Éstas, también desnudas, sostienen un paño con la mano derecha una y con la izquierda la otra, que se enrolla en la pierna respectiva. Las piernas están ligeramente flexionadas, pero el artista no ha conseguido que el cuerpo adquiera la ondulación en $S$ que resultaría de esta flexión. Este tipo iconográfico, con las Gracias entrelazadas que obliga a representar de espaldas a la Gracia central, se da a partir de la época hele-

\footnotetext{
${ }^{23}$ Agradecemos al profesor L. A. López Palomo el envio de las fotografías y el dibujo de este mosaico inédito. Un estudio de la villa ha sido publicado por este autor (LÓPEz PALOMO, $1987,105-115)$
} 


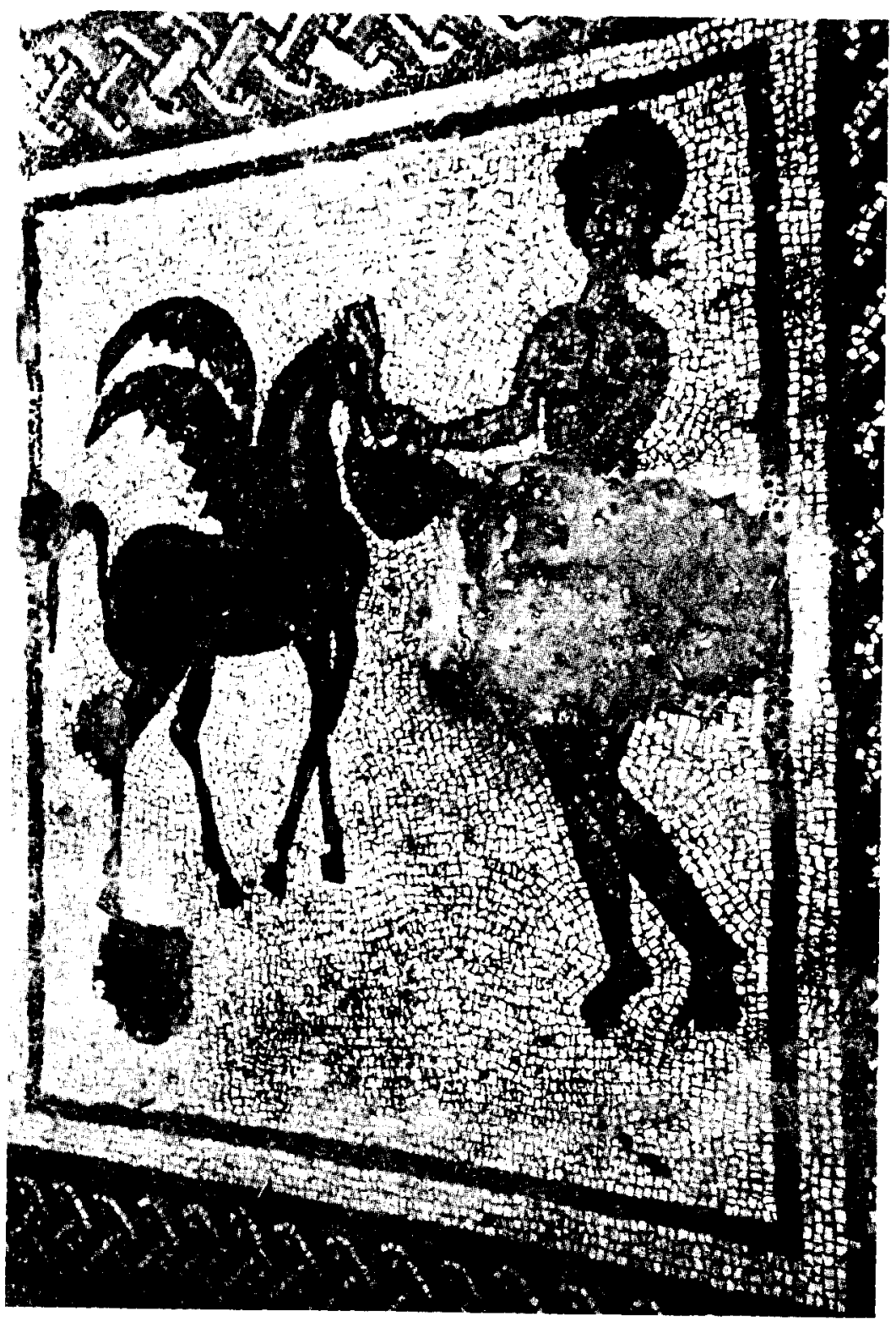

Fig. 36. Mosaico de Fuente Alamo (Cordoba) (Foto cortesia de L. A. Palomo). 


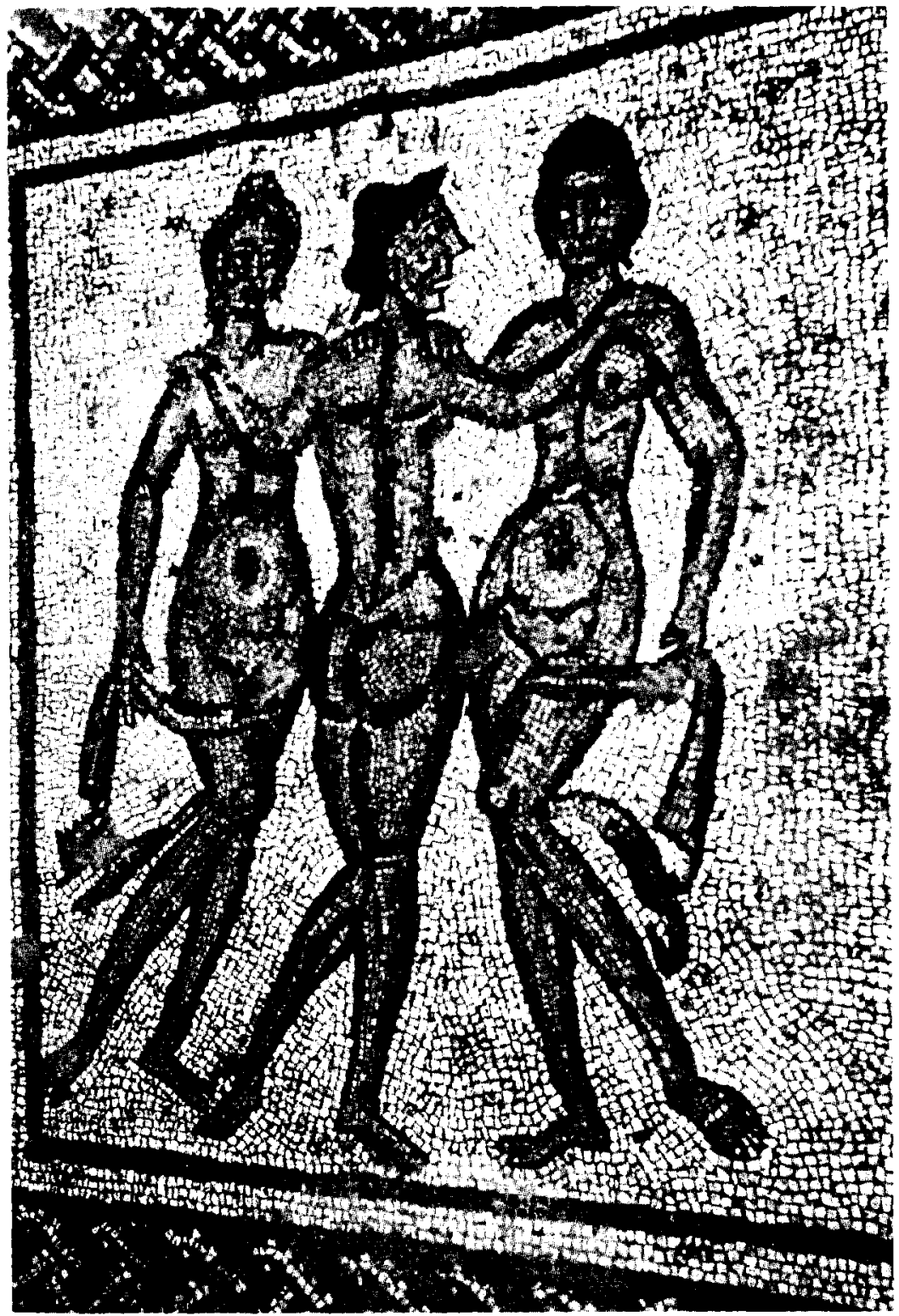

Fig. 37. Mosaico de Fuente Alamo (Cordoba) (Foto cortesia de L. A. Palomo). 


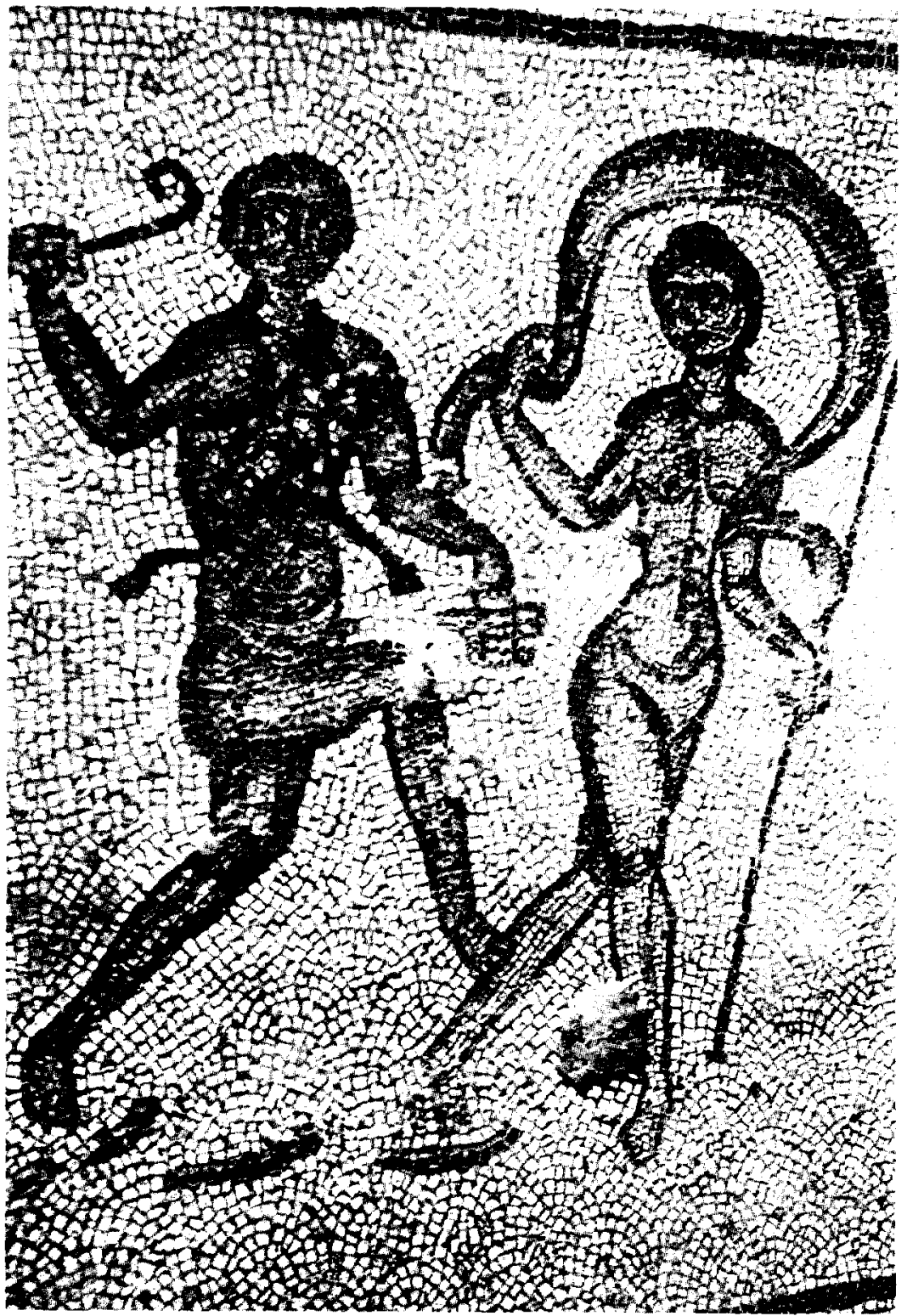

Fig. 38. Mosaico de Fuente Alamo (Cordoba) (Foto cortesia de L. A. Palomo). 
nística y fue reflejado por Servio en sus escritos (Ad. Aen. I, 820). La misma composición aparece en el mosaico de las Tres Gracias de Barcelona, datado a finales del siglo ॥, aunque en éste las Gracias aparecen totalmente desnudas, sin ningún paño, y el tipo iconográfico es totalmente diferente (BALIL, 1958, 63, fig. 2). Paralelos muy próximos se encuentran en los mosaicos de Kyrene (DONDERER, 1982, 125, pl. LXXXVI, 3) ${ }^{24}$ y de Cherchel (BALIL, 1958, fig. 9; DUNBABIN, 1978, 254), este último datado a fines del siglo Iv. En ambos la Gracia central apoya las dos manos sobre los hombros de sus compañeras. El peinado de las Gracias de Cherchel se asemeja bastante al de Fuente Álamo y la posición de las piernas de las Gracias laterales en ambos mosaicos es idéntica.

En el panel de la derecha se ha representado un sátiro, con pedum y cesto de frutos, persiguiendo a una ménade desnuda con tirso en la mano izquierda. Ella lleva un velo o manto, anudado a su brazo izquierdo por un lado y sujeto con su mano derecha por el otro, ondenado al viento y arqueándose por encima de su cabeza, tal y como aparece en numerosas representaciones de nereidas y de Europa durante el rapto. El carácter de los personajes y el tirso, que la ménade empuña en su mano izquierda, nos indican claramente que se trata de un tema de asunto báquico. Paralelos próximos se encuentran en un mosaico blanco y negro de Tor Marancia, conservado en el Museo Vaticano, con sátiro llevando tirso en la mano izquierda y persiguiendo a una ménade con el velo flotando sobre la cabeza (BLAKE II, lám. 39, 4) ${ }^{25}$; en un mosaico de Sousse (DUNBABIN, 1978,173 , pl. LXVIII); y en un mosaico dionisiaco de Colonia, en uno de cuyos recuadros se ha representado a una ménade danzando hacia la izquierda y con velo también ondeando sobre su cabeza, perseguida por un sátiro que lleva, como en el mosaico cordobés, pedum en la mano izquierda (PARLASCA, 1959, 77, lám. 69).

La greca de círculos imbricados es exactamente igual a las dos laterales que enmarcan el mosaico de las Metamorfosis de Carranque (Toledo), fechado en el siglo IV (ARCE, 1986, 374). Las figuras estilizadas también recuerdan a este mosaico. Estilísticamente el mosaico de Fuente Álamo pertenece a una época muy tardía que puede ponerse en el siglo iv o v d.C.

El autor da como inédito este mosaico, aunque con reservas

La autora fecha este mosaico entre el 123 y el 165 d.C 
CÁDIZ (fig. 39)

El mosaico gaditano está integrado en un pavimento de opus signinum con decoración floral estilizada. El rectángulo central, realizado en opus tessellatum en colores blanco, negro, azul y ocre, está enmarcado por una franja negra, a la que sigue una orla de semicírculos secantes y tangentes formando ojivas y escamas en oposición de colores. Viene después un filete doble en damero y otra franja negra que bordea la escena (BLÁzQUEZ et all., 1986c, 104-105, fig. 5).

La escena representa la disputa de Apolo y Marsias. De derecha a izquierda se ve un alto trípode. Apolo desnudo y sentado junto a la lira, Marsias colgado del árbol del que salen unas ramas, y el escita que se dirige a él para desollarlo. Esta parte del mosaico se halla muy deteriorada.

La disputa de Apolo y Marsias se representa también en el mosaico de Santisteban del Puerto (Jaén), que es uno de los mosaicos más tardios de Hispania (Blázquez y González, 1972-1974, 419; BlázQuez, 1981, 69, láms. 59, 91).

Según los excavadores, la casa donde apareció el mosaico gaditano, situada en Puerta de Tierra, se fecha en el siglo । a.C. y el pavimento debe

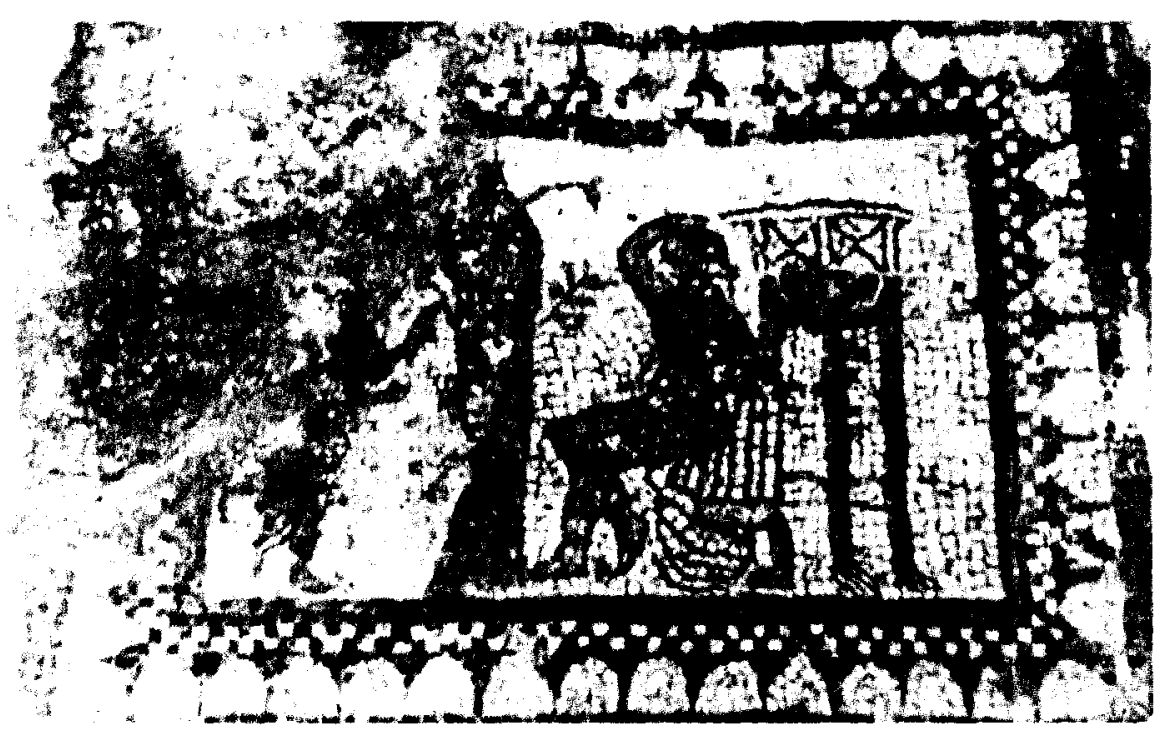

Fig. 39. Mosaico de Cádiz. 
ser anterior a ella. Creen que el mosaico fue traído desde Grecia a esta casa.

CASARICHE (SEVILLA) (fig. 40)

El mosaico con Océanos, hallado en 1919 y del que se desconocía su paradero actual, ha sido localizado e identificado por R. Mondelo y $\mathrm{M}$. Torres con el pavimento del Castillo de Viñuelas (Madrid), de donde pasó a Somosaguas, también en Madrid (MONDELo y ToRRES, 1985, 143-157, láms. I, II).

En el momento de su descubrimiento, el conjunto medía $5 \times 4 \mathrm{~m}$ y estaba formado por dos tapices yuxtapuestos. Uno de ellos, rectangular, iba ceñido por una línea de postas y en su interior presentaba fauna acuática, peces y crustáceos. No se conserva. La parte conservada, de forma cuadrada, mide $3,62 \mathrm{~m}$ de lado y está bordeada por un sogueado de dos cabos. El campo musivo presenta un esquema compositivo con círculo central, cuatro semicírculos laterales y cuatro cuartos de círculo en los ángulos, que determinan cuadrados curvilíneos. Es lo que se denomina mosaico de esquema a compás ${ }^{26}$. Los semicírculos o lunetas y los cuartos de círculo van enmarcados por una línea de cable reforzada interiormente por un filete dentado. Los cuartos de circulo llevan en su interior una crátera estilizada, mientras que las lunetas ostentan hipocampos y tritones, estos últimos con pedum, en un fondo marino indicado por rayas horizontales.

El círculo central, enmarcado por una orla de ojivas, encierra una cabeza de Oceános con pinzas de crustáceo sobre la frente y dos patas de cangrejo a cada lado de ellas. A ambos lados del cabello y de la barba de Océanos, un delfín de larga cola tripartita. Trazos horizontales indican el mar. Los espacios curvilíneos están ocupados por cuatro bustos femeninos, sin atributos, aunque pueden identificarse con las estaciones.

El interés del esquema compositivo de este mosaico estriba en el tipo de cenefa que delimita los diversos compartimentos mediante una línea de cable, tipo poco utilizado en los mosaicos hispanos. Algo parecido se ve en un mosaico de Carranque (Toledo), el cual presenta la misma composición de esquema a compás (ARCE, 1986, 365).

${ }^{26}$ Fernández Galiano recoge todos los mosaicos hallados en la Península lbérica que presentan este tipo de composición (FERnANDEZ Galiano, 1980, passim). A ellos hay que añadir los de Carranque (ARCE, 1986, 365-374) y Pisôes (MACMillan, 1986, 38 y ss.). 


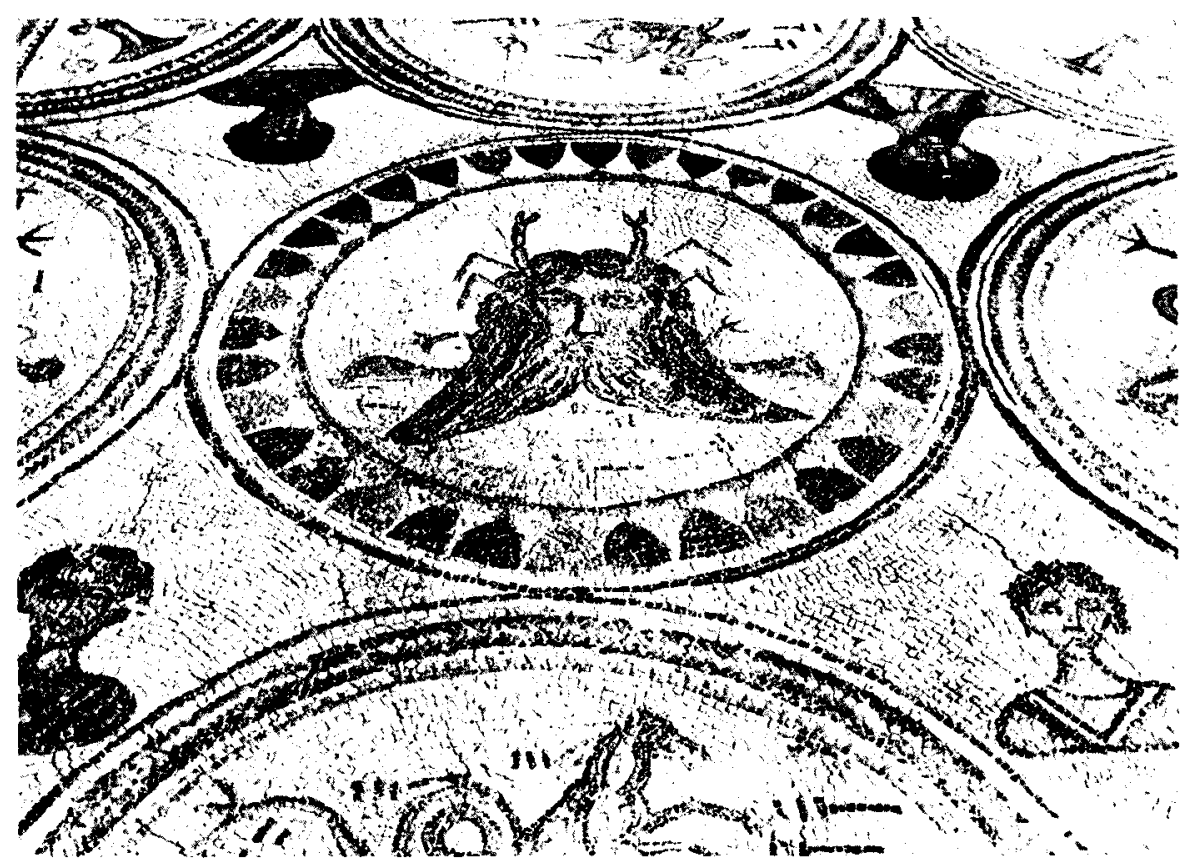

Fig. 40. Mosaico de Casariche (Sevilla) (según Mondelo).

La línea de ojivas que enmarca el círculo central se emplea casi exclusivamente en la Bética, al igual que la línea de cable. Ello evidencia la inserción del esquema del mosaico de Casariche en las corrientes artísticas andaluzas de finales del siglo $\|$ d.C. y comienzos del siguiente.

El tipo iconográfico de Océanos está muy difundido por las provincias occidentales, entre las que destaca África. En Hispania existen varias representaciones de Océanos (BLÁZQUEZ, 1981, 22-23; LANCHA, 1985, 151; BLÁZQUEZ et all., 1986c, 129-130), siendo el tema central también en los mosaicos de Faro (Portugal), Córdoba y Balazote (Albacete). Las pinzas de crustáceo aparece en los mosaicos con máscara de Océanos de Lugo, Milla del Río, Quintanilla de la Cueza, Dueñas, Faro y Córdoba. Los delfines, que aparecen a los lados de la melena del Océanos de Casariche, se ven igualmente en Faro y Córdoba. La relación de Océanos con las estaciones podría ponerse en relación con la de los vientos en los mosaicos de Faro y Balazote, fechados ambos en la primera mitad del siglo III.

R. Mondelo y M. Torres sitúan el mosaico de Casariche dentro del radio 
de influencia cordobés-italicense y apuntan una cronología en torno al primer cuarto del siglo III d.C.

\section{CASARICHE (SEVILLA) (fig. 41)}

En julio de 1985 apareció en Casariche un mosaico en el que está representado un tema inusual y desconocido hasta ese momento en la musivaria hispana, el Juicio de Paris ${ }^{27}$. Tres orlas, una de triángulos tangentes, otra de guiloches y la tercera de filetes, enmarcan la escena central. De derecha a izquierda figuran: Hermes, con caduceo y manto ondeando al viento; Paris, sentado con los pies cruzados sobre unas rocas ejecutadas de modo ilusionista, como en Cardeñajimeno (Burgos), muy propias del Bajo Imperio. Sostiene en su mano derecha levantada la manzana de oro. Viste traje oriental y calza botas. A continuación las tres diosas, que aparecen con túnica, sandalias, nimbo y el cabello peinado ajustándose a la cabeza y descendiendo hasta los oídos. Afrodita, con las piernas de perfil y en actitud de caminar, está semidesnuda y sujeta el manto que le cae por la espalda; mientras que en el caso de Hera y Atenea está recogido delante formando pliegues. Estas dos diosas doblan su brazo derecho por delante del pecho y parecen señalar con sus dedos índices y corazón a Paris o a Afrodita, la figura central. Unos descamados arbolillos y las rocas sitúan la escena en el campo.

El mito gozó de gran aceptación entre literatos y artistas en la antigüedad ${ }^{28}$, y fue frecuentemente representado en la pintura de vasos, pinturas parietales, relieves, espejos etruscos, gemas y monedas. Por el contrario, tan sólo conocemos cuatro representaciones del juicio de Paris en mosaicos, además del de Casariche, el de Antioquía (LEVI, 1947, 16), el conservado en el Museo de Cherchel, que K. M. D. Dunbabin (DuNBABIN, $1978,254)$ fecha en el siglo IV, el inédito de Cos (MORRICONE, 1950, 219) y el perdido de Transilvania (REINACH, 1922, 164).

El paralelo más próximo para la actitud de Afrodita, quien sujeta el manto sin que le cubra las piernas, se encuentra en un mosaico británico del siglo IV con escenas de la Eneida. La actitud de las piernas, con el vestido transparente, se repite exacta en otra figura femenina de este mismo mosaico (Frere, 1967, 313, 323, lám. 28b; ToYnbeE, 1963, 203,

\footnotetext{
${ }^{27}$ Las primeras noticias de su descubrimiento fueron dadas por Soledad Buero Martínez $(1986,59-60)$. Posteriormente ha sido estudiado por Blázquez $(1985,115-124)$

${ }^{28}$ La cita más antigua se conserva en Homero (II. XXIV, 25-30).
} 


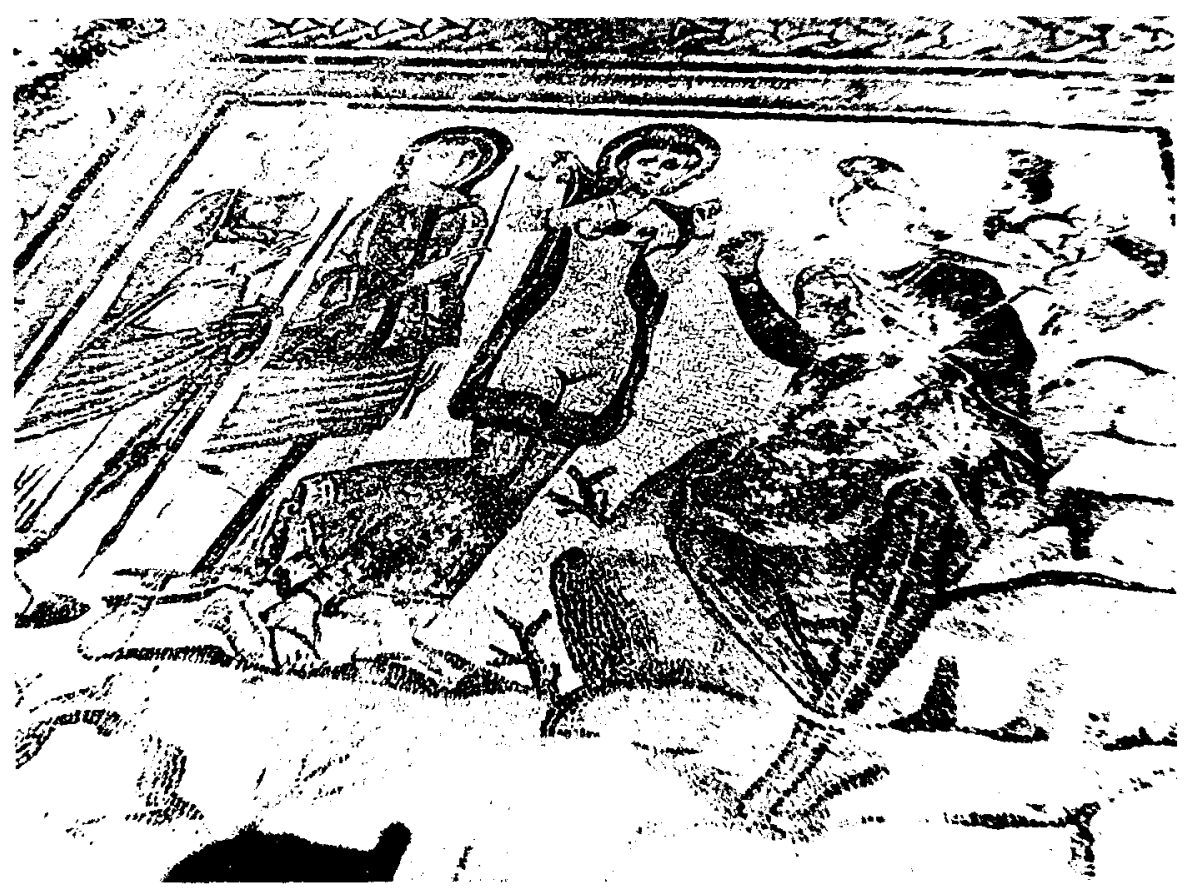

Fig. 41. Mosaico de Casariche (Sevilla) (Foto cortesia "ABC» de Sevilla).

lám. 235), semidesnuda como la Afrodita de Casariche. En un mosaico procedente de Palmira, datado a finales del siglo III o comienzos del siguiente, está representada Casiopea, con manto caído detrás de la espalda, como lo lleva Afrodita en el mosaico sevillano (BALTY, 1977, 32). La Anfitrite de un mosaico de Constantina, fechado en el segundo cuarto del siglo IV (DUNBABIN, 1978, 158, 114, lám. 154; BIANCHI, 1971, VIII, fig. 1; DoRIGo, 1966, 177, lám. XVIII), adorna sus antebrazos con brazaletes al igual que la Afrodita de Casariche, que también lleva pulseras en sus muñecas. La caída del manto sobre los muslos es idéntica en ambos. El cuerpo de Afrodita en Casariche tiene la misma forma que la Afrodita del plato de plata dorada, de la segunda mitad del siglo IV, que se conserva en la Biblioteca Nacional de París (Grabar, 1966, 239, fig. 271).

Sobre su cronología, el nuevo canon de belleza femenina -hombros huidos, cintura breve, cadera redonda y miembros cortos y afilados-, lejano reflejo de la copta, que desplazó al desnudo clásico en la Baja Antigüedad, según señaló A. Blanco (BLANCO, 1952, 48) al estudiar el mosaico 
báquico de Annius Ponnius, encaja perfectamente en la Venus de Casariche, y nos induce a fechar el mosaico en la primera mitad del siglo $\mathrm{v}$.

\section{CARRANQUE (TOLEDO) (figs. 42-45)}

La villa romana de Carranque, perteneciente al Bajo Imperio y en curso de excavación por el Dr. Fernández Galiano, ha dado varios mosaicos de tema mitológico ${ }^{29}$. El que ahora presentamos destaca por la variedad de los temas representados y por la inscripción que indica que un artesano hizo las pinturas y otro las ejecutó (ARCE, 1986, 372).

El mosaico pertenece al grupo de "esquema a compás", con círculo central, cuatro semicírculos laterales y cuatro cuadrados en los ángulos, todo ello enmarcado por tres cenefas: una de ajedrezado, otra de motivos

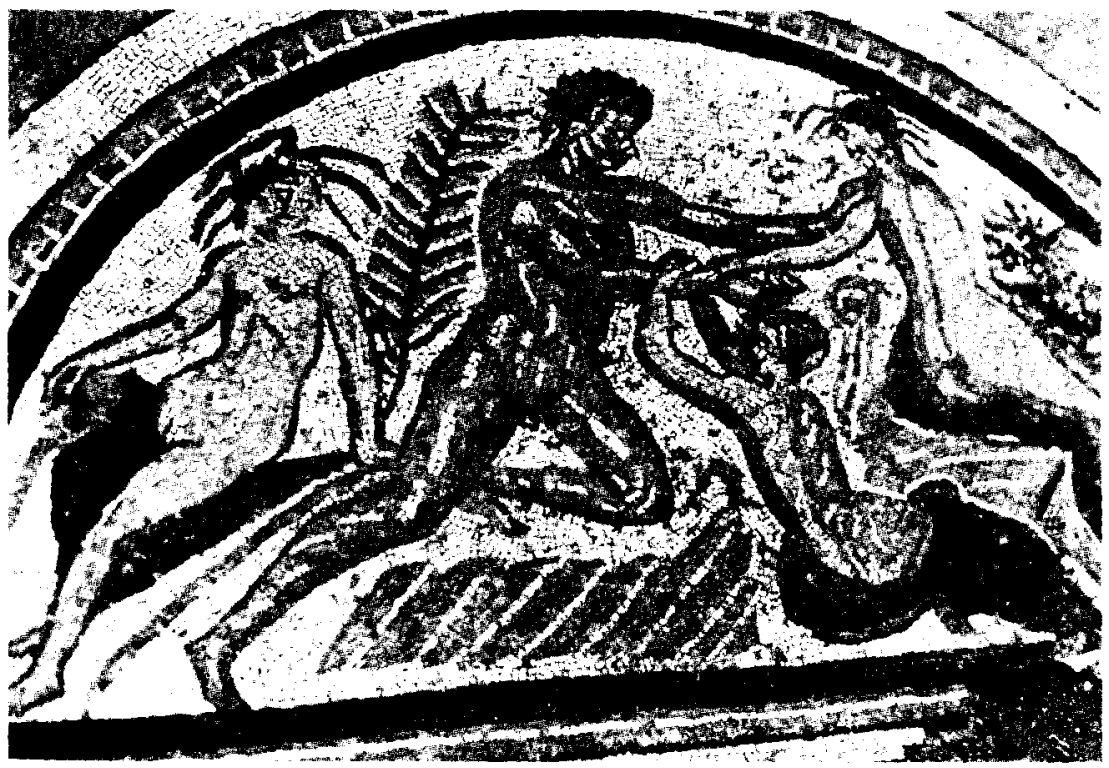

Fig. 42. Detalle del mosaico de Carranque (Toledo) (Foto cortesia J. Arce). 269).

${ }^{29}$ Un estudio de la villa y sus mosaicos ha sido realizado por Fernández Galiano (1989, 255 

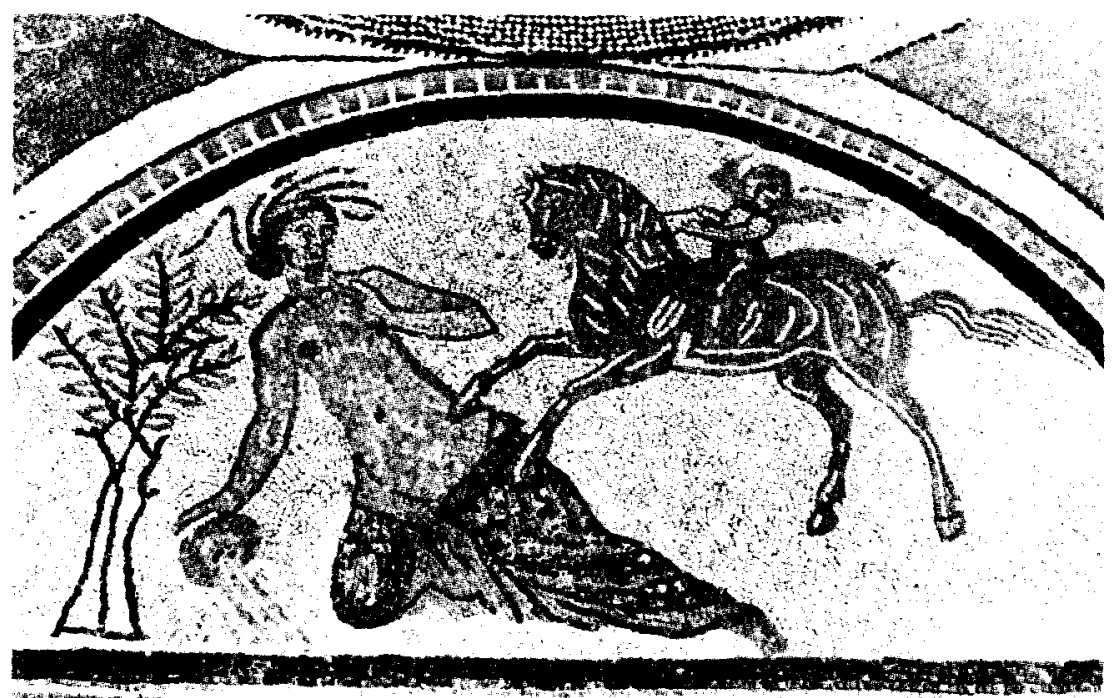
4

Fig. 43. Detalle del mosaico de Carranque (Toledo) (Foto cortesia J. Arce).

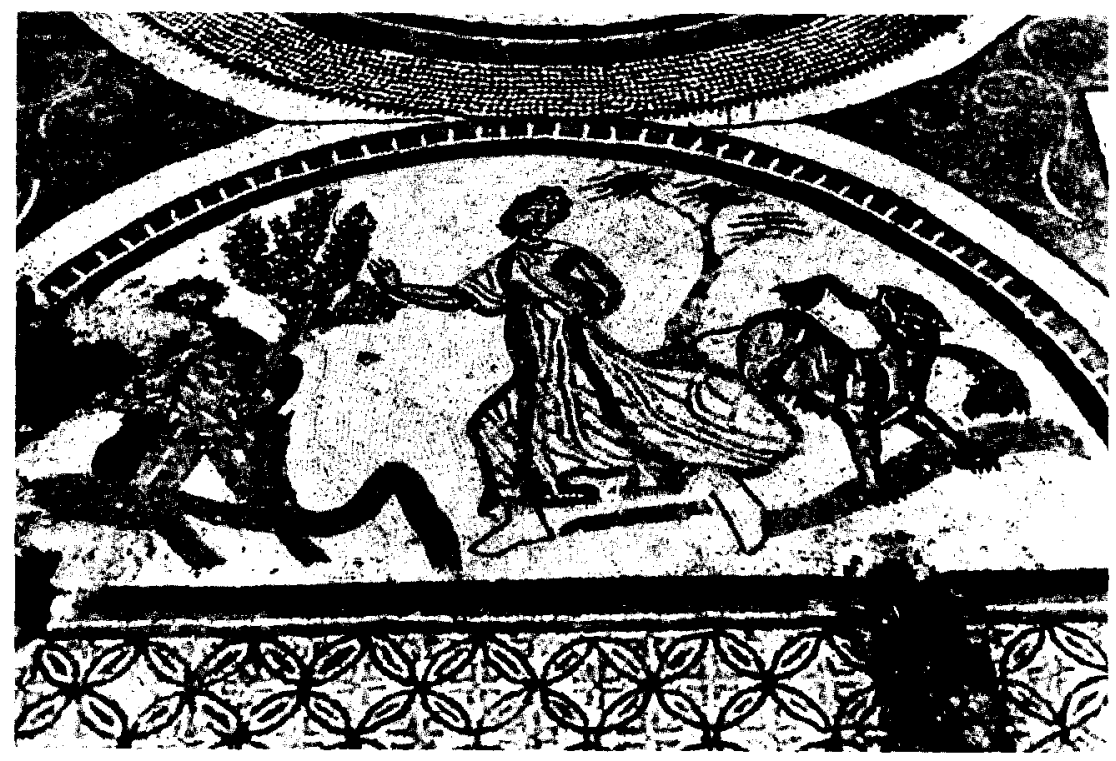

Fig. 44. Detalle del mosaico de Carranque (Toledo) (Foto cortesia J. Arce). 


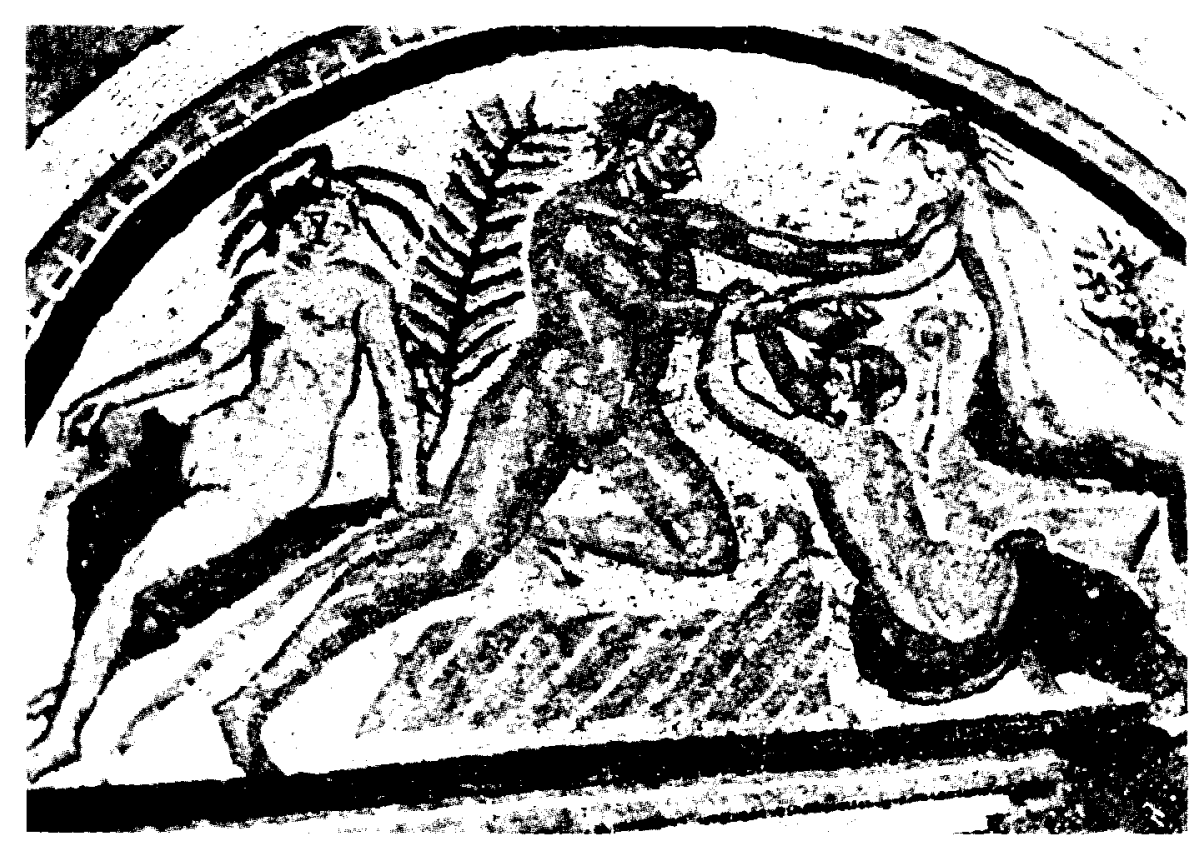

Fig. 45. Detalle del mosaico de Carranque (Toledo) (Foto cortesia J. Arce).

vegetales y la más ancha decorada con meandros de esvásticas continuas, tema muy frecuente en los mosaicos hispanos ${ }^{30}$. Dos de los laterales llevan sendas cenefas de círculos secantes, apareciendo la inscripción en uno de ellos, de donde deduce el autor que sería la entrada a la habitación.

En el círculo central se encuentra Afrodita vestida, con la cabeza nimbada y coronada de flores y hojas. Los cuadros de las esquinas llevan los bustos de Atenea con casco y tanza, Hércules con clava y Artemis con nimbus y carcaj, habiéndose perdido el cuarto. Más interesantes son las escenas representadas en las cuatro lunetas: Diana desnuda, acompañada de las ninfas, es sorprendida cuando se baña por Acteón, el cual aparece ya medio convertido en árbol; Poseidón, metamorfoseado en caballo y montado por Eros, seduce a la ninfa Amymone que aparece se-

30 Cenefas de meandros de esvásticas aparecen también en mosaicos de Portus Illicitanus y de Abicada, presentados al Coloquio de Bath. Fuera de Hispania se encuentran en Pompeya (OVADIAH, 1980, 100 y ss.). 
midesnuda y apoyada en un ánfora, un árbol representa el paisaje; Tisbe, vestida con túnica hasta los pies, huye despavorida de una tigresa que lleva entre sus fauces una tela ensangrentada, mientras que Píramo se transforma en roca detrás de un arbusto; Hylas y las ninfas.

Los paralelos iconográficos para este mosaico se encuentran en los mosaicos de la casa de Baco, en la villa chipriota de Nea Paphos (Nicolau, 1971, 143 y ss.), aunque tratados de forma diferente. El estilo de las figuras de Carranque es, por el contrario, típicamente africano.

En cuanto a la datación, el autor, basándose en criterios exclusivamente estilísticos lo sitúa en la segunda mitad del siglo IV o comienzos del $v$

\section{VALENCIA DE ALCÁNTARA (CÁCERES) (fig. 46)}

Se descubrió a finales de 1986 en la finca La Torre, término de Valencia de Alcántara (Cáceres) un mosaico romano. La aparición de otros mosaicos permite suponer que en estos terrenos, propiedad de don Pedro Díez, Conde de las Miranderas, se hallaba en la antigüedad una villa romana ${ }^{31}$.

Como orla, el mosaico presenta una trenza de cuatro cabos polícroma, sobre fondo oscuro, que enmarca el cuadro central. De esta escena sólo se puede ver el ángulo inferior izquierdo, donde se observa la rueda y el borde lateral de un carro, una tigresa y las patas posteriores de una segunda tigresa. Sin duda, se trata de un fragmento del triunfo de Baco, tema mayoritariamente representado en Hispania ${ }^{32}$ y en el norte de África (Dunbabin, 1971, 52-65), en el que, como es bien sabido, tigresas, tigres y panteras suelen tirar del carro triunfal del dios. En este mosaico las tigresas, en tonos ocres y marrones, avanzan hacia la derecha, como es usual en este tipo de representaciones. La que se ha conservado, situada en primer plano, está vista de perfil y con la cabeza casi vuelta hacia el

\footnotetext{
${ }^{31}$ El mosaico se encuentra en la actualidad en el Museo Provincial de Cáceres. Agradecemos al señor Conde de las Miranderas los datos proporcionados y las fotografías realizadas en el momento de su descubrimiento, a base de los cuales hemos hecho la descripción, ya que no nos ha sido posible verlo entero. Con posterioridad a este trabajo, el mosaico ha sido bien estudiado y publicado (GONZALEZ et all., 1990, 317-330).

${ }_{32}$ A los diez ejemplares recogidos por Fernández Galiano (1984b, 97-121, con toda la bibliografía), hay que añadir éste de Valencia de Alcántara y el de Andelos (Navarra), estudiado a continuación. Recientemente se han descubierto otros Triunfos báquicos en El Olivar del Centeno (Garcia Hoz et all, 1991, 387-402), Écija (Rodriguez Termiño y Núñez Pariente de León, 1985, 322) y Fuente Álamo (López PaLomo, 1987, 105-115).
} 


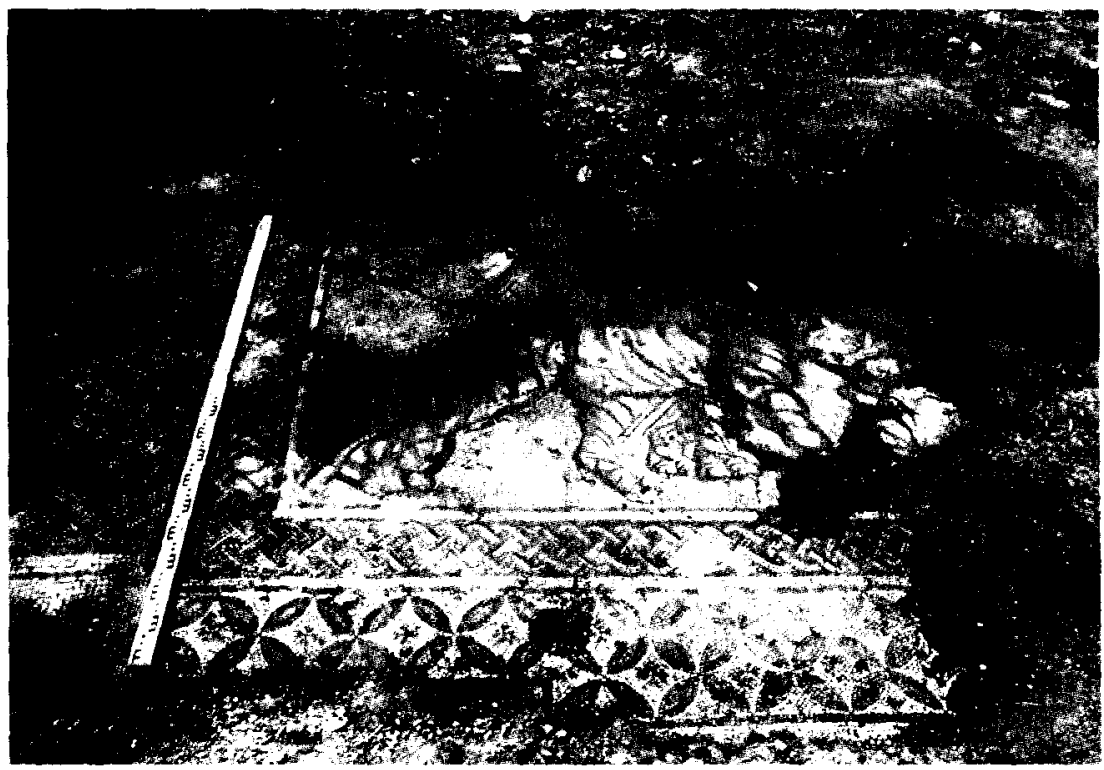

Fig. 46. Mosaico de Valencia de Alcántara (Cáceres) en el momento de su descubrimiento. (Foto cortesia Conde de las Miranderas).

espectador. Posee grandes dimensiones y un tratamiento volumétrico notable.

La imposibilidad de observar la escena completa no nos permite establecer paralelos certeros. No obstante, basándonos en los fragmentos conservados se pueden advertir similitudes y diferencias con otros mosaicos. La tigresa no adopta, aquí, ni la postura resignada, con la testuz baja, que se aprecia en los mosaicos de Torre de Palma y el Djem, ni la cabeza erguida de los felinos de Zaragoza, Écija y Sousse. Sin embargo, la posición de las patas es prácticamente idéntica a los ejemplares de Écija y Sousse. En el mosaico africano se ha representado incluso la cola de la tigresa, situada en segundo plano, entre las patas, como en el mosaico de Cáceres. Sobre el carro, del que se atisba una rueda detrás de la pata trasera derecha de la tigresa, y el borde lateral descendente de la caja, puede intuirse que estaría representado Baco visto de tres cuartos como en Zaragoza y Sousse. Estilísticamente su fecha no debe sobrepasar el siglo III.

En la parte inferior del mosaico se aprecia una greca de círculos imbricados con cruces de Malta en su interior, con paralelos exactos en 
otros mosaicos hispanos aquí estudiados, como son los de Carranque (Toledo) y Fuente Álamo (Córdoba).

Al lado del mosaico báquico hay otro mosaico con decoración geométrico-floral, muy parecido al hallado en la villa romana "La Malena", en Azuara (Zaragoza) (vid. supra).

\section{ANDELOS (NAVARRA) (fig. 47)}

Las excavaciones arqueológicas realizadas por el departamento de Educación y Cultura del Gobierno de Navarra en las campañas de 1985 y 1986 pusieron al descubierto un mosaico romano en la ciudad romana de Andelos, en el término de Mendigorría (MEzQuIRIz, 1987, 59-61).

El mosaico pavimenta los $6,20 \times 6,60 \mathrm{~m}$ de una habitación de una casa fechada en el siglo । d.C. Los $2,70 \times 2,30$ m que ocupa el "emblema", con una representacion del triunfo de Baco, aparecen rodeados por una zona de dibujos geométricos en blanco y negro: círculos enlazados que forman flores de cuatro pétalos y con decoración cruciforme a los pies de la escena, junto al umbral de la habitación, y un motivo de escuadras imbricadas en los otros tres lados (dando como resultado una composición en $U$ que parece indicar que nos hallamos ante un triclinium. El "emblema» aparece enmarcado por una segunda franja decorativa con motivos vegetales estilizados, roleos y hojas de hiedra con cráteras en los ángulos y un cordón ocre sobre fondo negro.

Dicha escena muestra un triunfo de Baco a su regreso de la India y, pese al mal estado del emblema, se puede reconstruir su composición: por una parte aparecen dos figuras. La del dios, de la cual sólo se conserva una mano con anillos que sostiene las riendas y un cantharos, y la de un personaje femenino, quizás Ariadna o una Victoria, de la que resta el contorno de parte de la cabeza, del cuerpo y de la clámide. El carro es el elemento que aparece más claro y completo, en especial una rueda y un fragmento de la caja; está tirado por dos tigres, uno de ellos apenas visible, el otro prácticamente completo con el cuerpo de perfil pero mirando de frente, con una enorme cola. El cuadro se completa con un último personaje, el dios Pan situado delante del carro, con todos sus rasgos característicos: torso desnudo, pieles sujetas a la cintura, patas de cabra, cuernos, barba y pelo largo cuyos trazos son remarcados por teselas negras. Aparece en actitud de fustigar a los animales. Tras él se adivinan las telas y la pierna de una bacante prácticamente perdida.

Todo el cuadro del triunfo báquico aparece resaltado por el contraste producido entre el fondo neutro blanco y los perfiles de las figuras a base 


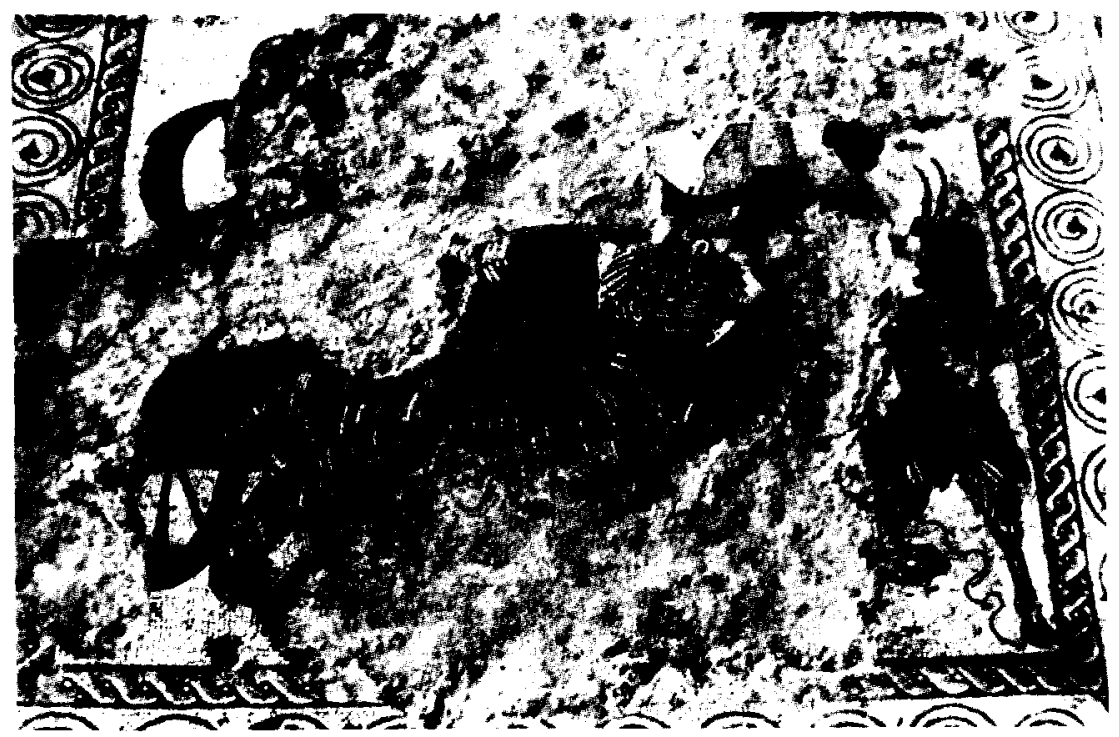

Fig. 47. Mosaico de Andelos (Navarra) (Según Mezquiriz).

de teselas oscuras - negras o marrones-

Es necesario hacer, por último, referencia a la presencia de la firma del autor en dos líneas sobre el mosaico en el ángulo superior derecho, aunque mal conservado: en la linea superior aparece una $R$ entre dos interpunciones, en la línea inferior aparecen las letras ON. F y a continuación una hedera. Quizás la terminación ON corresponde a un nombre griego; la $\mathrm{F}$ corresponde a FECIT, esto es todo lo que se puede apuntar al respecto, dado su estado.

Lo que del mosaico de Andelos ha sobrevivido nos muestra toda una serie de elementos asociados tradicionalmente a la iconografía báquica, tema tan querido en la Península Ibérica (Fernández Galiano, 1984b, 97121) y en el norte de África (DUNBABIN, 1971, 52-65; FOUCHER, 1974, 5561). Pese a que su deficiente conservación nos impide establecer paralelismos bien fundamentados, si podemos remarcar la presencia del dios Pan precediendo al carro, tal y como ocurre en Liédena o en el mosaico de El Djem. La postura de los felinos se aproxima al mosaico de Tarragona en el que el animal del primer término, visto de perfil se vuelve al espectador (BLÁZQUEZ et all., 1989b, 51-57, núm. 35, lám. 48). 
VAREA (LOGROÑO) (fig. 48)

En la segunda campaña de excavaciones de 1984 se descubrieron restos de un mosaico en la villa romana de Varea, la antigua Varia de los berones, situada en la desembocadura del Iregua, a unos $3 \mathrm{~km}$ al este de Logroño (Gómez, 1985, 56-57).

El mosaico, muy deteriorado especialmente en la parte central, se compone de una orla con cruces de Malta y una ancha franja de peltas contrapuestas en grupos de cuatro enmarcada por dos líneas que la separan de la orla exterior y de una trenza múltiple que bordea la parte central. Ésta contiene una escena figurada polícroma, de la que solamente se conservan restos de cuatro cabezas del cabello rizado y algún fragmento de los pies. Podría tratarse de una escena mitológica. El pavimento cubre una estancia de $7 \times 5 \mathrm{~m}$.

Mosaicos con peltas han aparecido; en Hispania, en Liédena (Navarra), Puig de Cebolla (Valencia), Barcelona, Mérida (Alcazaba y Casa del Anfiteatro), Córdoba, Málaga (BLÁzouez, 1981, 39-40, 90, láms. 24 y 77, con todos los paralelos) y Soria (BLÁzQUEz y ORTEGo, 1983, 78, fig. 21). La decoración lograda a base de peltas entrelazadas es muy conocida en

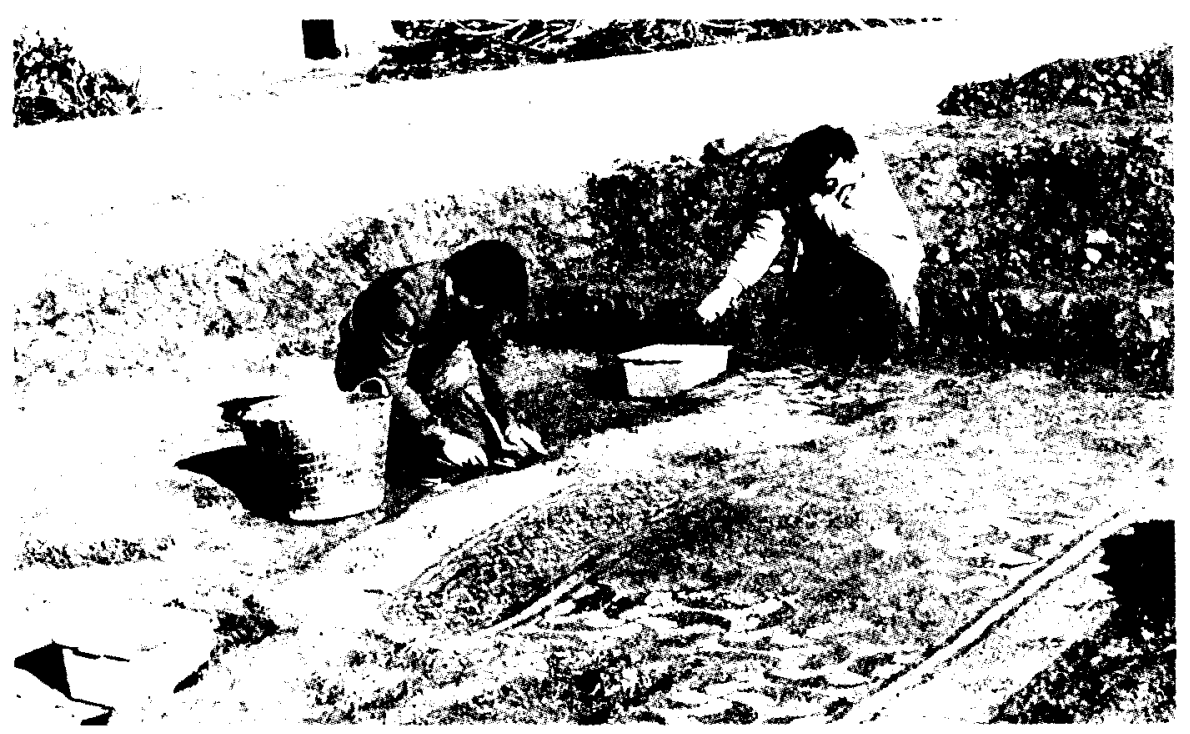

Fig. 48. Mosaico de Varea (Logrono) (Según Gómez). 
todo el Imperio, siendo muy frecuentemente utilizada en el norte de África donde S. Germain le señala un carácter profiláctico (GermaIN, 1969, 117, núm. 178, lám. LIX).

Los restos de las figuras conservadas en el mosaico de Varea se pueden encuadrar estilísticamente en el Bajo Imperio.

\section{MEDINACELI (SORIA) (figs. 49-51)}

La plaza del pueblo de Medinaceli, célebre por el arco de tres puertas de entrada a la ciudad, de comienzos del Imperio, está ocupada por mosaicos en curso de excavación. Uno de los que se encontraba dentro de una casa es el que nos proponemos estudiar ${ }^{33}$.

De fuera a dentro consta de los siguientes temas decorativos: filas de

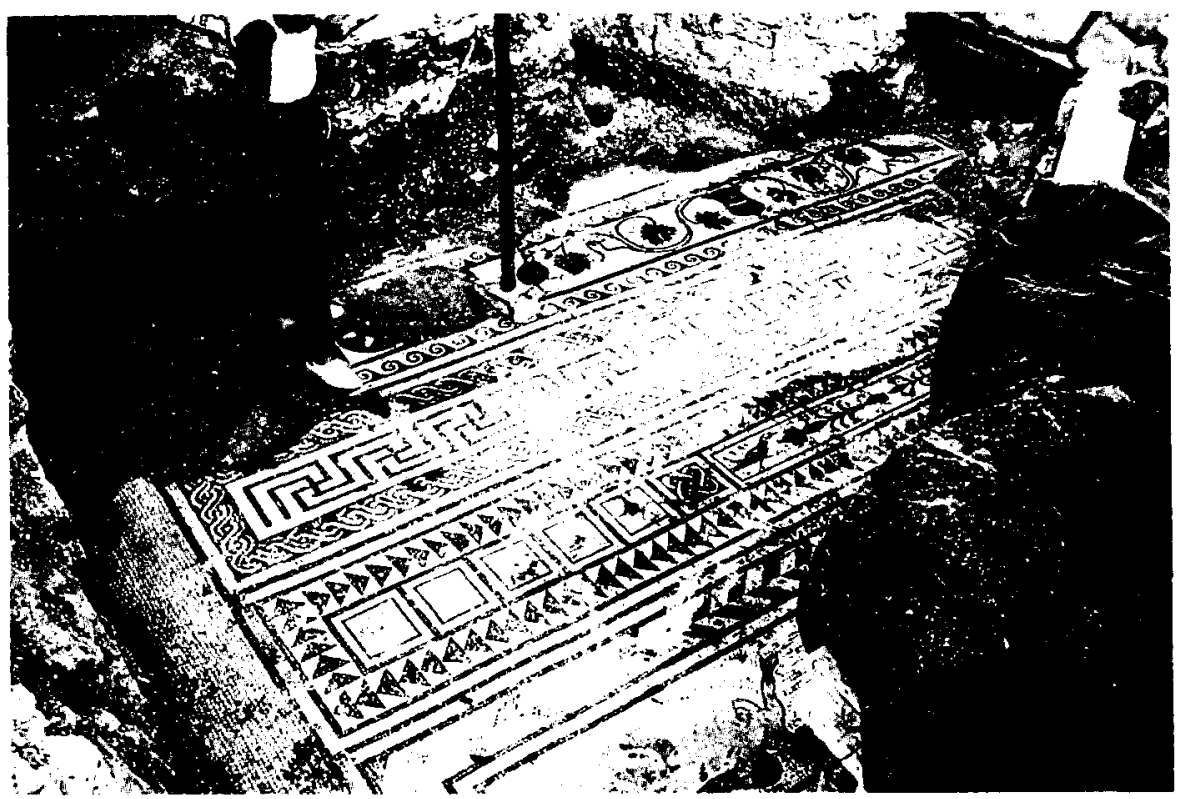

Fig. 49. Mosaico de Medinaceli (Soria) (Foto J. Cabrero).

${ }_{33}$ Publicado posteriormente por nosotros (LOPEZ MONTEAGUdo et all., 1988, 798-803, láms. XXI-XXIII). 


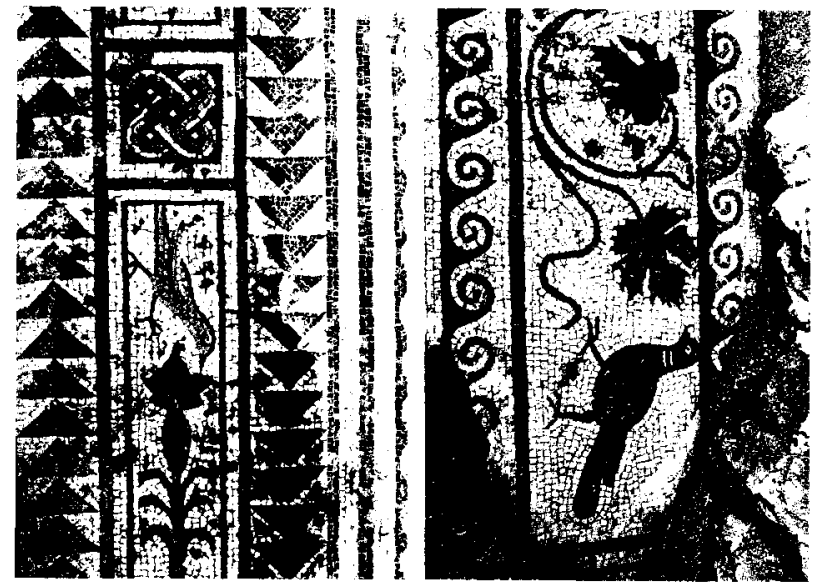

Fig. 50. Detalles del mosaico de Medinaceli (Soria). (Fotos J. Cabrero).

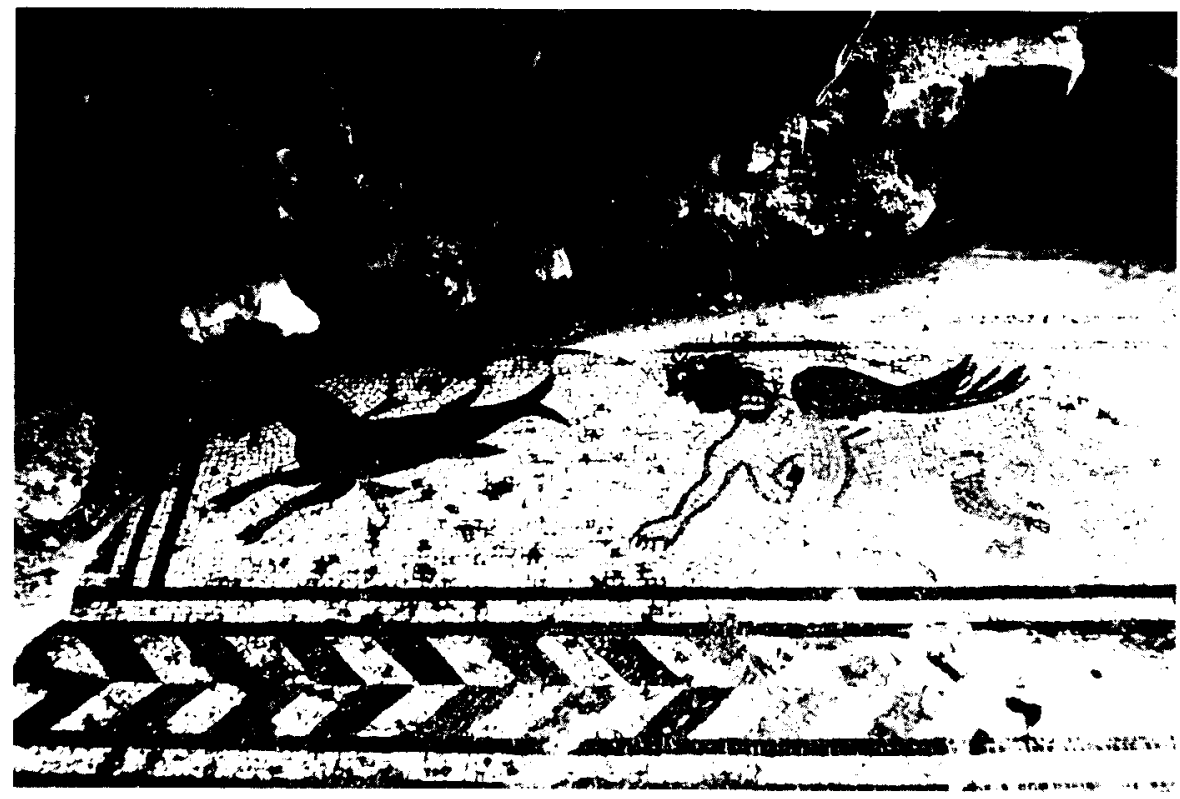

Fig. 51. Detalle del mosaico de Medinaceli (Soria). (Foto J. Cabrero). 
ondas negras sobre fondo blanco entre dos líneas del mismo color; crátera, de la que brotan zarcillos con hojas, en las esquinas hay sendas perdices y rosetas blancas sobre círculo oscuro; línea negra sobre fondo blanco; franja de meandros negros sobre fondo blanco dentro de recuadro sogueado; línea negra sobre fondo blanco semejante a la anterior; franja rectangular dentro de borde de triángulos en negro sobre fondo blanco, dentro de línea negra. El centro está ocupado por una banda con las siguientes decoraciones: seis cuadrados, en los que alternan rosetas de ocho pétalos con otras de cuatro pétalos alargados, todos dentro de cuadrados; cuadrado con rectángulos curvilíneos en el interior, en negro sobre fondo blanco; y nudo de Salomón sobre fondo oscuro. El centro está ocupado por franja con pájaros en los extremos, que rodean un tallo, y de hojas coronadas por capullos. Siguen línea negra sobre fondo blanco gemela a las anteriores; una banda de espiga, y una segunda en la que una esfinge alada persigue a un monstruo marino con la cabeza de cabra. Estas figuras están ejecutadas en colores sobre fondo blanco, dentro de marco blanco entre líneas negras.

La esfinge es poco frecuente en la musivaria hispana ${ }^{34}$. La originalidad del mosaico de Medinaceli consiste en representar a una esfinge persiguiendo a un monstruo marino. Monstruos marinos decoran con cierta frecuencia los mosaicos hispanos. Baste recordar mosaicos de Itálica de comienzos del siglo III (BLANCO, 1978a, 32, núm. 8, láms. 20-27); de Mérida (BLanco, 1978b, 29, núm. 7, láms. 8-9) de la misma fecha; del triunfo de Neptuno de Itálica (BLANCO y LúzON, 1974) de la segunda mitad del siglo II; de Córdoba (BLÁZQUEZ, 1981, 19, núm. 4, láms. 4-6) del siglo ॥; de Tetis de Jaén (BLÁZQUEZ, 1981, 59, núm. 37, lám. 44) de la segunda mitad del IV; de Barcelona y Badalona (BARRAL, 1978, 39) de la primera mitad del siglo $\|$, y de El Chorreadero (Paterna, Cádiz) de mediados del siglo " (BŁÁzQuez, 1982a, 52, núm. 49, lám. 20). El monstruo marino con cabeza de cabra se representó en el thyasos marino de Córdoba y fuera de Hispania en el mosaico ostiense de las Termas de Neptuno, fechado en torno al 139, o en el del Caseggiato del cane Monnus (BECATtI, Ostia IV, 48 y ss., núm. 70, láms. CXXIV-CXXV) de comienzos del III.

Filas de triángulos tangentes por el vértice, nudos de Salomón dentro de rectángulos, rosetas de ocho pétalos, trenza sencilla, y cráteras son

\footnotetext{
${ }^{34}$ Fuera de Hispania se la encuentra en un mosaico de la necrópolis de Pianabella en Ostia, en donde se la ha representado sobre una columna en compañia de Edipo (BECATTI, Ostia IV, 234, núm. 436, lám. CVI). Para abreviar el texto y las notas se ha prescindido de añadir nuevos paralelos de dentro y fuera de Hispania, por aparecer ya citados en la bibliografia hispana.
} 
motivos decorativos muy frecuentes en la musivaria hispana y de fuera de la Península.

El examen de estos mosaicos confirma lo escrito (FERnández Galiano, 1983) acerca de la existencia de unas especiales relaciones de los mosaicos de Complutum y de Medinaceli, localidad próxima relativamente a la anterior, con los de Mérida, capital de la Lusitania, que en el Bajo Imperio disfrutaba de un gran momento, pasada la crisis del siglo ii. Posiblemente en esta época hubo un desplazamiento del eje económico del sur, donde habia estado en los dos siglos imperiales, a la meseta. Esta zona artística y temática se hace extensiva a los pavimentos de Albadalejo, Alcázar de San Juan, Carabanchel, Tres Juncos, Huete y Gárgoles, desempeñando Mérida un papel importante.

\section{BIBLIOGRAFIA}

Abascal, Sánchez (1984): Abascal, J. M.; Sanchez, J., “El yacimiento romano altoimperial de "Los Palacios" (Luzaga, Guadalajara)", Wad-Al-Hayara 11, 313-325.

ABÁSOlo (1974): ABÁSOLO, J. A., Epigrafia romana de la región de Lara de los Infantes (Burgos). - (1983): Idem, J. A., “Excavaciones en San Martín de Losa (Burgos)", NAH 15, 247-255.

Aguilera (1916): Aguilera, E., Las necrópolis ibéricas (Madrid).

ARCE (1986): ARCE, J., "El mosaico de "Las Metamorfosis" de Carranque (Toledo)", MM 27, 365-374.

ARgente (1979): ARgente, J. L., La villa romana de Baños de Valdearados (Burgos) (Madrid).

ARIAS, HIRMER (1960): ARIAS, P. E.; HIRMER, M., Tausend Jahre griechische Vasenkunst (Munich). Atrian et all., (1980): Atrian, P. et all., Carta arqueológica de España (Teruel).

Aunigemma (1960): Aurigemma, S., L'ltalia in Africa. Tripolitania (Roma).

BalraÃo (1965): BaIrRão, M., "Mosaïques romaines de Portugal», CMGR 1, 257-265.

BALIL (1958): BALIL, A., "El mosaico de las "Tres Gracias" de Barcelona", AEArq. 31, 63-95.

- (1962): Idem, “Mosaicos circenses de Barcelona y Gerona", BRAH 51, 257 y ss.

- (1965): Idem, "Algunos mosaicos hispanorromanos de época tardia", Príncipe de Viana 26 , $281-293$.

- (1975): Idem, "Sobre los mosaicos romanos de Galicia: Identificación de un taller musivario", CMGR II, 259-263.

Balmelle et all., (1985): Balmelle, C. et all., Le Décor Géométrique de la Mosaique Romaine (París).

Balty (1977): Balty, J., Mosaiques antiques de Syrie (Bruselas).

BaARAL (1978): BarRaL, X., Les mosaiques romaines et médiévales de la regio Laietana (Barcelona).

Baral, Navarao (1975): Bafral, X.; Navarao, R., "Un motivo de orla itálico. Las representaciones de murallas en los mosaicos romanos de Hispania", BSAA XL-XLI, 503-522, con abundante bibliografía sobre el tema.

Beazley 1951, BeAzley, J. D., The Development of Attic Black-Figure (Londres).

BecattI, Ostia IV: Becatti, G., Scavi di Ostia IV: Mosaici e Pavimenti Marmorei (Roma).

BeltaÁn (1985): Beltrán, M., Celsa (Zaragoza).

Beltrán et all., (1984): Idem, Colonia Victrix lulia Lepida-Celsa Nelilla de Ebro, Zaragoza) (Zaragoza).

BIANCHI :971, BIANCHI, R., Roma. El fin del Arte Antiguo (Madrid).

BLAKE I: BLAKE, M. E., "The pavements of the Roman buildings of the Republic and early Empire", MAAR VIII. 
BLAKE II: Idem, "Roman Mosaics of the Second Century in Italy", MAAR XIII.

BLANCO (1952): BLANCO, A., Mosaicos de asunto báquico (Madrid)

- (1978a): Idem, Mosaicos romanos de Itálica, CME II (Madrid).

- (1978b): Idem, Mosaicos romanos de Mérida, CME I (Madrid).

Blanco, Luzón (1974): Blanco, A.; Luzón, J. M., El Mosaico de Neptuno de ltálica (Sevilla).

Blanchard (1975): Blancharo-LemÉ, M., Maisons à mosaíques du Quartier central de Djemila (Cuicul) (Aix-en-Provence).

Blázouez (1977-1978): Blázouez, J. M., "Mosaicos hispanos del Bajo Imperio", AEArq. 50-51. 269-293.

- (1981): Idem, Mosaicos romanos de Córdoba, Jaén y Málaga, CME III (Madrid)

- (1982a): Idem, Mosaicos romanos de Sevilla, Granada, Cádiz y Murcia. CME N (Madrid).

- (1982b): Idem, Mosaicos romanos de la Real Academia de la Historia, Ciudad Real, Toledo, Madrid y Cuenca. CME V (Madrid).

- (1982c): Idem, "El mosaico con el triunfo de Dionysos de la villa romana de Valdearados (Burgos)", Homenaje a Sáenz de Buruaga, 407 y ss.

- (1985): Idem, "Mosaicos romanos del Campo de Villavidel (León) y de Casariche (Sevilla)", AEArq. 58, 107-124.

- (1986): Idem, "Mosaicos hispanos de la época de las invasiones bárbaras. Problemas estéticos", Antigüedad y Cristianismo III. Los Visigodos, 463 y ss.

- (1987): ldem, “Transformaciones sociales. Descomposición de las formas artísticas en la Antigüedad Clásica", Fragmentos 10, 30 y ss.

BlázQuez, Gonzalez (1972-1974): Blázouez. J. M.; González, J., "Mosaicos hispanos del Bajo Imperio", AEArq. 45-47, 429 y ss.

Blázouez, Ortego (1983): Blazquez, J. M.; Ortego, T., Mosaicos romanos de Soria. Cme VI (Madrid).

Blázquez et all., (1985): Blazouez, J. M.; Mezouiriz, M. A., con la colaboración de Neira, M. L. y NiETo, M. Mosaicos romanos de Navarra. CME VII (Madrid).

- (1986a): Blazquez, J. M.; Elofza, J. C.; Bartolomé, A., «Atalanta y Meleagro en un mosáco romano de Cardeñajimeno (Burgos, España)", Latomus XLV, 3, 555-567.

- (1986b): Blázouez, J. M.; López Monteagudo, G.; Neira, M. L.; San Nicolás, M. P., “Hallazgo de mosaicos romanos en Beas de Segura (Jaén)", AEArq. 59, 227-232.

- (1986c): Idem, "La Mitología en los mosaicos hispano-romanos», AEArq. 59, 101-162.

- (1987): Idem, “Mosaico romano de Vilches (Jaén)», AEArq. 60, 275-279.

- (1989a): Idem, Mosaicos romanos de Lérida y Albacete. CME VIII (Madrid).

- (1989b): Idem, Mosaicos romanos del Museo Arqueológico Nacional. CME IX (Madrid).

- (1990): Idem, "Pavimentos africanos con espectáculos de toros", Antiquités Africaines 26 , 155-404.

Blázquez, López Monteagudo (1986): Blázquez, J. M.; López Monteagudo, G., “Mosaicos de Asia Menor", AEArq. 59, 233-252.

- (1990): Idem, "lconografía de la vida cotidiana: Temas de caza", en Mosaicos Romanos. Estudios sobre iconografia (= A. Balil in memoriam) (Guadalajara), 59-88.

BRommer (1961): Brommer, F., “Meleagro", EAA IV, 983-985.

Bueno (1986): Buero, S., "Excavaciones de urgencia en la provincia de Sevilla", Revista de Arqueologia 58, 59-60.

Carandini et all., (1982): Carandin, A. et all., Filosofiana. La villa di Piazza Armerina. Immagine di un aristocratico romano al tempo di Constantino (Palermo).

Castro (1976): CAStro, L., "Algunos yacimientos de la zona de Sahagún (León)", Sautuola II, 191-207.

CAStro el all., (1976): CASTRO, L. el all., “Un mosaico romano de Valdelaguna (León)", BSAA 6 , 28-30.

Celestino (1977): Celestino, S., "Mosaicos perdidos de Itálica", habis 8, 359-383.

Cortés, Palol (1967): Cortés, J.; PALOL, P., "Nuevos hallazgos arqueológicos de la zona de Valladolid", BSAA 33, 323.

CHËHAB (1971): CHÉHAB, M., “Mosaiques inédites du Liban", CMGR II, 372.

Donderer (1982): Donderer, M., "Ein verschollenes römisches Mosaik und die Gattung der Wandemblemata", Mosaïque. Récueil d'Hommages à Henri Stern, 125 y ss. 
DoRIgo (1966): DoRIgo, W., Pittura tardorromana (Milán).

Dulière (1969): Dulière, C., "Ateliers de mosaistes de la seconde moitié du Ve. siècle", Actes du Colloque Apamée de Syrie, 125 y ss.

DunbabIN (1971): DunbabIN, K. M. D., "The Triumph of Dionysos on Mosaics in North Africa», PBSR XXXIX, 52-65.

- (1978): Idem, The Mosaics of Roman North Africa (Oxford).

ENNAÏFER (1983): ENNAÏFER, M., «Le Thème des Chevaux Vainqueurs à travers la serie des Mosaïques Africaines", MEFRA 95, 817-858.

Escortell (1975): Escortell, M., Catálogo de las salas de cultura romana del Museo Arqueológico de Oviedo (Oviedo).

ESPINOSA (1986): ESPINOSA, U., Epigrafia romana de La Rioja (Logroño).

FENDRI (1965): FENDRI, M., "Evolution chronologique et stylistique d'un ensemble de mosaïques dans une station thermale à Djebel Oust (Tunisie)", CMGR I, 151-171.

Fernández Castro (1982): Fernández Castro, M. C., "Mosaicos de Rielves", en Blázquez 1982b, 61-75.

Fernández Galiano (1980): Fernández Galiano, D., Mosaicos hispanos de esquema a compás (Guadalajara).

- (1983): Idem, “Influencias orientales en la musivaria hispánica», CIMA III, 411-430.

- (1984a): Idem, Complutum II. Mosaicos.

- (1984b): Idem, "El triunfo de Dionisos en mosaicos hispanorromanos", AEArq. 57, 97-121.

- (1987): Idem, Mosaicos romanos del Convento Cesaraugustano (Zaragoza)

- (1989): Idem, "La villa de Materno", en Mosaicos Romanos. Actas de la / Mesa HispanoFrancesa sobre Mosaicos Romanos (Madrid 1985), 255-269.

Foucher (1960): Foucher, L., Inventaire des Mosaiques, Sousse (Túnez).

- (1963): Idem, La maison de la procession dionysiaque à El Jem (Túnez).

- (1965): Idem, La Maison des Masques à Sousse.

- (1974): Idem, "Le char de Dionysos", CMGR II, 55-61.

Frere (1967): Frere, S., Britannia. A History of Roman Britain (Londres).

GaGo (1984): GaGo, F., Informe sobre la extracción de los pavimentos musivos de Santa Cristina de la Polvorosa, (Zamora), Revista de Arqueología 41, 50-51.

Garcia y Bellido (1979): Garcia y Bellido, A., Colonia Aelia Augusta Italica (Madrid).

Garcia Guinea (1982): Garcia Guinea, M. A., Guía de la villa romana de Quintanilla de la Cueza (Palencia) (Palencia).

Garcia Hoz et all., (1991): García Hoz, M. C.; Alvarado Gonzalo, M. et all., "La villa romana del "Olivar del Centeno" (Millanes de la Mata, Cáceres)", Extremadura Arqueológica II, 387 402.

Germain (1969): Germain, S., Les mosaiques de Timgad. Étude descriptif et analytique (Paris).

- (1983): Idem, "Un schéma original sur une mosaique de Lambèse (Algérie)", Mosaiqque. Récueil d'Hommages à Henri Stern, 171-177.

Gómez (1985): Gómez, J. R., "La ciudad romana de Varea (Logroño)", Revista de Arqueologia $49,56-57$.

GonzAlez et all., (1990): Gonzalez Cordero, A. et all., "Mosaicos romanos de Torre Albarragena: Un nuevo triunto báquico en la Península ibérica", AEArq. 63, 317-330.

Gozlan (1983): Gozlan, S., "Deux mosaiques de Carthage au Kunsthistorisches Museum de Vienne", Mosaique. Récueil d'Hommages à Henri Stern, 179.

Grabar (1966): Grabar, A., La edad de oro de Justiniano. Desde la muerte de Teodosio hasta el Islam (Madrid).

HaUSCHILD (1979): HAUSCHILD, Th., “Milreu/Estoi (Algarve), Untersuchungen neben der Tauf-piscina und Sondagen in der Villa-Kampagnen 1971 und 1979", MM 21, 214 y ss.

Hernández (1982): HeRnández, J. A., Las ruinas de Inestrillas. Estudio arqueológico (Logroño).

Humphrey (1986): Humphrey, J. H., Roman Circuses. Arena for Chariot Racing (Londres).

Jimeno (1980): Jimeno, A., Epigratia romana de la provincia de Soria (Soria).

LANCHA (1977): LANCHA, J., Mosaïques Géométriques. Les Ateliers de Vienne-Isère (Roma).

- (1983): Idem, "Florilège viennois", Mosaïque. Récueil d'Hommages à Henri Stern, 245 y ss.

- (1985): Idem, «La mosaïque d'Ocean découverte à Faro (Algarve)", Conimbriga 44, 151 -175. 
Lancha, Bartolomé (1988): Lancha, J.; Bartolomé, A., "Les mosaïques de la villa romaine de Cardeñajimeno (Burgos)", AEArq. 61, 305-324.

LAVIN (1963): LAVIN, I., "The Hunting Mosaics of Antioch and their Sources", DOP 17, 179 y ss

LEVI (1947): LEVI, D., Antioch Mosaic Pavements (Princeton).

LóPez MONTEAGUdo (1991): López MONTEAGUdo, G., "La caza en el mosaico romano. Iconografía y simbolismo", Antigüedad y Cristianismo VIII (Murcia), 497-512.

- (1992): Idem, «Inscripciones sobre caballos en mosaicos romanos de Hispania y del norte de África", Atti del IX Convegno su l'Africa Romana (1991), 965-1011.

López Monteagudo et all., (1988): López Monteagudo, G.; BLÁzouez, J. M. et all., "El simbolismo del matrimonio en el mosaico de Fuente Álamo (Puente Genil, Córdoba) y otros mosaicos hispanos inéditos", Latomus XLVII/4, 785-816.

López Palomo (1987): López Palomo, L. A., "Excavaciones de urgencia en la villa romana de Fuente Álamo (Puente Genil, Córdoba)", Anuario Arqueológico de Andalucia (1985), 105. 115.

LUCAS (1986-1987): LUCAS, M. ${ }^{a}$ R., "La influencia africana en la iconografía equina de la villa de Aguilafuente (Segovia)”, Cuad. Preh. Arq. Univ. Autón. 13-14 (= Hom. al prof. G. Nieto II), 219-235.

LUCAS, VINAS (1977): LUCAS, M. ${ }^{a}$ R.; VIÑAS, V.. "La villa romana de Aguilafuente", Segovia y la Arqueologia Romana, 239-255.

Luzón (1975): Luzón, J. M., Arte hispalense. La ltálica de Adriano (Sevilla).

MacMillan (1986): MacMillan, C., Mosaiques romaines du Portugal (Paris)

MAÑANes (1982): MAÑANES, T., Epigrafia y numismática de Astorga romana y de su entorno (León).

Mezoviriz (1987): Mezoviriz, M. ${ }^{a}$ A., "Mosaico báquico hallado en Andelos", Revista de Arqueología $77,59-61$.

Mingarro et all., (1986): Mingarro, F.; Avello, J. L.; Amorós, J. L.; López de Azcona, M. C., La villa romana de Campo de Villadivel (León). Arqueología, simetria, color y petrologia de los mosaicos (Madrid).

Molinero (1952): Molinero, A., "Arévalo (Ávila). Magazos", NAH I, 159-163.

Molinos et all., (1982): Molinos, M. et all., "Excavaciones arqueológicas en la villa romana del Cerrillo del Cuco (Santagón, Vilches-Jaén)", Actas del I Congreso Andaluz de Estudios Clásicos (Jaén)

Mondelo, Torres (1985): Mondelo, R.; Torres, M., "El mosaico romano de Casariche (Sevilla)", BSAA LI, 143-157.

Morricone (1950): Morricone, M. ${ }^{2}$ L., "Scavi e ricerche a Cos (1935-1943). Relazione preliminare", Bollettino d'Arte 35,219 y ss.

Nicolau (1971): NicOLAU, K., "Some Problems arising from the Mosaics at Paphos", AAS 21, 143 y ss.

NONELL (1980): NONELL, C. Excavaciones en la villa romana de Gárgoles-Cifuentes (Guadalajara) (Ávila)

OVADIAH (1980): OVADIAH, A., Geometric and floral pattern in ancient mosaics (Roma).

PALOL (1976): PALOL, P., "Perduración de las ciudades augusteas en la zona norte y en la meseta", Simposium de ciudades augusteas, 263-288.

Palol, Cortés (1974): Palol, P.; Cortés, J., La villa romana de la Olmeda, Pedrosa de la Vega (Palencia). Excavaciones de 1969 y 1970 (Madrid).

Parlasca (1959): Parlasca, K., Die römischen Mosaiken in Deutschland (Berlín).

Pernice (1938): Pernice, E., Pavimente und figürliche Mosaiken Die Hellenistische Kunst in Pompeji VI (Berlín).

PICARD et all., (1977): PICARD, G. Ch. et all., Recherches archéologiques franco-tunisiennes à Mactar I. La Maison de Vénus (Roma).

PicCiRillo et all., (1986): PICCIRILlo, M. et all., I mosaici di Giordania (Roma).

PITA (1969): PITA, R., "Mosaicos romanos tardíos en las comarcas del Segre y Cinca", BSAA XXXV, 32-64.

Ramallo (1985): Ramallo, S., Mosaicos romanos de Carthago Nova (Hispania Citerior) (Murcia).

Ramallo, Jordán (1985): Ramallo, S.; Jordán, J. F., La villa romana de Hellín (Valencia) 
Ramos (1983): Ramos, R., La Alcudia de Elche (Elche).

Redón et all., (1986): Redón, V. et all., La ciudad celtibérica de "La Caridad" (Caminreal, Teruel) (Teruel).

-- (1989): Idem, "Un pavimento de opus signinum con epigrafe ibéricom, en Mosaicos romanos. Actas de la I Mesa Redonda Hispano-Francesa sobre Mosaicos Romanos (Madrid 1985). Madrid, 11-42.

Regueras (1984): Regueras, F., “La villa romana de Requejo (Zamora). Excepcional conjunto musivario", Revista de Arqueologia 41, 41-49.

- (1990): Idem, "Los mosaicos de la villa romana de Requejo (Santa Cristina de la Polvorosa)", Actas del I Congreso de Historia de Zamora II (Zamora), 637-696.

REINACH (1922): REINACH, S., Répertoire des peintures grecques et romaines (París).

Rivera, Wattenberg (1955): Rivera, S.; Wattenberg, $F_{\text {., }}$ "Las excavaciones de la Granja josé Antonio de Valladolid", BSAA 20, 145 y ss.

Rodriguez Termino, Núnez Pafiente de León (1987): Rodriguez Termiño, I.; Núñez Pariente de LEÓN, E., “Arqueología urbana de urgencia en Écija (Sevilla), 1985", Anuario Arqueológico de Andalucía (1985), 316-325.

Rovo (1991): Royo, J.I., "Memoria de la segunda campaña de excavaciones arqueológicas en La Malena, 1987", Arqueologia Aragonesa, 1986-1987, 231-235.

- (1992): Idem, "La villa tardorromana de "La Malena" en Azuara y el mosaico de las Bodas de Cadmo y Harmonia", JAA 5, 148-161.

Royo et all., (1991): Royo, J. I. et all., "Memorias de las excavaciones arqueológicas en la villa romana de "La Malena" (Azuara, Zaragoza). Campaña de 1986", Arqueología Aragonesa, 1986-1987, 225-230.

- (1991a): Royo, J. I. et all., "Excavaciones en La Malena (Azuara, Zaragoza) . 3. campaña, 1988", Arqueologia Aragonesa, 1988-1989, 209-214.

- (1991b): Rovo, J. I. et all., «Excavaciones en La Malena (Azuara, Zaragoza). Campaña de 1989", Arqueologia Aragonesa, 1988-1989, 215-221.

SAlomonson (1965): SAlOMONSON, J. V., Mosaïque aux Chevaux de l'Antiquarium de Carthage (La Haya).

SÁNCHEZ et all., (1986a): SÁNCHEZ, M. J. et all., EI Portus Illicitanus. Datos para una sintesis (Santa Pola).

- (1986b): SÁnchez, M. J. et all., "El Portus lllicitanus. Yacimiento romano en Santa Pola (Alicante)", Revista de Arqueologia 63, 58 y ss.

Schauenburg (1962): Schauenburg, K., "Eine neue Siriasschale», AA, 1962, 765-776.

SCHEFOld (1957): Schefold, K., Die Wände Pompeji. Topographisches Verzeichnis der Bildmotive (Berlín).

Schlunk (1988): Schlunk, H., Die Mosaikkuppel von Centcelles (Mainz).

SCHLUNk, HAuschild (1962): SChLUNk, H.; HAuSChILd, Th., Informe preliminar sobre los trabajos realizados en Centcelles (Madrid)

SiCHTERMANN (1975): SichtermanN, H., Griechische Mythen auf römischen Sarkophagen (Tübingen)

SpIRo (1978): Spiro, M., Critical Corpus of Mosaic Pavement on the Greek Mainland. Fourth/Sixth Centuries with architectural Surveys (Nueva York-Londres).

TARRATS I BOU (1985): TARRATS I BOU, F., "Mosaico con orla de murallas hallado en Huesca", Bolskan 2, 145-146.

TOYNBEe (1963): TOYNBEe, J. M. C., Art in Roman Britain (Londres)

VARGAS COSTA (1988): VARGAS CostA, M. L., "Contribução para o estudo de alguns dos mosaicos da villa romana de Pisôes", Arquivo de Beja II, 2. sárie, 95-135. 